INSTITUTO DE PESQUISAS ENERGÉTICAS E NUCLEARES

Autarquia associada à Universidade de São Paulo

Cálculo de Custo Ambiental das Usinas Nucleares de Angra 1, 2 e 3 utilizando o Programa SIMPACTS

\author{
Francine Menzel
}

Dissertação apresentada como parte dos requisitos para obtenção do Grau de Mestre em Ciências na Área de Tecnologia Nuclear - Reatores

Orientadora:

Prof. Dra. Gaianê Sabundjian

Versão Corrigida

Versão Original disponível no IPEN

São Paulo

2014 
Dedica este trabalha as meus pais, que estiveram aa meu lada em tadas as anas e mamentas da minha vida, me apaianda e me ensinanda a ir atrás das meus sanhas e persistir na lusca das meus abjetivas. 


\section{Agradecimentos}

Agradecimentos especiais à minha querida Orientadora Gaianê Sabundjian, que mais do que me orientar, esteve ao meu lado me apoiando todos os dias e, com paciência, me ajudou a caminhar para a conclusão deste trabalho.

Ao Leslie, pelo seu auxílio em relação aos dados da estação meteorológica do IPEN.

Ao Dr. Laércio Vinhas, que nos forneceu o programa SIMPACTS, tornando possível o desenvolvimento desse trabalho.

Aos meus companheiros do CEN, que entre uma conversa e outra nos corredores e nas inesquecíveis viagens a Congressos, me mostraram a importância dos amigos no desenvolvimento de um trabalho.

Ao $\mathrm{CNPq}$, pelo suporte financeiro oferecido como apoio para o desenvolvimento desta dissertação.

E ao Centro Tecnológico da Marinha em São Paulo, por todo o apoio na etapa final de desenvolvimento desta dissertação. 


\title{
Cálculo do Custo Ambiental das Usinas Nucleares de Angra 1, 2 e 3 utilizando o Programa SIMPACTS
}

\author{
Francine Menzel
}

\section{RESUMO}

Cálculo de custo ambiental é um conceito que surgiu a partir da crescente atenção dada às questões ambientais. Um impacto ambiental, convertido em termos econômicos, é um custo ambiental. Para esse cálculo, são utilizados programas computacionais, como o Simplified Approach of Estimating Impacts of Electricity Generation (SIMPACTS), que é um código que estima e quantifica os custos dos danos ambientais e danos à saúde ocasionados por diferentes tecnologias de geração de eletricidade. O objetivo desse trabalho é realizar o cálculo de custo ambiental das usinas nucleares de Angra 1, 2 e 3. Os resultados foram comparados com os dados do reator de Balakovo, da hidrelétrica Serra da Mesa e de uma usina a carvão genérica na França, contidos no próprio programa. $O$ SIMPACTS possui três módulos: AIRPACTS, para quantificar os impactos e custos dos danos causados pelas emissões atmosféricas; NUKPACTS, para avaliar as doses coletivas e os efeitos na saúde latentes da operação de rotina de instalações nucleares e usinas a carvão; HYDROPACTS, para calcular os custos dos danos das barragens de hidrelétricas decorrentes da reinstalação de pessoas em virtude de inundações e perda de uso da terra. Nesse trabalho, foram utilizados os módulos NUKPACTS e HYDROPACTS para a realização dos cálculos. Os resultados indicam que um reator nuclear, quando comparado a uma hidrelétrica e termoelétrica de potência similar, causa menores impactos associados e, portanto, um menor custo ambiental. Por essa razão, do ponto de vista dos seus impactos ambientais, os reatores nucleares se tornam uma fonte de geração de energia atrativa. 
Calculating Environmental Cost of Nuclear Power Plants Angra 1, 2 and 3 using the SIMPACTS Program

\begin{abstract}
Calculating the environmental cost is a concept that emerged from the increased attention given to environmental issues. Environmental impact, converted into economic terms, is an environmental cost. For this calculation computational programs, such as Simplified Approach of Estimating Impacts of Electricity Generation (SIMPACTS) are used. SIMPACTS is a code that estimates and quantifies the costs of both, environmental and health damage, caused by different electricity generation technologies. The aim of this work is the calculation of the environmental cost of the nuclear power plants Angra 1, 2 and 3. The results were compared with data provided in the program of the following power plants: the reactor Balakovo, the Serra da Mesa hydroelectric dam and a generic coal plant in France. The SIMPACTS has three modules: AIRPACTS to quantify the impacts and costs of the damage caused by atmospheric emissions; NUKPACTS to assess collective doses and latent health effects of routine operation of nuclear power plants and coal power plants; HYDROPACTS to calculate the damage costs of hydroelectric dams resulting from the relocation of people due to flooding and loss of land use. For this research, NUKPACTS and HYDROPACTS modules were used for calculations. The results indicate that a nuclear reactor, compared with a hydropower plant with similar capacity, causes lower impacts associated and, consequently, lower environmental cost. For this reason, nuclear reactors are an attractive source of power generation from the point of view of the environmental impacts.
\end{abstract}




\section{SUMÁRIO}

Página

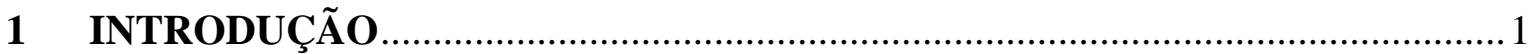

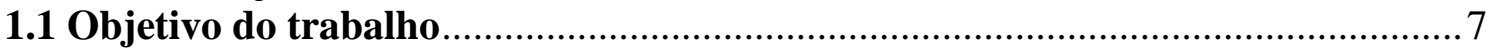

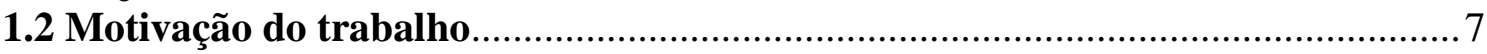

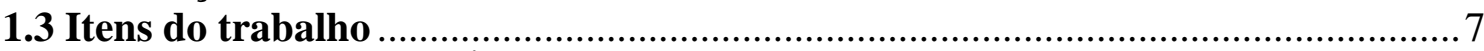

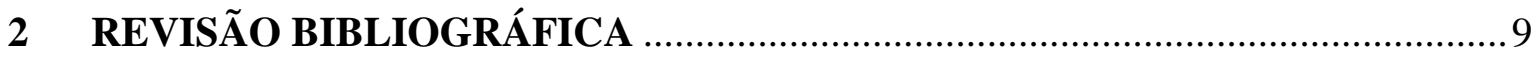

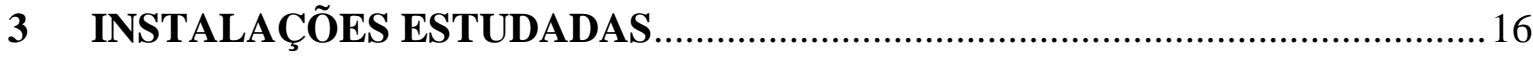

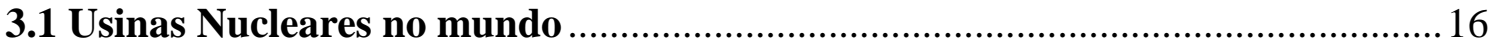

3.1.1 Instituto de Pesquisas Energéticas e Nucleares (IPEN) - IEA-R1 ............... 17

3.1.2 Reatores Nucleares de Angra 1, 2 e 3 ..................................................... 19

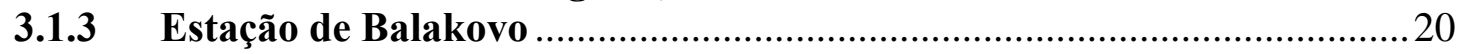

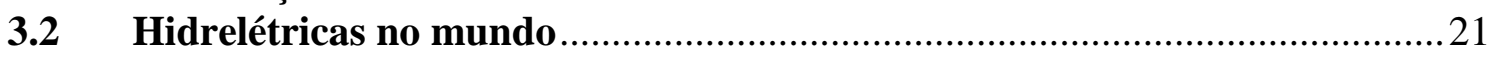

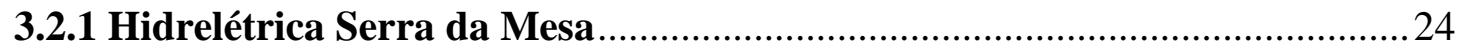

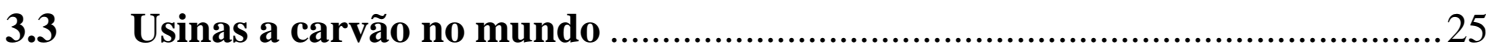

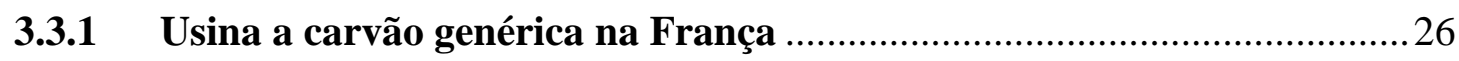

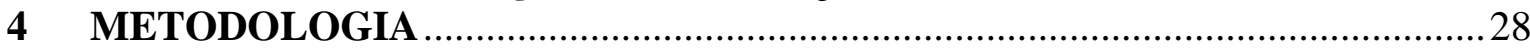

4.1 Introdução

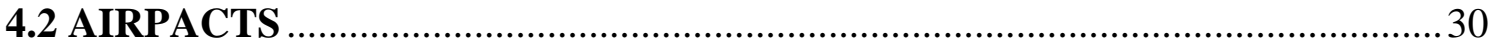

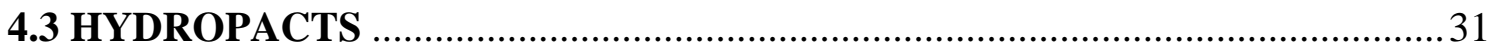

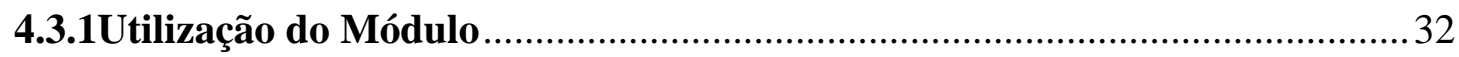

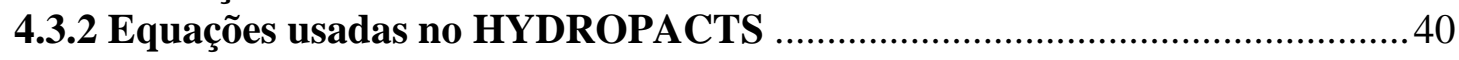

4.3.2.1 Estimativa da área inundada pelo reservatório .................................... 40

4.3.2.2 Estimativa da altura da barragem .................................................. 42

4.3.2.3 Estimativa da população deslocada por causa do reservatório ............. 44

4.3.2.4 Estimativa das emissões atmosféricas .................................................4 44

4.3.2.4.1 Emissões durante a construção de uma nova barragem ................. 44

4.3.2.4.2 Emissões de Gases do efeito estufa durante a operação da

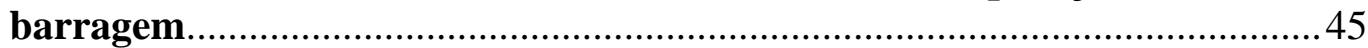

4.3.2.5 Estimativa de impactos de acidentes .................................................... 47

4.3.2.6 Custo externo de perda de recursos culturais e naturais ....................... 49

4.3.2.7 Custo externo do aumento de incidentes por doenças........................... 49

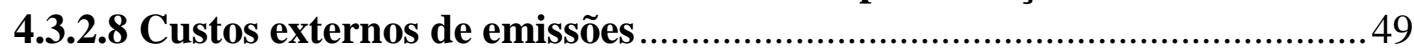

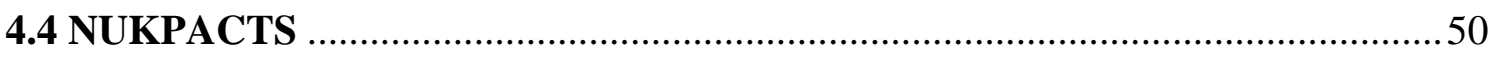

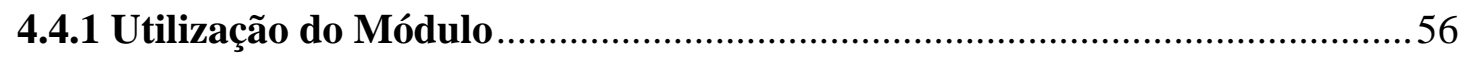

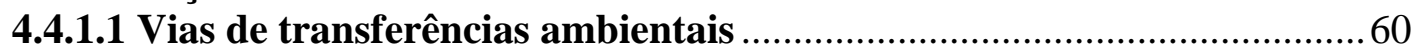

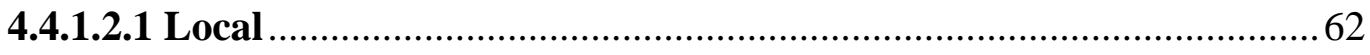

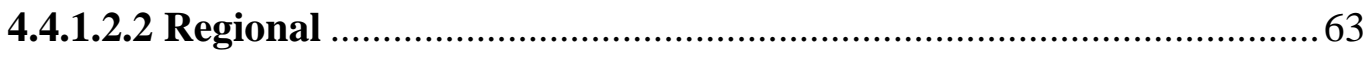

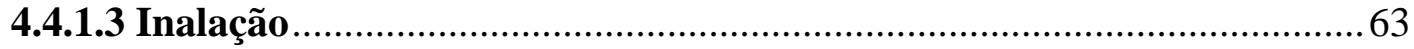

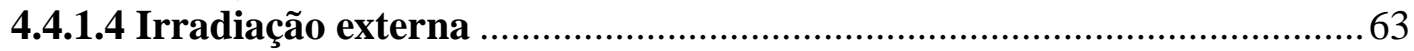

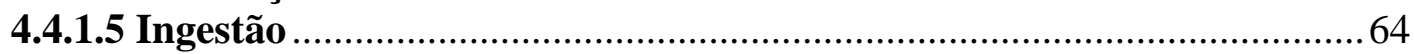

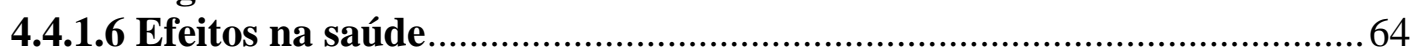

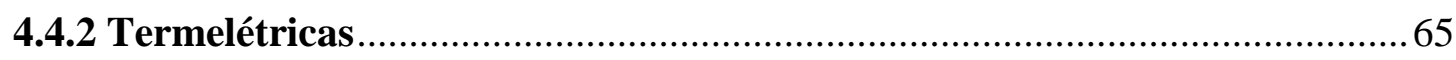

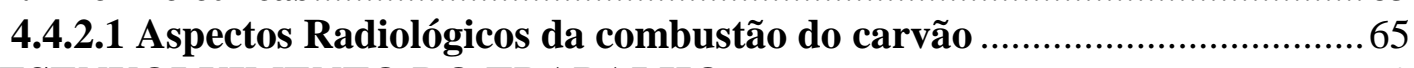

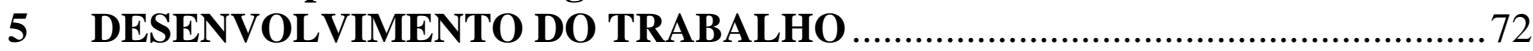

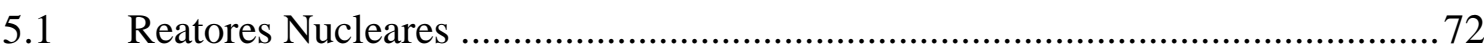

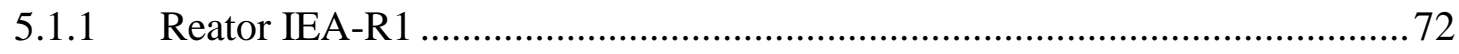

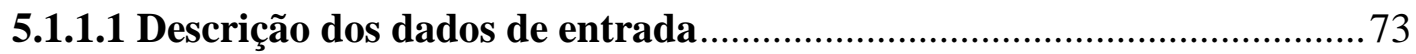




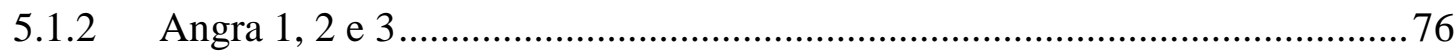

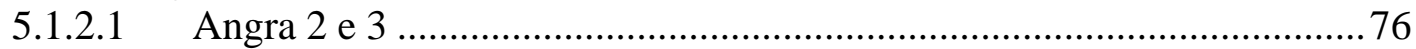

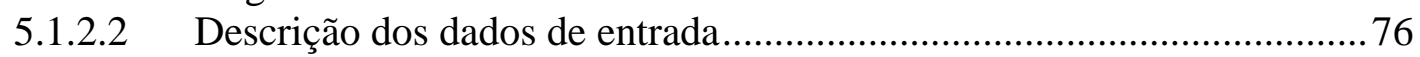

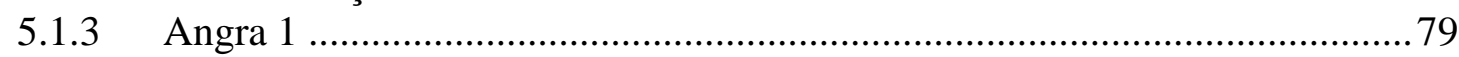

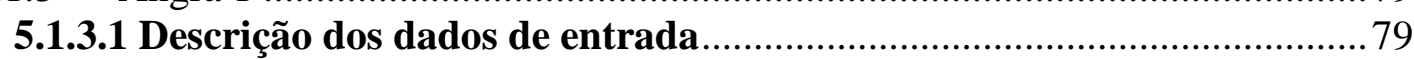

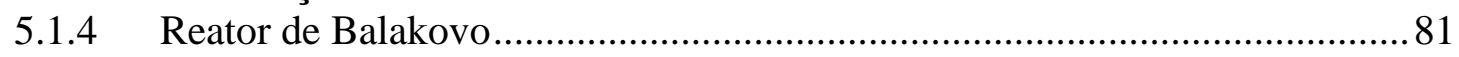

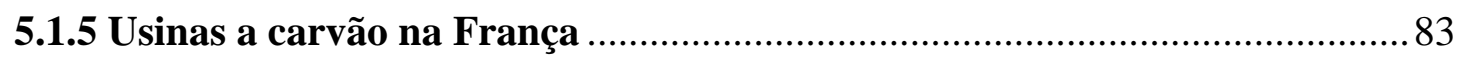

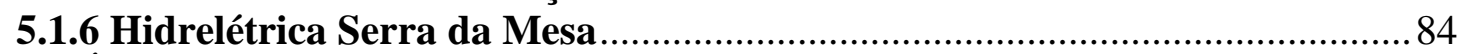

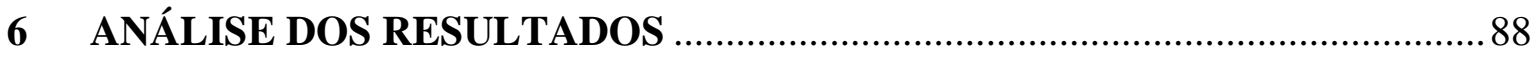

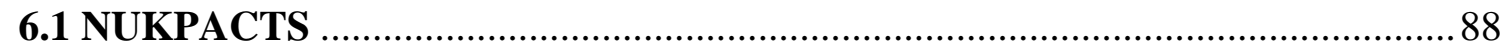

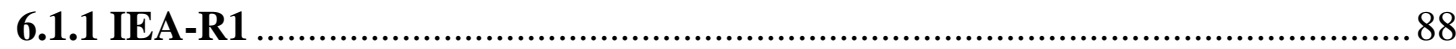

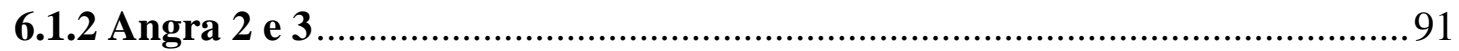

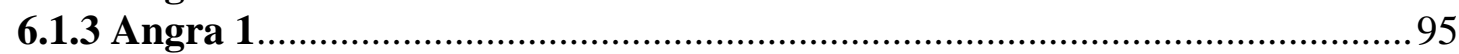

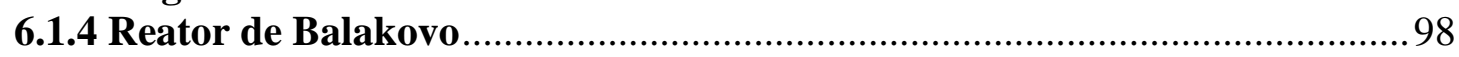

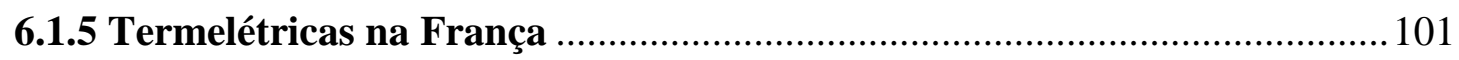

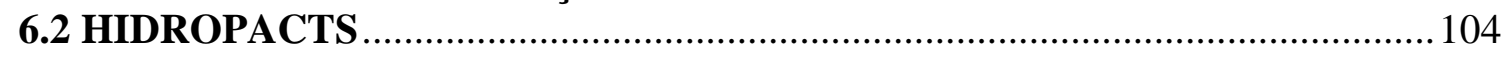

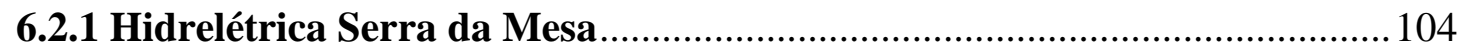

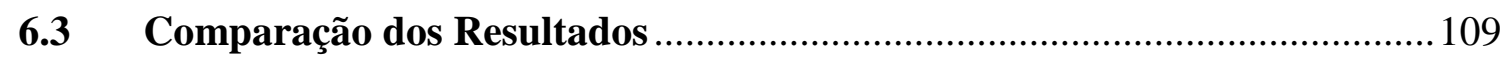

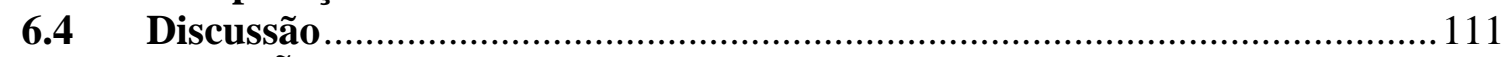

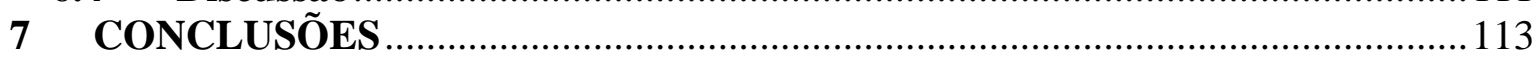

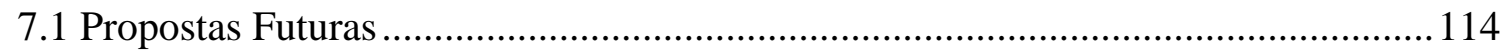

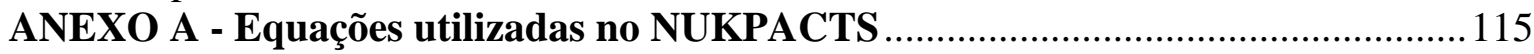

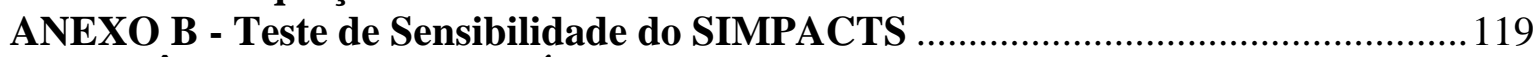

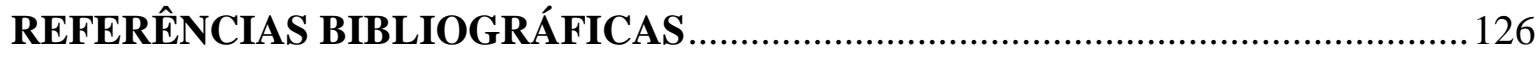




\section{LISTA DE TABELAS}

TABELA 3.1 - Resumo breve dos impactos da energia hidrelétrica..................................2. 23

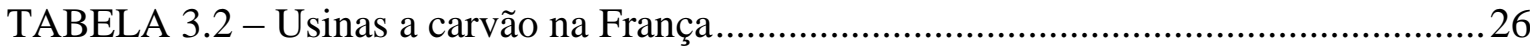

TABELA 4.1 - Emissões durante a construção de uma nova barragem ............................. 45

TABELA 4.2 - Emissão de gases durante operação da reserva existente ............................. 46

TABELA 4.3 - Causas de Falha na Barragem ...................................................................... 47

TABELA 4.4 - Principais radionuclídeos liberados para o ar e suas respectivas meias-vidas

TABELA.................................................................................... 54

TABELA 4.6 - Parâmetros de entrada do NUKPACTS ……............................................58

TABELA 4.7 - Fatores de conversão de dose do NUKPACTS para ingestão de

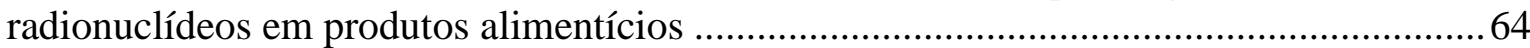

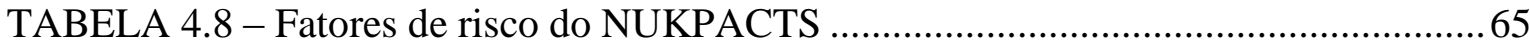

TABELA 4.9 - Coeficientes de transferência para elementos radioativos envolvidos na combustão de carvão.

TABELA 4.10 - Fatores de conversão de doses para radionuclídeos envolvidos na combustão de carvão para exposição externa de nuvens passageiras e deposições no solo 67 TABELA 4.11 - Fatores de conversão de dose para radionuclídeos envolvidos na inalação de combustão de carvão

TABELA 4.12 - Fatores de conversão de risco para radionuclídeos envolvidos na ingestão

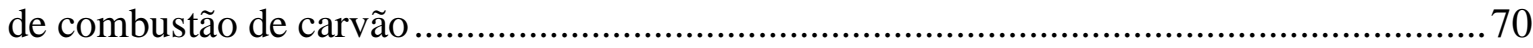

TABELA 5.1 - Dados de entrada do SIMPACTS para o IEA-R1 .........................................75

TABELA 5.2 - Dados de entrada do SIMPACTS para Angra 2 e Angra 3 ......................... 78

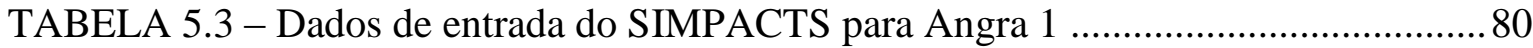

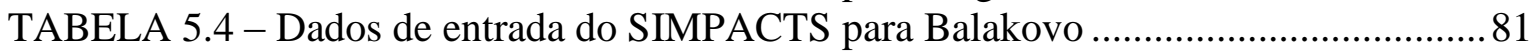

TABELA 5.5 - Dados de entrada do SIMPACTS para termelétrica ................................... 83

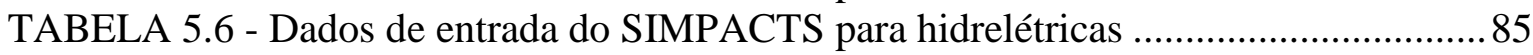

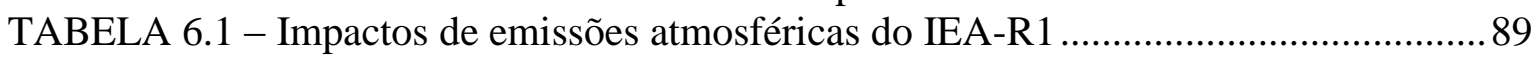

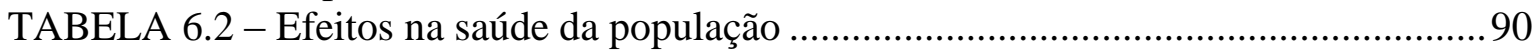

TABELA 6.3 - Resultados parciais do custo ambiental do reator IEA-R1 .........................91

TABELA 6.4 - Impactos das emissões atmosféricas de Angra 2 e 3 .................................. 92

TABELA 6.5 - Efeitos na saúde da população ...............................................................94

TABELA 6.6 - Resultados parciais do custo ambiental dos reatores de Angra 2 e 3 ........ 95

TABELA 6.7 - Impactos de emissões atmosféricas de Angra 1 ......................................95

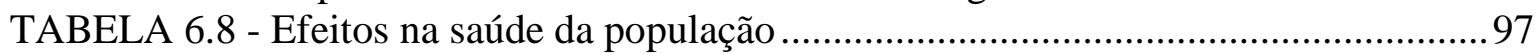

TABELA 6.9 - Resultados parciais do custo ambiental do reator de Angra 1 ....................97

TABELA 6.10 - Impactos locais de emissões atmosféricas de Balakovo ...........................98

TABELA 6.11 - Impactos regionais de emissões atmosféricas de Balakovo .......................99

TABELA 6.12 - Impactos locais e regionais de emissões atmosféricas de Balakovo .......100

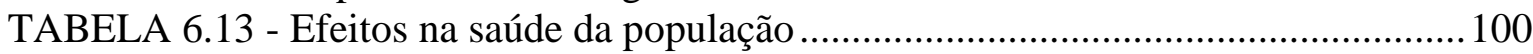

TABELA 6.14 - Resultados parciais do custo ambiental do reator de Balakovo................101

TABELA 6.15 - Impactos locais de emissões atmosféricas de termelétricas ....................102

TABELA 6.16 - Impactos regionais de emissões atmosféricas de termelétricas ............... 102

TABELA 6.17 - Impactos locais e regionais de emissões atmosféricas de termelétricas 103

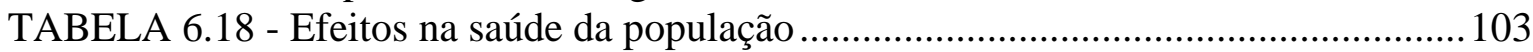

TABELA 6.19 - Resultados parciais do custo ambiental de termelétricas...........................104

TABELA 6.20 - Resumo dos impactos físicos para a hidrelétrica de Serra da Mesa ........105

TABELA 6.21 - Impactos físicos - Emissões ……....................................................... 105 
TABELA 6.22 - Resumo dos impactos econômicos para a hidrelétrica de Serra da Mesa

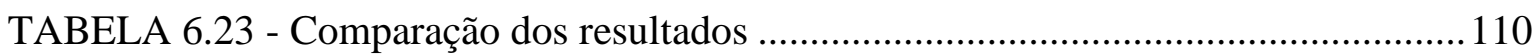

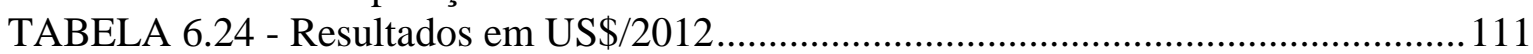

TABELA 6.25 - Vantagens e desvantagens dos tipos de instalação considerados no trabalho 


\section{LISTA DE FIGURAS}

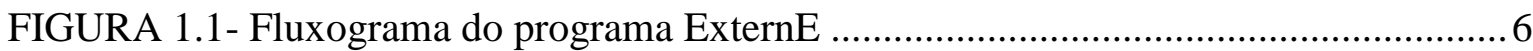

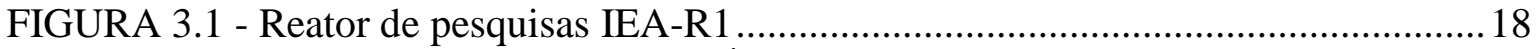

FIGURA 3.2 - Central Nuclear Almirante Álvaro Alberto ................................................ 20

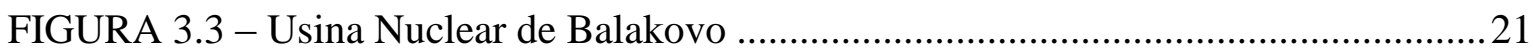

FIGURA 4.1 - Principais entradas e saídas do programa SIMPACTS ...............................2 29

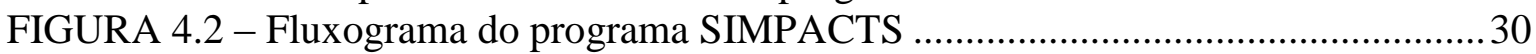

FIGURA 4.3 - Exibição da entrada do modelo para barragem e características do local ... 33

FIGURA 4.4 - Índices de Terreno Atuais Disponíveis no Modelo ...................................... 34

FIGURA 4.5 - Tela de Entrada do Modelo para Características da População e da Terra . 34

FIGURA 4.6 - Tela de Entrada do Modelo para Características de Custo ............................. 35

FIGURA 4.7 - Tela de Entrada do Modelo para Características de Emissão......................... 35

FIGURA 4.8 - Tela de Entrada do Modelo para Perda de Produção Agrícola e de Gado .. 36 FIGURA 4.9 - Tela de Entrada do Modelo para de Recursos Naturais e Culturais e Custo

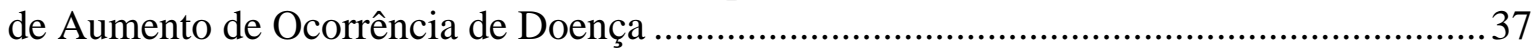

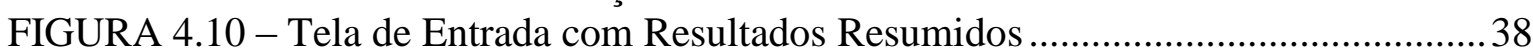

FIGURA 4.11 - Tela de Entrada com Gráficos dos Resultados das Emissões ........................ 38

FIGURA 4.12 - Tela de Entrada do Modelo para Características de Custo ..........................39

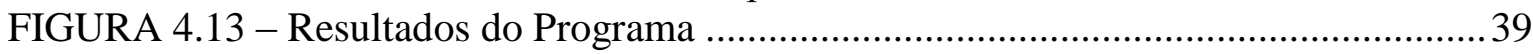

FIGURA 4.14 - Modelo 3D do Reservatório - Cubo Triangular .......................................... 41

FIGURA 4.15 - Caminhos para as emissões atmosféricas de radionuclídeos (a) e Caminhos para a descarga líquida de radionuclídeos em ambiente aquático (b).................................52

FIGURA 4.16 - Fluxograma demonstrativo da metodologia de cálculo do módulo

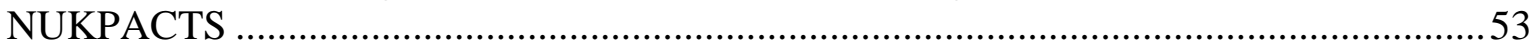

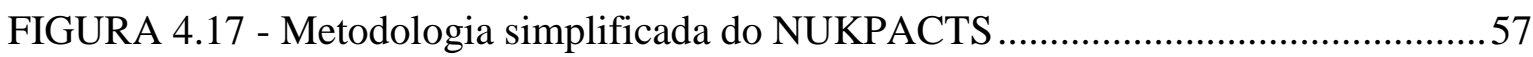

FIGURA 4.18 - Telas de entrada do modelo para Dispersão e Recepção ............................59

FIGURA 4.19 - Telas de entrada do modelo para Emissões e Meteorologia.......................59

FIGURA 4.20 - Telas de entrada do modelo para Consumo de alimentos .......................... 60

FIGURA 4.21 - Telas de entrada do modelo para Efeitos na saúde e Valoração.................. 60

FIGURA 4.22 - Vias de transferência de exposição atmosférica usada no NUKPACTS...61

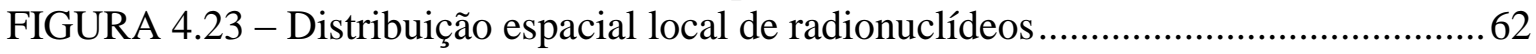

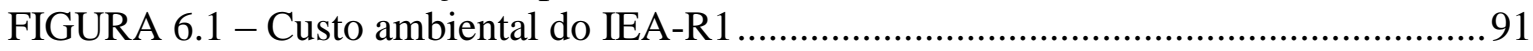

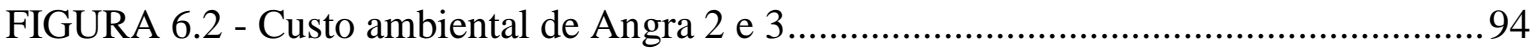

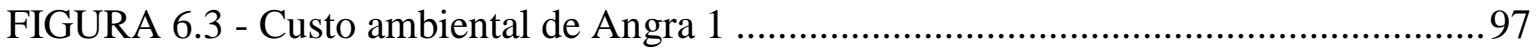

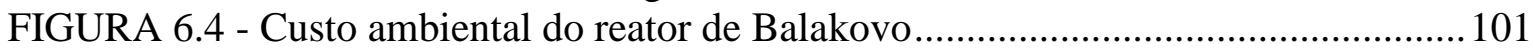

FIGURA 6.5 - Custo ambiental de usina a carvão na França ............................................ 104

FIGURA 6.6 - Custo ambiental da energia hidrelétrica................................................. 108

FIGURA 6.7 - Emissões durante a operação da usina hidrelétrica ................................... 109 


\section{INTRODUÇÃO}

O crescimento rápido e mal planejado da produção e do consumo energético leva a impactos ambientais que podem comprometer o desenvolvimento sustentável. A produção de energia a partir de combustíveis fósseis ou nucleares, por meio da exploração em grande escala de hidroeletricidade ou ainda de recursos de biomassa, provoca os mais severos impactos ambientais, tanto em nações em desenvolvimento como nas industrializadas (JANNUZZI; SWISHER 1997).

No passado, as questões ambientais eram consideradas secundárias, face à necessidade do contínuo crescimento econômico das nações. Recentemente, tanto impactos ambientais globais como locais têm sido identificados como uma restrição potencial ao desenvolvimento. Dessa forma, o setor energético passou a ocupar um lugar diferenciado no sistema econômico e, consequentemente, passou a ser pensado de maneira mais cautelosa (JANNUZZI; SWISHER 1997).

A energia tornou-se fator primordial nos países em desenvolvimento. O crescimento econômico nesses países tem implicado em um aumento ao acesso à energia comercial. O aumento da urbanização e a industrialização, que se processam em paralelo, são atividades que contribuem ainda mais para o uso intensivo de energia (JANNUZZI; SWISHER 1997).

Uma das características mais importantes do setor energético é a necessidade de grandes investimentos de capital. Algumas nações em desenvolvimento, por exemplo, gastam mais de $30 \%$ do seu orçamento total com empreendimentos energéticos (JANNUZZI; SWISHER 1997).

A produção de eletricidade é vital para o ser humano moderno, uma vez que a energia elétrica auxilia no desempenho de grande parte das atividades diárias, tais como a produção de alimentos, a construção de prédios e a produção em larga escala. A produção de eletricidade é responsável por quase $20 \%$ do consumo de energia primária mundial e ainda dois bilhões de pessoas em todo o mundo não têm acesso a esse bem. Por tal razão, os programas de eletrificação - como o Programa Luz para Todos no Brasil - são prioritários e têm sido adotados em países em desenvolvimento (BRASIL, 2012).

Nos anos 70, a crise do petróleo fez com que o seu preço aumentasse consideravelmente e, combinado esse fato com o aumento das taxas internacionais de 
juros, deu-se o fim da era da energia barata, resultando no questionamento do modelo de desenvolvimento adotado até aquele momento. Desde então, a energia se tornou uma forte limitação para o progresso econômico de muitos países em desenvolvimento, representando um fator de preocupação tanto na área econômica quanto na ambiental (JANNUZZI; SWISHER 1997).

Grande parte da energia gerada no mundo é proveniente de fontes fósseis. O modelo energético da maioria dos países está baseado no consumo de combustíveis fósseis, ou seja, petróleo, gás natural e carvão. O principal problema desse modelo é que os recursos utilizados não são renováveis e, dessa forma, sua utilização está limitada em longo, médio ou até curto prazo. Além disso, os combustíveis fósseis causam muitos danos ao meio ambiente, como a poluição atmosférica, que afeta diretamente a saúde das pessoas e dos seres vivos como um todo.

Por utilizarem matérias-primas renováveis para produção de energia, as fontes alternativas surgem como opção e ganham destaque, pois não emitem gases poluentes e, ao utilizar matérias-primas renováveis e abundantes, contribuem para garantir a sustentabilidade almejada, principalmente, nos países em desenvolvimento (GOLDEMBERG; LUCON 2007).

A classificação das fontes como renováveis ou não pode ser controversa. Em princípio, nenhuma fonte pode ser considerada absolutamente inesgotável. No entanto, algumas fontes de energia são consideradas renováveis se o seu uso pela humanidade não causar uma variação significativa nos seus potenciais e se suas reposições em curto prazo forem relativamente certas (JANNUZZI; SWISHER 1997).

As principais fontes alternativas de energia são: eólica, solar e biomassa. Entre as fontes alternativas, está a energia nuclear, que tem se destacado no Brasil, com a operação das Usinas Nucleares Angra 1 e 2, em Angra dos Reis, e mais recentemente com a construção de Angra 3 (ELETRONUCLEAR, 2009).

A energia nuclear não é baseada na combustão de hidrocarbonetos e tampouco acompanhada pelos poluentes usuais resultantes da queima dos combustíveis fósseis. Sob esse aspecto, é considerada uma fonte de energia limpa. Contudo, seu problema está nos rejeitos radioativos, na segurança e nas emissões de carbono durante todo o seu ciclo de vida, que inclui a desativação de minas e reatores (ALVIM et al., 2007).

O uso da energia nuclear para a produção de eletricidade foi um subproduto do desenvolvimento dos reatores nucleares com fins militares durante e após a Segunda Guerra Mundial (1939-1945). A fonte da energia nuclear é a desintegração do núcleo do 
átomo de urânio, que libera uma quantidade considerável de energia na forma de energia cinética dos fragmentos como estrôncio e xenônio que, em geral, são radioativos. Esse processo é chamado de físsão nuclear e pode ser produzido bombardeando átomos de urânio com nêutrons. A fissão nuclear é acompanhada pela emissão de nêutrons, de prótons, de radiações como os raios X e liberação de $200 \mathrm{MeV}$ de energia por fissão. Os fragmentos finais radioativos constituem os rejeitos nucleares, que constituem um dos problemas mais sérios resultante do uso desse tipo de energia (CARDOSO, 2011).

No ano 2000, as usinas nucleares geraram $16 \%$ da eletricidade mundial, num total de 14.115 TWh (IEA, 2005). Atualmente, a maioria dos 438 reatores em operação no mundo está em países membros da OCDE (Organização para a Cooperação e Desenvolvimento Econômico), que gera 64\% de toda a energia nuclear mundial, e na exURSS. A capacidade instalada total é de cerca de 374 MW (IAEA, 2014).

A grande maioria dos reatores foi construída durante a "era de ouro" da energia nuclear, entre 1975 e 1990. A construção da maior parte desses reatores teve início antes de 1975 e foi finalizada por volta de 1985. Após os acidentes de Chernobyl e Three Mile Island, sérias preocupações levaram a uma estabilização nesse número. Ainda que a capacidade tenha crescido pouco, as condições operacionais dos reatores estão se aprimorando, aumentando assim a quantidade de energia produzida (DONALD, 2004).

O incremento na capacidade nuclear diminuiu a partir de 1995 devido, principalmente, à vantagem econômica das usinas termelétricas com combustíveis fósseis, com menor custo de capital. $\mathrm{O}$ aumento das exigências de segurança e os custos de descomissionamento também afetaram a viabilidade econômica da energia nuclear. Ao contrário de outras tecnologias e contrariando previsões otimistas, a energia nuclear não tem demonstrado seguir um processo de curva de aprendizado, pela qual os custos decrescem com os ganhos de escala (NAKICENOVIC, 2012).

No Brasil, a utilização da energia nuclear cresceu nas últimas décadas, mas ainda é pequena em comparação com outros países. Recentemente o governo brasileiro manifestou interesse em aprovar o Plano Nacional de Energia Nuclear, que começou com a decisão de retomar a construção de Angra 3 e fazer um escalonamento para que a cada dois ou três anos, seja implantada uma nova usina de pequeno porte.

Sob o ponto de vista ambiental, a energia nuclear é frequentemente apresentada por seus defensores como uma alternativa eficiente para o problema das emissões de gases de efeito estufa. Por outro lado, os ambientalistas, em geral, se opõem aos reatores 
nucleares por conta dos riscos de acidentes, das incertezas no gerenciamento dos resíduos e dos perigos da proliferação de armas atômicas (RIBEIRO, 2007).

Percebe-se, porém, que nos últimos anos as objeções ambientais diminuíram de intensidade. A razão principal para isto baseia-se na percepção de que a questão dos resíduos gerados atinge não só a energia nuclear como também todo o conjunto das energias térmicas, no qual a energia nuclear está incluída, sendo que as demais ainda possuem o agravante de emitir gases causadores do efeito estufa (ALVIM et. al, 2007). Como se sabe, o efeito estufa é algo benéfico para o planeta, pois o mantém aquecido tornando a vida na Terra possível. No entanto, o aumento da concentração de determinados gases na atmosfera provoca o efeito estufa adicional, aquecendo assim demasiadamente o planeta e alterando seu equilíbrio natural.

As fontes alternativas de energia, incluindo a nuclear, apresentam vantagens com relação às externalidades. Externalidade é um termo que representa os efeitos colaterais da produção de bens ou serviços sobre outras pessoas que não estão diretamente envolvidas com a atividade (THOMAS; CALLAN, 2010). Assim, as externalidades referem-se aos resultados de uma decisão sobre aqueles que não participaram da mesma. As externalidades podem ter efeitos positivos ou negativos, gerando custos ou benefícios para a sociedade. Quanto à utilização de combustíveis fósseis, a poluição por eles gerada afeta agentes externos que não necessariamente compartilham os benefícios, somente os prejuízos.

As externalidades ambientais podem ser definidas como custos não valorados em transações de mercado com o qual toda a sociedade acaba arcando em decorrência de uma atividade realizada por determinados agentes privados. A presença do Estado é necessária para internalizar tais custos a fim de conciliar as atividades econômicas com a proteção ambiental. Se internalizados, os custos sociais aumentam os preços dos produtos e reduzem a demanda. Na maioria das vezes, isso não ocorre, e a sociedade acaba por pagar a diferença.

As externalidades podem ser identificadas e relacionadas ao termo custo ambiental. O custo ambiental é uma externalidade negativa que prejudica, de alguma forma, o meio ambiente e, convertida em termos econômicos, pode então ser comparada aos demais custos de uma ação e/ou empreendimento (THOMAS; CALLAN, 2010).

Cálculo de custo ambiental é um conceito que surgiu a partir da maior atenção que vem sendo dada às questões ambientais. Um impacto ambiental, convertido em termos econômicos, é um custo ambiental, que muitas vezes a sociedade arca sem usufruir dos 
benefícios de determinada atividade. Grande parte dos estudos de cálculo de custo ambiental é feita a partir de fontes de energia elétrica, atividade muito importante mundialmente, com impactos ambientais significativos.

Para uma completa avaliação dos custos, os danos e custos externos devem ser primeiramente quantificados e depois integrados ao processo de tomada de decisão. $\mathrm{Na}$ maioria dos casos, estimar danos é o maior desafio, em parte devido aos limites atuais de conhecimentos no assunto e em parte por causa da grande quantidade de dados necessários para realizar a análise. Para estes cálculos, existem alguns programas específicos que possibilitam a conversão dos danos em termos econômicos e a inclusão do custo ambiental na análise de custo de determinado projeto.

$\mathrm{Na}$ literatura, existem alguns programas que realizam o cálculo de custo ambiental, aplicáveis a diferentes fontes e cadeias energéticas, como: o ExternE, o Decades (Databases and Methodologies for Comparative Assessment of Different Energy Sources for Electricity Generation) (IAEA, 2000) e o B-Glad (IAEA, 1999), entre outros.

O programa ExternE foi desenvolvido pela Comissão Europeia para quantificar os impactos e custos sociais decorrentes de contaminantes atmosféricos. O EcoSense faz parte do programa ExternE, sendo um modelo integrado de Avaliação de Impacto Ambiental, que considera os impactos causados pela emissão de poluentes de uma instalação genérica na saúde humana, no clima e nos ecossistemas (IAEA, 2012). Na FIG. 1.1 está demonstrado o fluxograma com a sequência de cálculos. 


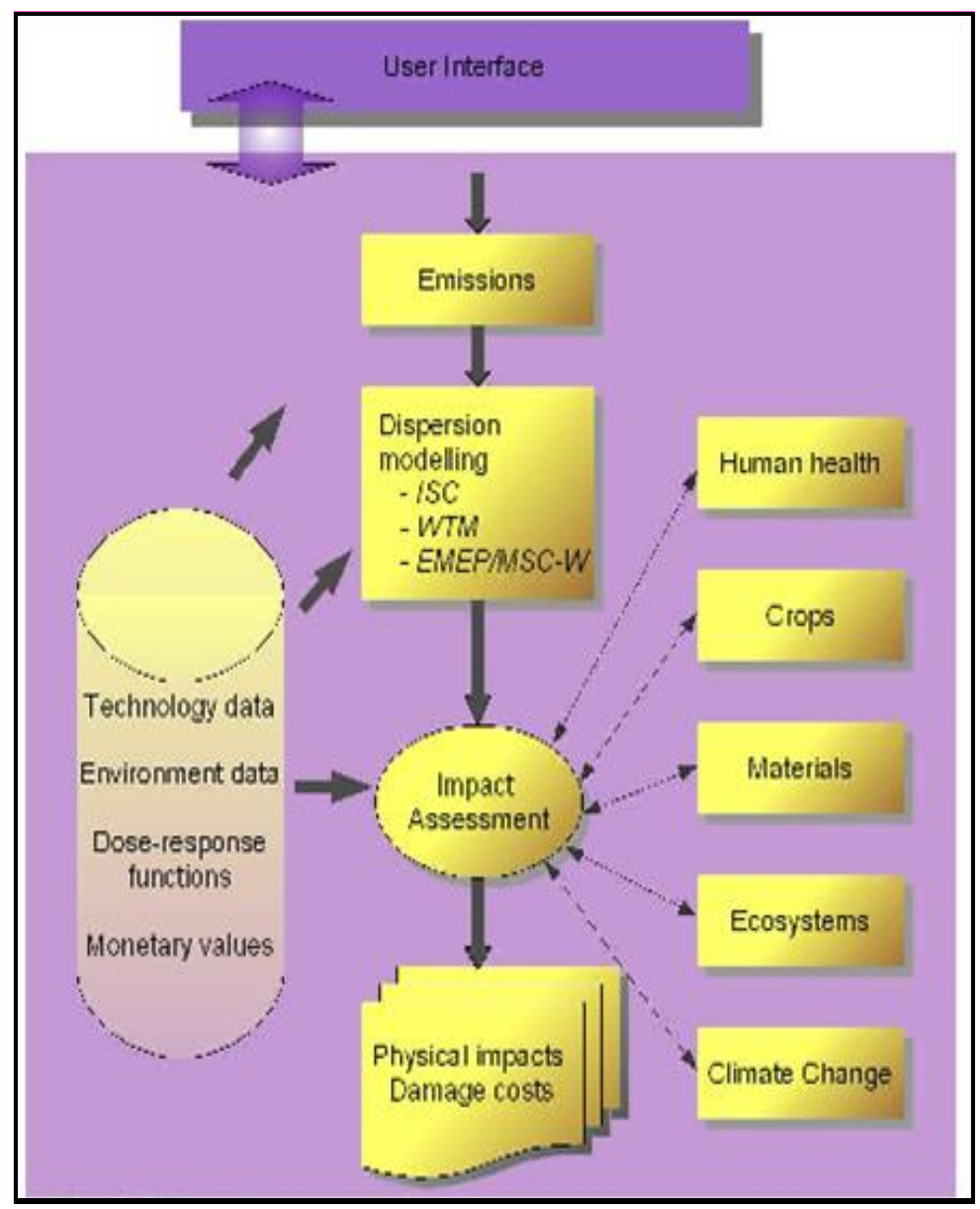

FIGURA 1.1- Fluxograma do programa ExternE

O programa Decades foi criado no fim de 1992, com o objetivo de facilitar o desenvolvimento de estratégias sustentáveis que possam fornecer serviços necessários de energia para suportar o crescimento econômico e melhorar a qualidade de vida, enquanto minimiza os impactos adversos para o ambiente e para a saúde (IAEA, 2009).

No caso mais específico de centrais nucleares, o programa B-Glad, desenvolvido pela Agência Internacional de Energia Atômica (AIEA), em 1999 (IAEA, 1999), é utilizado. O programa B-Glad apresenta uma série de planilhas que deverão ser preenchidas com as devidas informações sobre a instalação nuclear em estudo. No entanto, esse programa necessita de uma série de informações da instalação que nem sempre estão disponíveis.

Outro programa desenvolvido pela AIEA para o cálculo de custo ambiental de centrais nucleares é o SIMPACTS (Simplified Approach of Estimating Impacts of Electricity Generation) (IAEA, 2011), que é o objeto do presente estudo e será descrito de forma detalhada durante o trabalho. 


\subsection{Objetivo do trabalho}

O objetivo deste trabalho é realizar, por meio do programa SIMPACTS, o cálculo de custo ambiental das usinas nucleares de Angra 1, 2 e 3, localizadas na cidade de Angra dos Reis, no Rio de Janeiro, e comparar os resultados com os das instalações cujos dados estão no próprio programa.

\subsection{Motivação do trabalho}

A motivação deste trabalho surgiu devido à necessidade de uma completa avaliação dos custos ambientais provenientes de reatores nucleares de potência, embora já se conheça que esse tipo de forma de geração de energia apresente certa vantagem em relação às demais, no que diz respeito às externalidades. Não há nenhum estudo desse tipo no Brasil; assim, é importante fazer esses cálculos para a nossa área de estudo e comparálos com os custos ambientais de diferentes formas de energia. Isso será feito de forma parcial no presente trabalho.

Outra motivação do trabalho seria a necessidade da desmistificação dos conceitos errados a cerca da energia nuclear. Face aos problemas de abastecimento energético no país, a energia nuclear torna-se competitiva e suas vantagens como fonte de energia elétrica, além de outros usos, devem ser expostas à sociedade.

\subsection{Itens do trabalho}

No capítulo 2, a revisão bibliográfica dos cálculos de custo ambiental encontrados na literatura para várias fontes de energia é apresentada. $\mathrm{O}$ capítulo 3 descreve brevemente as instalações estudadas. O capítulo 4 contém a metodologia empregada para o cálculo do custo ambiental, ou seja, o modo de funcionamento do programa SIMPACTS. No capítulo 5, são apresentadas as aplicações do modelo de cálculo de custo ambiental para as instalações nucleares IEA-R1 e Angra 1, 2 e 3, como também para o reator nuclear de Balakovo, hidroelétrica Serra da Mesa e uma termoelétrica genérica na França. O capítulo 6 apresenta uma análise dos resultados obtidos e uma discussão destes e, no

capítulo 7, estão as conclusões e as propostas para trabalhos futuros. Por fim, são apresentadas as referências bibliográficas utilizadas no trabalho. 
O ANEXO A contém as equações utilizadas pelo módulo NUKPACTS para realizar o cálculo do custo ambiental.

O ANEXO B contém o Teste de Sensibilidade realizado para o programa SIMPACTS. 


\section{REVISÃO BIBLIOGRÁFICA}

A revisão bibliográfica apresentada considera alguns trabalhos referentes ao cálculo de custo ambiental e externalidades, assim como demonstrações práticas do uso do programa SIMPACTS.

A questão das externalidades tem sido debatida intensamente nas últimas décadas em razão do maior destaque dado às questões ambientais. Coase (1960) foi um dos primeiros a tratar do tema, argumentando que as externalidades existem devido à ausência de mercado e de direitos de propriedade bem definidos. No caso da poluição da água, por exemplo, ninguém é proprietário da água poluída e, por isso, falta um mercado: o mercado da poluição. Segundo o autor, internalizar essa externalidade significa incluir no preço pago pela água os custos causados pela poluição para que se usufrua dos resultados de sua produção e utilização. Coase desenvolveu o Teorema de Coase, uma teoria que busca resolver as externalidades provocadas pelos mercados. Segundo o Teorema, se os agentes envolvidos com as externalidades puderem negociar (sem custos de transação) a partir de direitos de propriedade bem definidos pelo Estado, esses poderão chegar a um acordo, que terá como resultado a internalização das externalidades.

$\mathrm{Na}$ economia do meio ambiente, usa-se o termo externalidades, como um dos conceitos para se tratar dos recursos naturais e bens públicos. Segundo Reis (2001), externalidades são os efeitos do comportamento de pessoas ou empresas no bem-estar de outras pessoas ou empresas, que não se refletem diretamente no mercado. As externalidades podem ser positivas, quando o comportamento de um indivíduo ou empresa beneficia outros, mesmo involuntariamente; ou negativas, no caso oposto. O autor defende que a presença dessas externalidades distorce o sistema de incentivos constituinte do sistema de preços, tornando ineficiente a alocação de recursos naturais e afetando outros fatores de produção, como a repartição dos bens produzidos. Isso faz com que alguns bens sejam produzidos em excesso enquanto outros são produzidos de maneira insuficiente, da mesma maneira que certos agentes consomem muito desses bens e outros, pouco. Por fim, o autor afirma que a fim de remediar as deficiências de mercado citadas, pode-se fazer uso de instrumentos econômicos e, antes de tudo, deve-se quantificar o valor do bem ou serviço não contabilizado proporcionado pela natureza, ou seja, a própria externalidade. 
Pereira e Franco (1992) definiram custo como "um sacrifício de recursos com vista a atingir determinado objetivo". Se esse sacrifício diz respeito aos recursos naturais e à qualidade de vida, estamos perante aos custos ambientais.

Em 1993, Goddard e Goddard identificaram e compararam os custos ambientais dos sistemas de geração de energia elétrica. Ao identificar os custos totais de um sistema de obtenção de energia, os autores levaram em consideração os custos externos de diferentes formas de produção. A energia eólica tem o menor custo ambiental dentre as fontes de energia analisadas no artigo, seguida das pequenas centrais hidrelétricas, solar, geotermal, biomassa, nuclear, gás natural e carvão.

Krewitt (1997) também abordou o tema das externalidades em relação à geração de eletricidade. Segundo o autor, os estudos sobre os custos externos da geração de eletricidade em geral visam o cálculo dos custos marginais para um incremento de novas fontes de geração de energia. Dessa forma, o autor desenvolveu uma metodologia para calcular a média dos custos dos danos da geração de eletricidade provenientes de fontes fósseis na Alemanha e na Europa, como um todo, em relação à saúde e ao meio ambiente. Os resultados demonstram que os custos por tonelada de poluente emitido podem variar consideravelmente de acordo com a planta e com mudanças estruturais. A quantificação dos impactos ambientais e custos de danos resultantes seguiu a abordagem metodológica desenvolvida no ExternE. O autor afirma que, no passado, os estudos sobre externalidade eram muito focados na análise de custos marginais externos de geração de eletricidade em uma planta específica.

Diversos autores fizeram diferentes classificações dos custos ambientais de acordo com perspectivas distintas. Soler (1997) dividiu os custos ambientais em diretos, ocultos, intangíveis e futuros. Os diretos são os de transporte e tratamento e eliminação de resíduos; os ocultos são aqueles relacionados às notificações, análises, declarações, medidas de segurança, etiquetas e seguros de acidentes; os intangíveis são os de qualidade do produto, impacto ambiental, imagem da empresa e higiene; e os futuros são os relacionados à responsabilidade de saneamento do solo, substituição de recursos, causas civis e criminais e danos sanitários.

Hochman (1998) apresenta outra classificação sob o ponto de vista da sustentabilidade: custos ambientais implícitos, custos derivados de investimentos, custos de produção e custos sociais. Os primeiros dizem respeito aos que produzem efeitos irreparáveis sobre o meio ambiente, representando um elevado custo para a sociedade. Os danos causados não permitem renovação, o que representa graves riscos para a 
sobrevivência das espécies e manutenção da qualidade de vida. Os derivados de investimento dizem respeito aos custos que são gerados com o objetivo de adotar processos produtivos ambientalmente mais corretos. Os custos de produção são aqueles em que as empresas incorrem com o objetivo de realizar suas atividades industriais, destacando-se a contratação de mão-de-obra qualificada e sua formação. Os últimos referem-se aos impostos, sanções, multas, seguros e outros custos.

Muralha (1999) classificou os custos relacionados ao meio ambiente em custos ecológicos e custos ambientais. Custos ecológicos são aqueles relacionados à prevenção, enquanto os custos ambientais são os custos externos que incluem não somente as indenizações, mas também os custos relacionados à restauração do ambiente. Apesar das diferentes classificações possíveis, os autores concordam que, ao se considerar os custos ambientais, a melhor classificação é aquela que está na base de um sistema de informações adequadas, que levam os gestores a tomarem as melhores decisões.

Motta (2000) desenvolveu inúmeros estudos acerca de temas inseridos na economia ambiental, tratando de custo ambiental e valoração do meio ambiente. Em seu trabalho, aborda os instrumentos econômicos e afirma que, para a formulação de um preço econômico, é preciso considerar o preço da externalidade, além do preço de indução (aquele que é baseado em simulações para identificar como os indivíduos alterariam seu comportamento de uso do recurso frente ao preço) e o preço de financiamento. Sua definição de preço de externalidade é que este adota o critério do nível ótimo econômico de uso do recurso quando as externalidades negativas são internalizadas no preço desse.

Reis (2001) escreveu um artigo em que tratou da aplicação de métodos de valoração econômica do meio ambiente para a quantificação dos principais impactos associados à geração de energia elétrica. Segundo o autor, o grande problema na junção dos aspectos econômicos com os ambientais é que os dispositivos econômicos atuais não percebem a degradação do meio ambiente. Os atuais Sistemas de Contabilidade Nacional não refletem a degradação da base de recursos, e os preços dos produtos também não internalizam a degradação do meio ambiente e os serviços prestados pela natureza. A internalização desses custos de degradação requer a valorização do serviço proporcionado pela natureza em termos monetários e, neste contexto, estão inseridos os métodos de valoração econômica.

Markandya \& Boyd (2002) afirmaram que, para obter os custos dos danos, deve-se multiplicar os impactos pelo seu custo unitário. Por exemplo, custos unitários de impactos sobre a saúde incluem o custo do salário doença e as perdas de produtividade. Os 
custos unitários devem basear-se em estudos específicos da valoração econômica de cada país. Na ausência de tais informações, os autores afirmam que os valores existentes de uma localização podem ser transferidos para outro país, após o ajuste adequado em relação à paridade do poder de compra entre os dois lugares.

Kammen e Pacca (2004) compararam métodos de identificar e analisar os custos associados a diferentes formas de energia. Segundo os autores, energia é a commodity mais importante em nível internacional, em termos de fluxos de materiais, transferências financeiras e impactos sócio-políticos e ambientais. Ao mesmo tempo, os métodos usados para avaliar os custos dos recursos energéticos e serviços diferem muito em termos de perspectivas teóricas e filosóficas, sendo frequentemente usados para destacar os pressupostos diferentes de segurança econômica, social, e valor ambiental de energia renováveis e recursos não renováveis. No artigo, afirma-se que os efeitos externos não são adequadamente precificados e alocados pelo mercado. Esforços para quantificar as externalidades resultantes do uso da energia não são amplamente debatidos, sendo necessários mais estudos na área. Como resultado, foi apresentada uma avaliação monetária parcial dos serviços ecossistêmicos mundiais, sendo que o valor calculado foi entre 18 e 56 trilhões de dólares. Os autores discutiram as externalidades envolvidas com a construção e operação de uma hidroelétrica e de usina movidas a combustíveis fósseis. A planta hidroelétrica tem suas externalidades concentradas nos custos de aquisição de terras e reassentamento das pessoas, sendo o custo médio de reassentamento de U\$S 3.000 per capita. Esses custos, muitas vezes, não são contabilizados e inclusos no valor total estimado da construção de uma hidrelétrica. No caso de plantas movidas a combustíveis fósseis, estudos recentes acerca dos impactos na saúde, realizados em Illinois, Estados Unidos, demonstram que ocorrem, em média, 300 mortes anuais por causa da poluição atmosférica proveniente de emissões dos combustíveis fósseis. O custo anual atribuído à operação de tais plantas foi de 450 milhões de dólares, ou US\$0,50/kWh. Os autores também abordaram temas relacionados, como estratégias de valoração e avaliação de ciclo de vida.

Em 2008, Nisan e Benzarti publicaram um trabalho onde fizeram uma comparação entre os custos externos de alguns combustíveis fósseis, como carvão e tecnologias a óleo; geração nuclear; e algumas fontes renováveis, como eólica, fotovoltaica, hidroeletricidade e biomassa para dessalinização da água do mar. Segundo os autores, a produção e o consumo de energia estão relacionados a uma ampla gama de problemas ambientais e sociais, como os efeitos na saúde decorrentes da poluição do ar, 
água e solo, distúrbios ecológicos e perda de espécies e danos na paisagem. Os custos desses danos são definidos como externalidades ou custos externos. O estudo foi feito com base nas condições específicas reais de plantas localizadas no sul da Europa. Também foram realizados estudos de sensibilidade para diferentes parâmetros, tais como preço dos combustíveis fósseis, taxas de juros e descontos e custos de energia. Os resultados obtidos pelos autores são extremamente dependentes do local analisado. Eles concluem que a fonte eólica é a melhor no que diz respeito à emissão de poluentes, mas salientam que nem todo local possui as condições ideais para a implantação dessa fonte de energia. Também se conclui no artigo que a geração nuclear tem os menores custos externos, depois da geração eólica, mesmo quando a baixa probabilidade de acidentes com graves consequências é integrada ao cálculo.

Czarnowska e Frangopoulos (2011) desenvolveram um trabalho em que caracterizaram a emissão de poluentes como óxidos nitrogenados e materiais particulados provenientes de sistemas de conversão de energia. Esses poluentes causam danos para o ambiente e para a sociedade, não só vizinha do sistema, como também de áreas distantes. Os custos desses danos provocados por agentes distantes, que vão impactar aqueles que não participaram da decisão da ação, são expressos pelo termo externalidades. Foram identificadas as externalidades referentes a usinas de carvão localizadas em diferentes países da Europa, e o programa ExternE foi utilizado para estimar os poluentes atmosféricos. Alguns resultados apresentados demonstraram que o maior valor de custo externo relacionado ao dióxido de enxofre foi na Suíça $\left(15,08\right.$ euros por $\mathrm{Kg}$ de $\left.\mathrm{SO}_{2}\right)$ e o menor valor foi na Noruega (3,27 euros por $\mathrm{Kg}$ de $\mathrm{SO}_{2}$ ). Ao se considerar o $\mathrm{NOx}$, o maior custo externo foi atribuído também à Suíça $(20,27$ euros por $\mathrm{Kg})$ e o menor, a Portugal $(1,09$ euros por $\mathrm{Kg})$. Os autores constatam que a discrepância entre os países da Europa, em relação aos custos externos de poluentes, é muito grande, sendo que os custos na Suíça são 4,6 vezes maiores do que na Noruega, por exemplo. Segundo os autores, os custos externos resultam de danos que não estão refletidos nos preços de mercado dos produtos, mas os governos começaram a levar em consideração esses custos nas decisões de gestão como resultado de leis. O trabalho desenvolvido pelos autores salienta que é necessário identificar esses danos, estimar os custos associados e internalizá-los a fim de revelar o verdadeiro desempenho econômico do sistema. Uma das conclusões é que o custo ambiental e social externo relacionado à poluição tem um impacto significativo no custo da eletricidade e, portanto, não deve ser ignorado. Os estudos devem ser realizados em plantas particulares e em localizações e níveis diferentes para se obter o efeito completo da 
poluição no ambiente. A localização da fonte de emissão também tem um efeito significativo no custo externo da poluição e está em função de fatores como: concentração de fundo de determinada localidade, dispersão da poluição e densidade da população.

A utilização do programa SIMPACTS para a realização de cálculo de custo ambiental ainda é pouco revelante em termos quantitativos. O programa ainda é pouco conhecido e, no Brasil, não há nenhum estudo realizado com a utilização do mesmo. A seguir serão descritos alguns exemplos encontrados na literatura da aplicação prática do programa em diferentes partes do mundo.

Foi realizado um estudo a partir de dados de um reator nuclear na França, obtidos com a utilização do SIMPACTS. Os dados obtidos são de ocorrência de um acidente severo, cujo risco é de cerca de 1,9E-6. Os seguintes parâmetros são calculados a partir desses dados: o número de mortes (3.000), número de casos de câncer não fatal (9.000) e indivíduos realocados (10.000). A soma de todos os custos para esse reator francês, convertido em valores monetários, foi de cerca de 18 bilhões de dólares. Além disso, os danos esperados em termos de níveis de radiação para essa usina francesa, que produz 7,6 TWh, são em torno de 0,0044 mills / kWh (CARBONELL, 2003).

Liun et al (2007) publicaram um trabalho avaliando os impactos ambientais nas principais usinas produtoras de energia elétrica da Ilha de Java. Foram avaliadas usinas de carvão, gás natural e nuclear. O objetivo dos autores foi explorar o futuro energético na Indonésia utilizando uma abordagem que leva em conta os aspectos econômicos e os ambientais na análise do sistema de energia em longo prazo. Os danos são muitas vezes referidos como custos externos ou sociais e, uma vez que esses custos não são geralmente refletidos no preço de mercado da energia elétrica, acabam sendo um custo assumido obrigatoriamente pela sociedade. Os resultados da análise demonstram que, dentre todas as alternativas de geração de eletricidade consideradas, a usina nuclear tem o menor custo externo. $\mathrm{O}$ valor de expectativa de dano foi inferior a um décimo de uma fábrica por Kwh de energia elétrica.

O programa SIMPACTS também é usado para avaliar o custo do dano produzido por usinas de energia elétrica. Foi feita uma avaliação das externalidades de usinas de energia elétrica na Região Metropolitana da Cidade do México e um método foi desenvolvido por meio da utilização da abordagem dos caminhos do impacto para estimar os custos dos danos neste caso. A estimativa mostra que os custos anuais totais são de cerca de US\$ 71 milhões (ISLAS, 2010). 
Um estudo semelhante foi realizado para os custos dos danos de geração de eletricidade na Síria. Os resultados obtidos indicaram que os impactos ambientais podem adicionar custos externos consideráveis para os custos típicos de geração, dos quais as externalidades variam entre 0,07 e 2,5 centavos de dólar por kWh gerado (HAINOUN et. al, 2010).

A Agência Internacional de Energia Atômica usou o SIMPACTS no seu próprio trabalho analítico. Em cooperação com o Banco Mundial, completou uma avaliação preliminar dos custos externos dos danos ambientais do acidente de Chernobyl. O projeto concentrou-se principalmente na avaliação dos setores agrícolas, florestais e recursos aquáticos, na necessidade de uma valoração adicional e, especialmente, nos efeitos causados pela produção agrícola na saúde e nos impactos ambientais causados pela exposição ao césio-137, decorrente do acidente de Chernobyl em 1986 (LIUN et. al, 2007).

Todos os estudos enfatizam a importância da quantificação das externalidades em processos de geração de energia e na minimização dos impactos ambientais.

Na próxima seção, serão descritas as instalações utilizadas neste trabalho. 


\section{INSTALAÇÕES ESTUDADAS}

Uma descrição das usinas nucleares será feita inicialmente, abordando o seu contexto no mundo.

\subsection{Usinas Nucleares no mundo}

A energia nuclear foi amplamente difundida durante o início da década de 1940, quando vários países adotaram o uso de reatores nucleares como parte de suas respectivas matrizes energéticas (CARDOSO, 2011). Porém, depois de acidentes como o de Chernobyl, em 1986, o desenvolvimento de novas usinas nucleares no mundo sofreu um período de estagnação (ELETRONUCLEAR, 2009).

Esse período de estagnação teve seu fim nos últimos anos, com o aumento do interesse pela fonte nuclear de geração de eletricidade. Os motivos para o renascimento da energia nuclear podem estar relacionados ao volume de energia produzido e à ausência de emissões de poluentes em um espaço físico considerado reduzido, quando comparado com outras fontes de energia elétrica, como hidrelétricas, por exemplo (ELETRONUCLEAR, 2009).

Atualmente, há 438 reatores nucleares de potência em operação distribuídos entre os países de maneira heterogênea. Na França, há 58 reatores em operação; nos Estados Unidos há 100, na Rússia há 33 e na China, 21, com mais 28 em construção (AIEA, 2014).

Os impactos atribuídos à geração de energia elétrica por meio de centrais nucleares estão associados aos acidentes que já ocorreram e aos rejeitos do processo. A confiança na utilização de energia nuclear diminuiu bastante nas últimas décadas, principalmente, em razão de dois acidentes. O primeiro foi o de Three Miles Island, nos Estados Unidos e o de Chernobyl, na Ucrânia (GONÇALVES \& ALMEIDA, 2005).

Grande parte dos países que investiam em energia nuclear não considerou que a usina de Chernobyl possuía projeto e dispositivos de segurança bem diferentes dos utilizados no ocidente. Isso fez com que muitos países deixassem de investir em centrais nucleares por um tempo, com exceção da França, que se tornou o grande exportador de energia elétrica da Europa (GONÇALVES \& ALMEIDA, 2005).

Entre as formas de geração de energia, a energia nuclear é uma das que produzem menor volume de rejeitos. No entanto, sua maior dificuldade consiste no 
condicionamento dos rejeitos, em razão da sua radioatividade, que pode durar até milhares de anos, gerando a necessidade de isolamento e proteção máxima (GONÇALVES \& ALMEIDA, 2005).

O maior volume de rejeitos é de baixa radioatividade e média radioatividade, provenientes das áreas médica e industrial. Os rejeitos de alta radioatividade provêm dos combustíveis já utilizados nas usinas nucleares que são armazenados nas próprias usinas em um local adequado durante toda a sua vida útil (GONÇALVES \& ALMEIDA, 2005).

Há muito investimento e pesquisa na área, sendo que milhões de dólares são gastos na busca de uma solução para os resíduos. O ideal seria torná-los não radioativos e inócuos, de forma que não provocassem nenhuma alteração no meio ambiente. Os depósitos de rejeitos radioativos são obrigatoriamente gerenciados e administrados pelo país, controlados pelas respectivas agências reguladoras de atividades nucleares, de acordo com normas nacionais e internacionais, visando garantir a segurança da população (GONÇALVES \& ALMEIDA, 2005).

Uma breve descrição das instalações nucleares utilizadas nesse trabalho será apresentada a seguir.

\subsubsection{Instituto de Pesquisas Energéticas e Nucleares (IPEN) - IEA-R1}

O Instituto de Pesquisas Energéticas e Nucleares (IPEN) é uma autarquia do Governo do Estado de São Paulo, gerenciado pela Comissão Nacional de Energia Nuclear e associado à Universidade de São Paulo, no que diz respeito ao programa de pósgraduação.

Localizado na Universidade de São Paulo, o IPEN ocupa uma área de 500.000 $\mathrm{m}^{2}$ e se destaca em diversas áreas relacionadas à atividade nuclear, como nas aplicações das radiações e radioisótopos, materiais e ciclo do combustível, radioproteção e dosimetria, produção de materiais e prestação de serviços de valor econômico e estratégico para o país (IPEN, 2012).

O reator IEA-R1, localizado no IPEN, apresentou sua primeira criticalidade em 16 de setembro de 1957. Após os testes iniciais, passou a operar na potência de $2 \mathrm{MW}$, durante 8 horas por dia, 5 dias por semana. A partir de 1993, começou a operar em ciclos de 64 horas contínuas semanais a 3,5 MW de potência, permitindo irradiar materiais com fluxos de nêutrons térmicos de até $8,5 \times 10^{13} \mathrm{n} \cdot \mathrm{cm}^{-2} \cdot \mathrm{s}^{-1}$ e nêutrons epitérmicos e rápidos da 
ordem de $10^{13} \mathrm{n} \cdot \mathrm{cm}^{-2} \cdot \mathrm{s}^{-1}$, em um arranjo de 24 elementos combustíveis padrões, fabricados no próprio Instituto (IPEN, 2012). Na FIG. 3.1, o reator IEA-R1 será apresentado.

Atualmente, o reator é utilizado principalmente para: produção de radioisótopos para uso em medicina nuclear; produção de fontes radioativas para gamagrafia industrial e de radioisótopos; irradiação de amostras para a realização de análises multielementares; pesquisas em física nuclear; serviços de neutrongrafia; e treinamento de pessoal licenciado para operação de reatores (IPEN, 2012).

Cabe destacar a importância dos reatores de pesquisa, pois neles são produzidos os radioisótopos utilizados na área médica. Por essa razão, o Brasil tem investido fortemente no novo Reator Multipropósito Brasileiro (RMB), que poderá tornar o país autossuficiente na produção de radioisótopos (CNEN, 2011). Os principais objetivos do RMB são a produção de radiofármacos e testes de materiais, além da produção de radioisótopos que poderão ser usados na agricultura (CORREIO BRASILIENSE, 2010). Os reatores de pesquisa são muito importantes para o país, e a construção de novas unidades justifica tal fato.

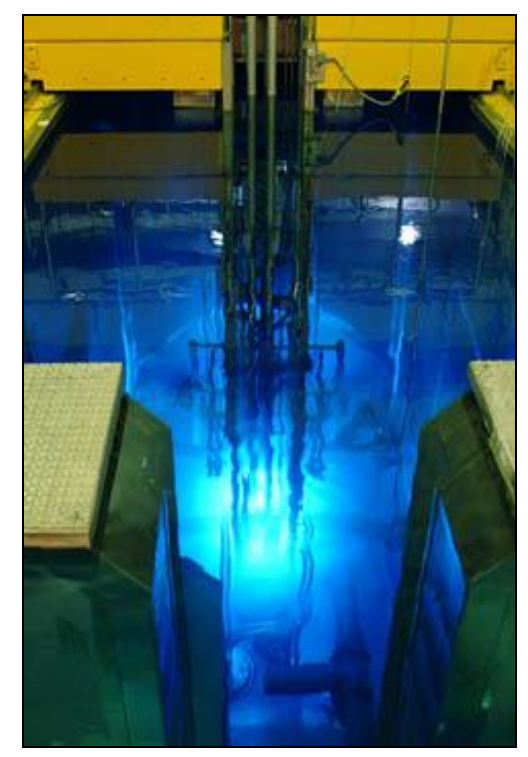

FIGURA 3.1 - Reator de pesquisas IEA-R1

\section{Estação meteorológica (IPEN)}

A torre meteorológica, localizada na parte mais elevada da região do IPEN, é um sistema acompanhado e mantido pela operação do reator e faz parte do programa de monitoração ambiental em operação normal e do planejamento de emergência da 
instalação. Tem a altura de trinta metros e três níveis instrumentados (3m, 10m e 30m). Em cada um dos níveis, estão instalados sensores de temperatura e umidade relativa do ar, velocidade e direção do vento. Na superfície está localizado o sensor de precipitação pluviométrica e no nível de $1 \mathrm{~m}$ está localizado o sensor de pressão atmosférica (MOLNARY, 2012).

Nesse trabalho, foram utilizados dados referentes à ocorrência de classes de estabilidade da atmosfera.

\subsubsection{Reatores Nucleares de Angra 1, 2 e 3}

Angra 1 foi a primeira usina nuclear brasileira e entrou em operação comercial em 1985. Angra 1 opera com um Reator de Água Pressurizada (PWR, do inglês Pressurized Water Reactor), o mais utilizado e seguro do mundo. A usina possui 640 MW de potência, gerando energia suficiente para suprir uma cidade de um milhão de habitantes, como Porto Alegre, por exemplo (ELETRONUCLEAR, 2013).

Essa primeira usina foi adquirida da empresa America Westinghouse. A experiência acumulada permitiu que a Eletrobrás Eletronuclear tivesse a capacidade de realizar um programa contínuo de melhoria tecnológica e incorporar os mais recentes avanços da indústria nuclear, como a troca dos geradores de vapor, o que fez com que a vida útil de Angra 1 fosse estendida (ELETRONUCLEAR, 2013).

Angra 2 começou a operar comercialmente em 2001 e foi a segunda usina nuclear brasileira. Com potência de $1.350 \mathrm{MW}$, é capaz de suprir uma cidade de 2 milhões de habitantes, como Belo Horizonte, por exemplo (ELETRONUCLEAR, 2013).

Assim como Angra 1, essa usina possui um reator do tipo PWR, mas de tecnologia alemã, fruto de um acordo nuclear entre Brasil e Alemanha assinado em 1975. Sua construção propiciou a transferência de tecnologia para o Brasil, o que levou o país a um desenvolvimento tecnológico próprio, resultando em um domínio sobre praticamente todas as etapas de fabricação do combustível nuclear (ELETRONUCLEAR, 2013).

Juntas, Angra 1 e Angra 2 constituem a Central Nuclear Almirante Álvaro Alberto (CNAAA), mostrada na FIG. 3.2. Com obras em andamento, a entrada em operação de Angra 3, que terá $1.405 \mathrm{MW}$, está prevista para dezembro de 2015. Embora seja uma réplica de Angra 2, Angra 3 incorporará avanços tecnológicos desenvolvidos desde então (ELETRONUCLEAR, 2013). 
Angra 3 será a terceira usina da CNAAA e será capaz de gerar mais de 10 milhões de $\mathrm{MW} / \mathrm{h}$ anuais, energia suficiente para abastecer as cidades de Brasília e Belo Horizonte durante um ano inteiro (ELETRONUCLEAR, 2013).

As usinas nucleares geram o equivalente a um terço do consumo de energia elétrica do estado do Rio de Janeiro e representam 3\% da geração nacional de energia elétrica. Além disso, as usinas permitem a regulação do nível dos reservatórios das hidrelétricas, por meio do Operador Nacional do Sistema Elétrico (ONS) (ELETRONUCLEAR, 2013).

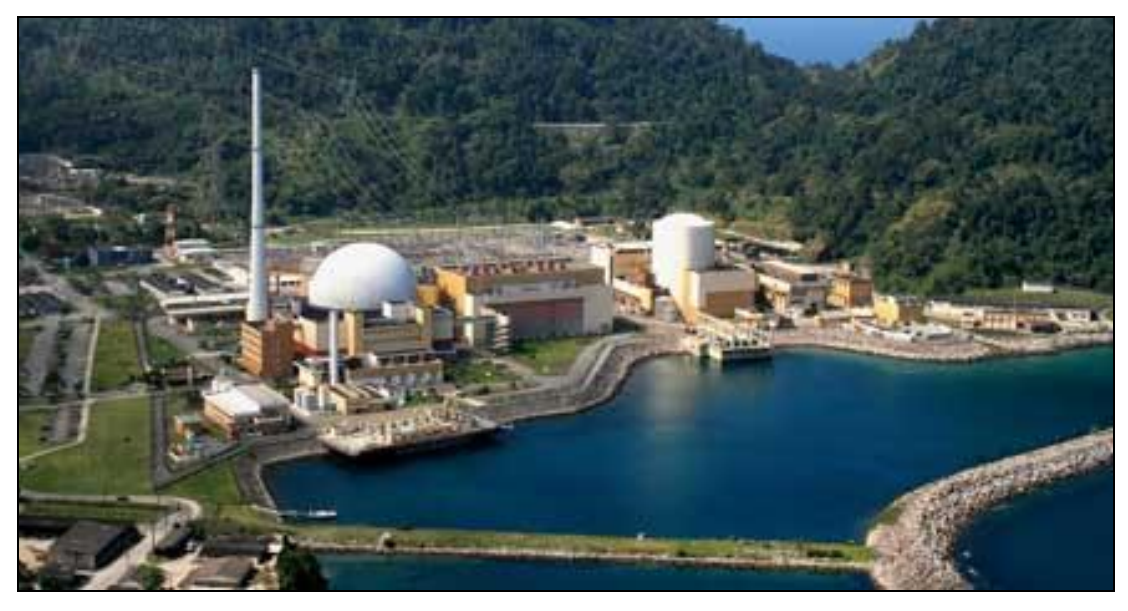

FIGURA 3.2 - Central Nuclear Almirante Álvaro Alberto

\subsubsection{Estação de Balakovo}

A estação de energia nuclear de Balakovo está localizada na cidade de Balakovo, na Rússia, cerca de 900 km a sudeste de Moscou. A estação é composta de quatro reatores idênticos em operação, sendo que uma quinta unidade ainda está em construção e uma sexta teve sua construção interrompida na década de 90. Os reatores em operação são denominados Balakovo 1, 2, 3 e 4, do tipo PWR. A proprietária e operadora da usina nuclear é Rosenergoatom. O mais antigo reator opera desde 1985, e o mais novo, desde 1993. Cada um deles opera com potência de 950MW (IAEA, 2014).

Em 27 de junho de 1985, durante a partida da primeira unidade do reator, por um erro humano, atribuído à inexperiência e pressa, uma válvula de alívio de pressurizador foi aberta, ocasionando a entrada de um vapor de $300^{\circ} \mathrm{C}$ na área de trabalho dos operadores, causando a morte de 14 pessoas (NUCLEAR FILES, 2013). 
Na Rússia, quase $18 \%$ da energia elétrica é proveniente de usinas nucleares. Há 33 reatores nucleares em operação e 10 em construção (IAEA, 2014). A Usina de Balakovo é apresentada na FIG 3.3.

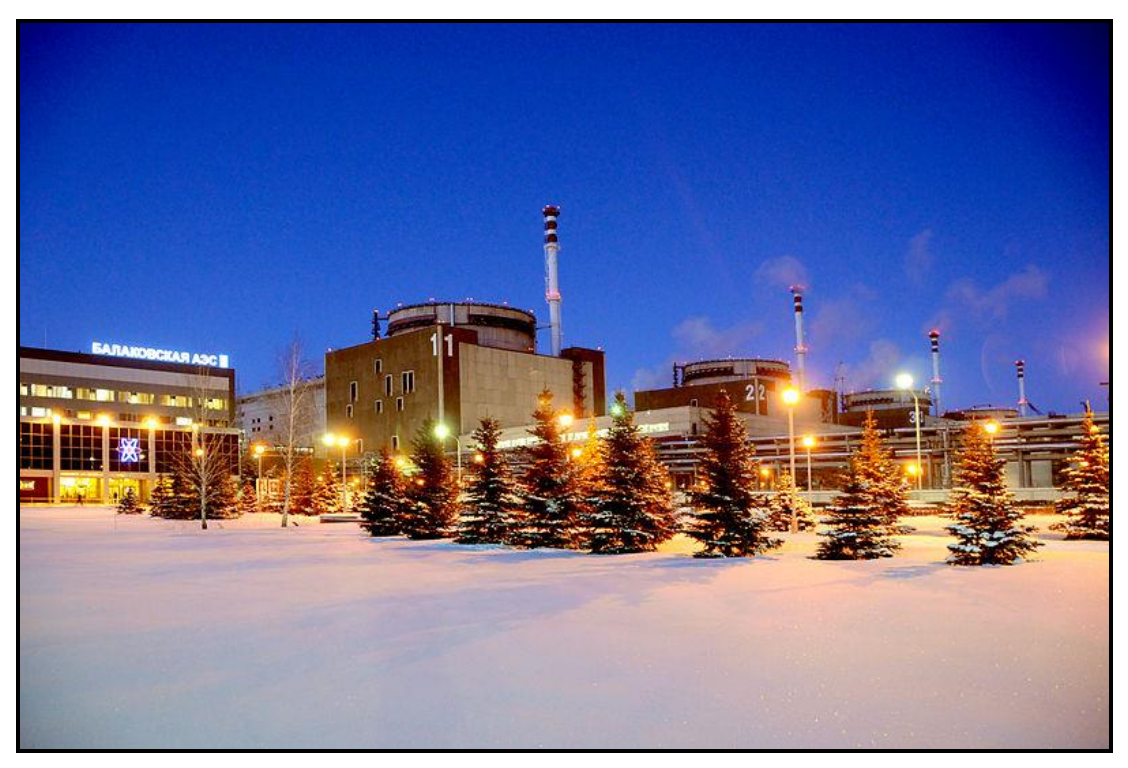

FIGURA 3.3 - Usina Nuclear de Balakovo

As instalações de geração de hidrelétricas no mundo, bem como a que foi utilizada nesse trabalho serão descritas a seguir.

\subsection{Hidrelétricas no mundo}

O século XX foi um período de expansão na construção de grandes barragens. Entretanto, seu maior desenvolvimento teve início nos anos 50, culminando nos anos 70 e, acentuadamente, diminuindo até o fim do século. De forma geral, em torno de 45.000 grandes barragens foram construídas mundialmente, fragmentando mais de $46 \%$ dos rios em um estimado custo de investimento de dois trilhões de dólares, aproximadamente (IAEA, 2003a).

A habilidade de administrar recursos hídricos tornou-se um símbolo de modernização e progresso. Isso gerou um debate crescente a respeito das consequências sociais e ambientais, dos verdadeiros custos econômicos e benefícios dos projetos hídricos, ocasionando uma queda na construção de barragens nos anos 80 e 90.

Centrais hidrelétricas têm desvantagens inerentes em mercados competitivos, onde as decisões do investidor tendem a ser orientadas em curto prazo. Os 
desenvolvimentos hídricos em larga escala, com verbas consideráveis, períodos de construção extensos e períodos longos de amortização carregam uma taxa de risco elevada e são, portanto, prováveis de receber um financiamento privado.

A energia hidrelétrica fornece cerca de $20 \%$ da eletricidade mundial (DOE/EIA, 2001). Em 63 países, ela representa aproximadamente 50\% dos fornecedores nacionais e, em 24 países, em torno de $90 \%$ dos fornecedores nacionais de energia. A América Central e do Sul são as regiões que mais utilizam energia hidrelétrica, com uma média de $75 \%$ do fornecimento regional de eletricidade. A DOE/EIA (2001) projeta que essa divisão terá um declínio de 55\% em 2020 devido ao deslocamento para diversificação de fontes de energia a fim de enfrentar os recentes problemas, como blecautes relacionados com a seca e seus custos excessivos.

Na TAB. 3.1 é apresentado o resumo de alguns dos mais frequentes impactos associados à energia hidrelétrica (IEA, 1998). 
TABELA 3.1 - Resumo breve dos impactos da energia hidrelétrica

\begin{tabular}{|c|c|c|c|}
\hline & Impacto & Prioridade & Detalhes \\
\hline \multicolumn{4}{|c|}{ CONSTRUÇÃO } \\
\hline \multirow[b]{2}{*}{ Estradas de acesso } & Barulhos, emissões & Baixo & \\
\hline & $\begin{array}{l}\text { Acesso crescente de } \\
\text { áreas remotas }\end{array}$ & Médio & $\begin{array}{c}\text { Estradas de acesso poderão } \\
\text { facilitar a migração de } \\
\text { pessoas }\end{array}$ \\
\hline $\begin{array}{l}\text { Acidentes de } \\
\text { construção }\end{array}$ & $\begin{array}{l}\text { Ferimentos e mortes } \\
\text { relacionados ao } \\
\text { trabalho }\end{array}$ & Médio a alto & \\
\hline $\begin{array}{l}\text { Trabalhos locais e } \\
\text { renda }\end{array}$ & $\begin{array}{l}\text { Benefícios de } \\
\text { empregos nacionais e } \\
\text { locais, efeitos } \\
\text { econômicos }\end{array}$ & Alto & \\
\hline \multicolumn{4}{|c|}{ OPERAÇÃO } \\
\hline \multirow{7}{*}{$\begin{array}{l}\text { Represamento e } \\
\text { inundação }\end{array}$} & $\begin{array}{l}\text { Perda de terras } \\
\text { agrícolas }\end{array}$ & Alto & \\
\hline & $\begin{array}{l}\text { Perda de produção de } \\
\text { madeira }\end{array}$ & Alto & \\
\hline & $\begin{array}{c}\text { Perda do habitat de } \\
\text { peixes, pássaros, usinas } \\
\text { e vida selvagem }\end{array}$ & Médio a alto & \\
\hline & $\begin{array}{l}\text { Perda ou mudança de } \\
\text { potencial recreativo }\end{array}$ & Alto & \\
\hline & Reassentamento & Alto & $\begin{array}{l}\text { Reassentamento involuntário } \\
\text { de pessoas que vivem em } \\
\text { áreas de inundação }\end{array}$ \\
\hline & Efeitos na saúde & Alto & $\begin{array}{l}\text { Aumento de doenças } \\
\text { relacionadas à água, como } \\
\text { esquistossomose, malária, } \\
\text { oncocercose, encefalite B } \\
\text { japonesa }\end{array}$ \\
\hline & $\begin{array}{l}\text { Perda de objetos } \\
\text { culturais e } \\
\text { arqueológicos }\end{array}$ & Alto & $\begin{array}{l}\text { Ferimentos e mortes } \\
\text { relacionados ao trabalho }\end{array}$ \\
\hline
\end{tabular}




\begin{tabular}{|c|c|c|c|}
\hline \multirow{3}{*}{$\begin{array}{l}\text { Represamento e } \\
\text { Inundação }\end{array}$} & Impacto & Prioridade & Detalhes \\
\hline & \multicolumn{3}{|c|}{ OPERAÇÃO } \\
\hline & Sedimentação & Alto & $\begin{array}{c}\text { Aumento de sedimentação } \\
\text { que leva a uma perda de } \\
\text { estoque ativo }\end{array}$ \\
\hline \multirow{3}{*}{$\begin{array}{l}\text { Mudança no fluxo } \\
\text { (regime de } \\
\text { volume e fluxo) }\end{array}$} & $\begin{array}{c}\text { Perda do habitat de } \\
\text { peixes, pássaros, usinas } \\
\text { e vida selvagem }\end{array}$ & Médio a alto & $\begin{array}{l}\text { Interrupção de pescarias } \\
\text { ribeirinhas por causa de } \\
\text { mudanças na qualidade de } \\
\text { água e fluxo e bloqueio da } \\
\text { migração de peixes }\end{array}$ \\
\hline & $\begin{array}{c}\text { Mudança na qualidade } \\
\text { de água }\end{array}$ & Médio & \multirow{2}{*}{$\begin{array}{l}\text { Deterioração da qualidade } \\
\text { de água (eutrofização, } \\
\text { acidificação) por causa da } \\
\text { decomposição anaeróbica de } \\
\text { vegetação submersa, do } \\
\text { aumento de nutrientes em } \\
\text { reservatório, da poluição, e } \\
\text { da mudança no fluxo; } \\
\text { afetando a adequação para } \\
\text { bebidas, irrigação, pescarias } \\
\text { e outros usos. }\end{array}$} \\
\hline & $\begin{array}{l}\text { Perda ou mudança no } \\
\text { fornecimento de água }\end{array}$ & Alto & \\
\hline $\begin{array}{l}\text { Falhas nas } \\
\text { Barragens }\end{array}$ & $\begin{array}{l}\text { Lesões e mortes do } \\
\text { público em geral }\end{array}$ & Médio & \\
\hline
\end{tabular}

\subsubsection{Hidrelétrica Serra da Mesa}

A Hidrelétrica Serra da Mesa está localizada no Estado de Goiás, entre os municípios de Minaçu e Colinas do Sul, no rio Tocantins (REIS, 2001).

Sua construção teve início em 1986, mas somente em 1998 a usina começou a funcionar, após a obtenção da Licença de Operação em 1996 (REIS, 2001).

A entrada em operação de Serra da Mesa proporcionou uma solução definitiva para a questão energética no estado de Goiás, assim como no Distrito Federal, produzindo cerca de $6.300 \mathrm{GW} /$ ano. O reservatório dessa usina é o maior do Brasil em volume de água, com 54,4 bilhões de $\mathrm{m}^{3}$ em uma área de $1.784 \mathrm{~km}^{2}$ (FURNAS, 2013).

A construção da Hidrelétrica Serra da Mesa representou uma nova etapa nos empreendimentos do setor elétrico brasileiro no que diz respeito ao automatismo da obra e por ser fruto de uma parceria com a iniciativa privada. A empresa Serra da Mesa Energia 
S.A fez essa parceria com o setor público, assumindo a responsabilidade de conclusão da usina e recebendo $51,54 \%$ da energia que a usina produz. O gerenciamento do empreendimento, assim como a responsabilidade pela operação da usina coube a FURNAS (FURNAS, 2013).

A potência instalada nessa hidrelétrica é de 1275 MW (REIS, 2001). Por ocasião da obtenção do programa SIMPACTS, por meio da AIEA, os dados e o cálculo de custo ambiental já estavam prontos para essa hidrelétrica, por isso seu uso nesse trabalho. A hidrelétrica Serra da Mesa é apresentada na FIG 3.4.

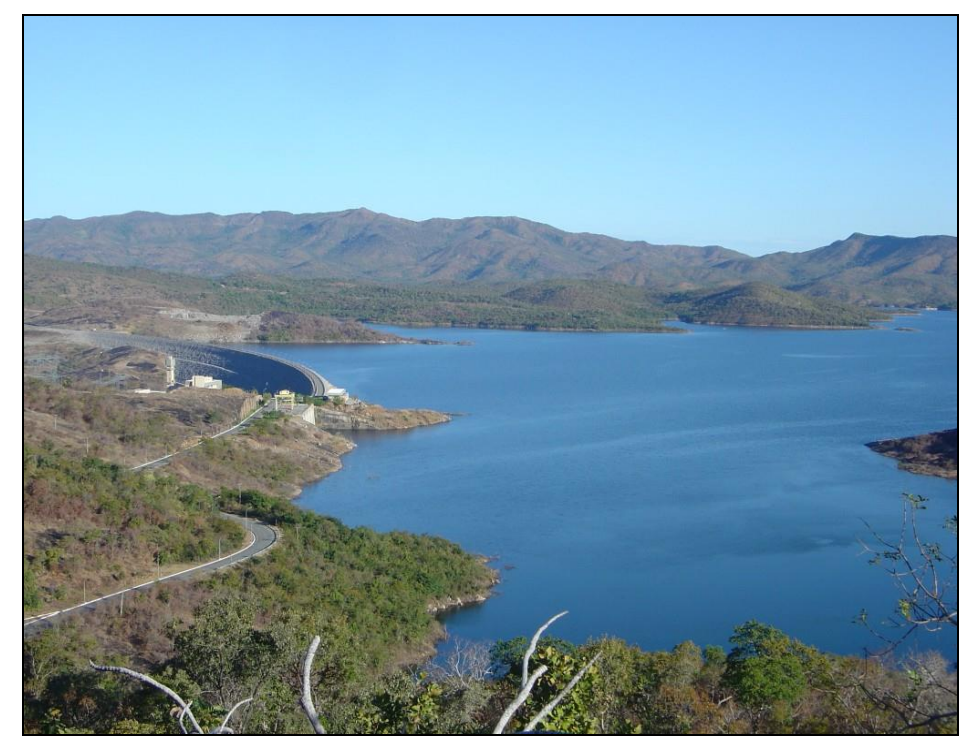

FIGURA 3.4 - Hidrelétrica Serra da Mesa

A seguir é apresentada uma descrição das instalações de geração de energia elétrica no mundo que utilizam o carvão, assim como a que a foi utilizada nesse trabalho.

\subsection{Usinas a carvão no mundo}

As usinas a carvão são amplamente difundidas no mundo, constituindo mais de $40 \%$ da fonte de produção de energia elétrica (IEA, 2011).

O carvão é uma das mais antigas formas de produção de energia elétrica. As máquinas a vapor, alimentadas pelo carvão, surgiram em meados de 1700 e foram aperfeiçoadas por Watt, que passou a construi-las comercialmente na Inglaterra entre 1774 e 1800. A combustão direta do carvão para a produção de vapor foi o principal acontecimento para o progresso da industrialização. Atualmente, o principal uso da 
combustão direta do carvão é na geração de eletricidade por meio de usinas termoelétricas. Essa tecnologia está bem desenvolvida e é economicamente competitiva (CEPA, 2013).

Grande parte dos países do mundo é dependente do carvão. A África do Sul, por exemplo, produz 93\% da energia elétrica que utiliza a partir do carvão. Países como a Polônia, China e Austrália tem, respectivamente, 87\%, 79\% e 78\% da energia produzida a partir do carvão (IEA, 2011).

Os impactos ambientais das usinas a carvão são significativos e se relacionam com as emissões atmosféricas de gases poluentes, assim como o descarte de resíduos sólidos e poluição térmica, além dos riscos inerentes à mineração (CEPA, 2013).

\subsubsection{Usina a carvão genérica na França}

Na França há 10 usinas a carvão, sendo que uma delas não está mais em operação. As potências das usinas variam de 250 a 2600 MW elétricos. Na TAB. 3.2 são apresentadas as usinas e suas respectivas potências e localizações (GEO, 2013).

TABELA 3.2 - Usinas a carvão na França

\begin{tabular}{l|c|l}
\hline \multicolumn{1}{c|}{ Nome da Usina } & Potência (MWE) & \multicolumn{1}{c}{$\begin{array}{c}\text { Estado onde está } \\
\text { localizada }\end{array}$} \\
\hline Provence & 868 & Alpes-de-Haute-Provence \\
\hline Cordemais & 2600 & Loire-Atlantique \\
\hline Blénod & 750 & Meurthe-et-Moselle \\
\hline Emile-Huchet & 1086 & Moselle \\
\hline Le Maxe & 500 & Moselle \\
\hline Bouchain & 250 & Nord \\
\hline Courrieres & Fora de operação & Pas-de-Calais \\
\hline Hornaing B & 253 & Pas-de-Calais \\
\hline Centrale de Lucy & 270 & Saone-et-Loire \\
\hline EdF Le Havre & 1995 & Seine-Maritime \\
\hline
\end{tabular}

O programa não especifica uma usina a carvão da França, somente dá um exemplo genérico. Por esta razão, não se tem informação sobre a potência dessa usina 
considerada e, também por esta razão, neste item são abordadas as usinas a carvão na França como um todo. A usina Courrieres é apresentada como exemplo na FIG. 3.5.

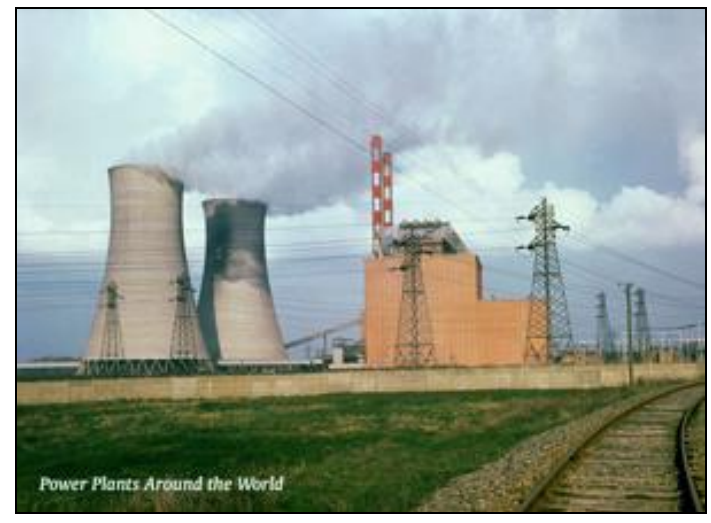

FIGURA 3.5 - Usina a carvão Courrieres, França 


\section{METODOLOGIA}

\subsection{Introdução}

A familiarização com o Programa SIMPACTS foi feita em parceria com a Agência Internacional de Energia Atômica (AIEA). O programa SIMPACTS é uma ferramenta que estima e quantifica os custos dos danos ambientais e à saúde ocasionados por diferentes tecnologias de geração de eletricidade. Essa ferramenta é particularmente útil para análises comparativas de fonte fóssil, nuclear e geração renovável de eletricidade (hidrelétrica). A maior vantagem de tal ferramenta em detrimento das demais é a possibilidade de sua utilização quando há uma limitação de dados disponíveis da instalação estudada (IAEA, 2011).

O SIMPACTS consiste em módulos separados para estimar os impactos na saúde humana, nas culturas agrícolas e nas construções, resultantes das emissões atmosféricas provenientes de instalações de energia. Esse programa estima os danos físicos e oferece uma estimativa de custos financeiros externos. O aspecto mais significante do programa é a sua simplicidade, pois pode ser implantado em qualquer computador e necessita de poucos dados de entrada, quando comparado a outros programas de custos externos que são complexos e necessitam de muitos dados (IAEA, 2011).

Para a poluição atmosférica proveniente tanto das usinas de energia fóssil quanto das nucleares, o modelo segue uma abordagem que leva em consideração o caminho do impacto. Nessa abordagem, a fonte de emissão é caracterizada e o inventário é preparado com base nas mudanças da concentração no ambiente de vários poluentes, usando modelos de dispersão atmosférica e, no caso de emissões radioativas, é considerada a deposição. Funções de resposta à exposição são usadas para relacionar a mudança na concentração de poluentes com o impacto físico sobre os receptores relevantes (saúde humana, ecossistemas, etc.) (IAEA, 2011).

O modelo permite que o usuário estabeleça um intervalo de estimativa de custos externos, variando de uma estimativa geral para uma mais precisa, dependendo da disponibilidade de dados. Uma estimativa aproximada pode ser obtida com dados de concentração populacional, características e emissões das instalações, mesmo se não há dados disponíveis das condições meteorológicas do local. Em uma aplicação típica, o usuário pode começar a análise com o mínimo de dados para obter uma estimativa aproximada e, 
gradualmente, adicionar mais informações, à medida que forem disponibilizadas, a fim de obter resultados mais precisos. A FIG. 4.1 ilustra três exemplos desse tipo de análise, que variam em grau de especificidade, de acordo com a disponibilidade de dados da instalação (IAEA, 2011).

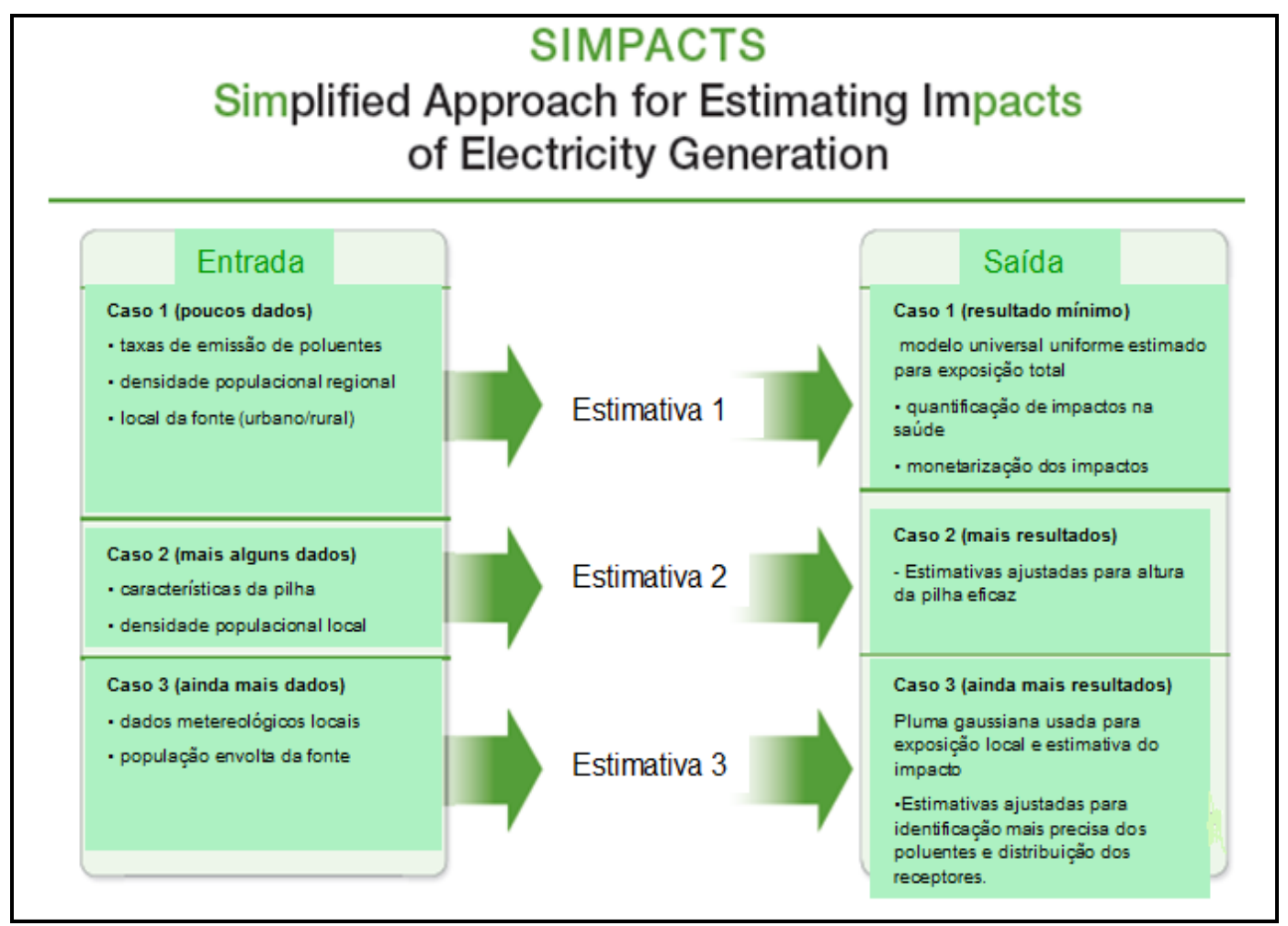

FIGURA 4.1 - Principais entradas e saídas do programa SIMPACTS

O SIMPACTS possui três módulos: AIRPACTS, para quantificar os impactos e custos dos danos causados pelas emissões atmosféricas; NUKPACTS, para avaliação das doses coletivas e efeitos na saúde latentes da operação de rotina de instalações nucleares e os custos externos dos acidentes das deposições de resíduos; e HYDROPACTS, para calcular os custos dos danos das barragens de hidrelétricas decorrentes da reinstalação de pessoas devido a inundações e perda de uso da terra (IAEA, 2001), conforme fluxograma apresentado na FIG. 4.2 . 


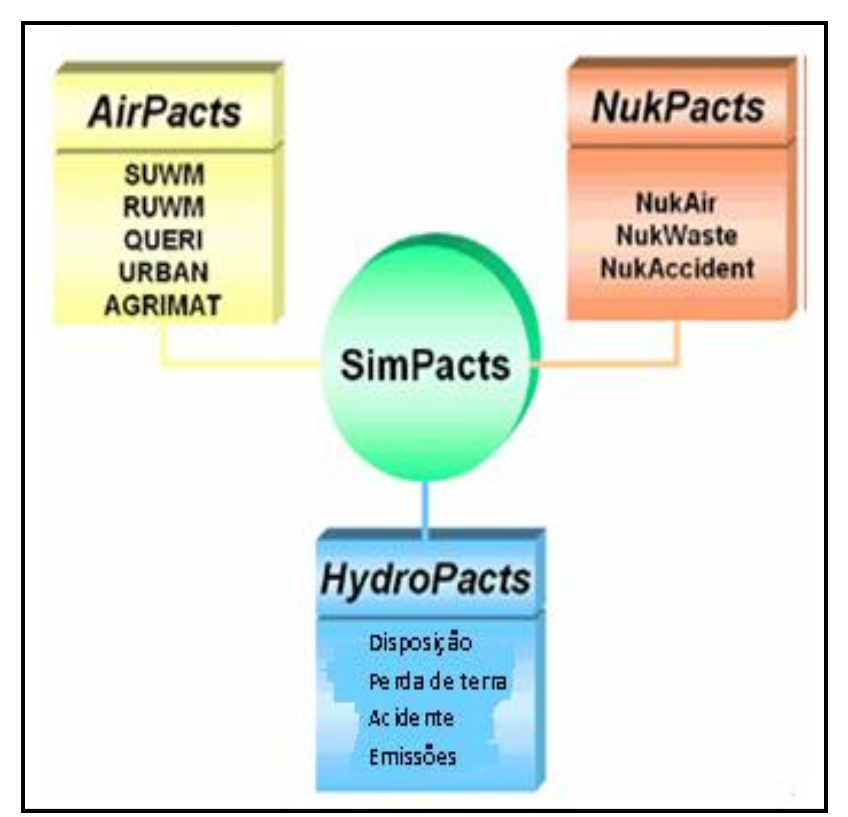

FIGURA 4.2 - Fluxograma do programa SIMPACTS

Para obter os custos dos danos, como resultado da análise do SIMPACTS, os impactos devem ser multiplicados pelo seu custo unitário. No programa, os danos são expressos em dólares por ano de exposição ou dólares normalizados por unidade de kilowatthora de eletricidade entregue. O ideal seria que os custos unitários fossem baseados em estudos específicos da valoração econômica de cada localidade, mas na ausência de tal informação, os valores existentes de outras localidades podem ser adaptados e utilizados (LIUN et. al; 2007). A seguir estão descritos cada um dos módulos do SIMPACTS.

\subsection{AIRPACTS}

O módulo AIRPACTS inclui vários modelos que representam diferentes níveis de abordagem analítica para o problema em questão. São eles: o Modelo Simplificado Melhorado, Robust Uniform World Models (RUWM); Modelo para a estimativa dos impactos na saúde, Quick Estimation of Respiratory health Impacts (QUERI) e Modelo para ambientes urbanos (URBAN) (SEMARNAT, 2004).

A fim de exemplificação, os dados necessários no RUWN são: densidade populacional, taxa de emissão de poluentes em toneladas por ano, grupos de risco, taxa de decomposição dos contaminantes na atmosfera e custo dos impactos nos Estados Unidos, na ausência de dados específicos (SEMARNAT, 2004). 
O modelo URBAN estima os impactos sobre a saúde e os respectivos custos decorrentes da emissão de poluentes primários (liberados diretamente das fontes de emissão) e secundários (formados na atmosfera através de reações químicas) por uma fonte localizada em uma área urbana ou muito perto dela. Os dados sobre a população local podem ser especificados com uma resolução de $5 \mathrm{~km}$ x $5 \mathrm{~km}$, tendo como ponto de partida uma fonte central de emissão, estendendo-se até $50 \mathrm{~km}$ ao redor dele. Sua distribuição é calculada através de uma curva de Gauss, e é necessário conhecer a densidade de fundo ( $\left.\rho_{\text {fondo }}\right)$, a posição do valor máximo $\left(\mathrm{X}_{\max }, \mathrm{Y}_{\max }\right)$, o desvio padrão $\left(\sigma_{D}\right)$, o pico da distribuição $\left(\rho_{\max }\right)$ e a densidade de pessoas no X e Y calculado (SEMARNAT, 2004), conforme a equação (4.1):

$$
\rho=\left(\rho_{\text {max }}-\rho_{\text {fondo }}\right) e^{\left\{-\frac{\left[\left(X-X{ }_{\text {max }}\right)^{2}+\left(Y-Y_{\text {max }}\right)^{2}\right]}{2 \sigma_{D}^{2}}\right\}}+\rho_{\text {fondo }}
$$

\subsection{HYDROPACTS}

Outro módulo do programa SIMPACTS é o HYDROPACTS, que realiza cálculos de custos em hidrelétricas, desenvolvido para estimar alguns dos seus impactos e quantificar seus custos correspondentes. O modelo mencionado permite o cálculo do número de pessoas deslocadas, das emissões de gases contaminantes durante a construção e operação da barragem e dos impactos dos acidentes ocorridos, a saber: vidas perdidas e anos de vida perdidos por invalidez (SEMARNAT, 2004).

O modelo HIDROPACTS permite valorar, principalmente, os custos sociais com base em:

1. deslocamento forçado da população;

2. perda de terrenos;

3. perda de produção agrícola;

4. perda de recursos naturais e culturais;

5. acidentes ou falhas no dique;

6. aumento do número de doenças;

7. emissões de gases causadores do efeito estufa e gases tóxicos em geral (SEMARNAT, 2004). 
Os impactos decorrentes da construção e operação de uma hidrelétrica são muito específicos e variam muito conforme a localidade. No entanto, o HIDROPACTS oferece uma abordagem simplificada na ausência de mais informações e permite uma rápida estimativa da área inundada e seus impactos potenciais (SEMARNAT, 2004).

Em suma, o modelo necessita dos seguintes dados de entrada: características da barragem, como taxa média do rompimento da barragem e altura da barragem; características do sítio, como tipo do terreno e inclinação média; características da população e do uso das terras que serão inundadas, como densidade populacional, população exposta ao risco de acidentes e porcentagem da terra ocupada; e dados econômicos, como PIB por pessoa, tempo de vida útil do projeto e taxa de desconto ${ }^{1}$ (SEMARNAT, 2004).

Os impactos de projetos hidrelétricos aumentam proporcionalmente com o tamanho do reservatório. Sendo assim, para uma avaliação de um reservatório futuro, o usuário terá que ter uma estimativa da área a ser inundada. A metodologia apresentada para o cálculo fornece uma abordagem simplificada que, mesmo sem muita informação, permite ao usuário desenvolver uma estimativa rápida da área inundada e dos potenciais impactos. A metodologia é uma substituta para uma rigorosa e específica análise, e esse módulo foi feito para uma avaliação inicial dos impactos hidrelétricos (IAEA, 2003a).

A utilização do módulo HYDROPACTS será demonstrada a seguir.

\subsubsection{Utilização do Módulo}

Ao abrir o modelo SIMPACTS, o usuário poderá escolher entre várias opções para realizar o cálculo de custo ambiental. Uma delas dá acesso ao HYDROPACTS. A entrada do modelo requerida para as características da barragem e tela para as características do local são apresentadas na FIG.4.3. Se for conhecida a altura da barragem, pode-se colocar esse valor no campo Hd. Se a altura da barragem não é conhecida, o modelo pode estimá-la.

\footnotetext{
1 Taxa de juros cobrada pelos Bancos Centrais nos empréstimos que concedem aos bancos comerciais. Constitui um importante instrumento de política monetária que permite regular a oferta de moeda e influenciar as taxas de juros do mercado (PUCCINI, 2006).
} 


\begin{tabular}{|c|c|c|c|}
\hline \multicolumn{4}{|l|}{ DAM CHARACTERISTICS } \\
\hline Name of Facility & \multicolumn{3}{|l|}{ Hydro Dam 1} \\
\hline Location/Description & \multicolumn{3}{|c|}{$\begin{array}{l}\text { General description of location, such as country, region, } \\
\text { water shediriver system, latitude/longitude if available }\end{array}$} \\
\hline Characteristic & Value Unit & Valid Data Range & \\
\hline Average Dam Failure Rate & 1.0E-04 fraction & see comment & $\checkmark$ \\
\hline Dam Height $\left(\mathrm{H}_{0}\right)$ & $128 \mathrm{~m}$ & & \\
\hline Nominal Net Head & $100 \mathrm{~m}$ & & \\
\hline Additional Head Correction $\left(\boldsymbol{\Delta}_{H}\right)$ & $-20 m$ & see comment & v \\
\hline Plant Capacity (P) & $15,000 \mathrm{MW}$ & & \\
\hline Average Plant Capacity Factor (CF) & $50 \%$ & & \\
\hline Turbine Flow $\left(Q_{w}\right)$ all Turbines & $13,270 \mathrm{~m}^{3} / \mathrm{s}$ & & \\
\hline Additional Head Correction $\left(\boldsymbol{\Delta}_{H}\right)$ & $5.0 \mathrm{~m}$ & see comment & $\checkmark$ \\
\hline
\end{tabular}

\section{SITE CHARACTERISTICS}

Characteristic

Region ID

Terrain index (TI)

Type of terrain

Average Accident Warning Time

Average terrain incline ( $\alpha$ )

Average river incline ( $\beta$ )

Reservoir Inundated Area

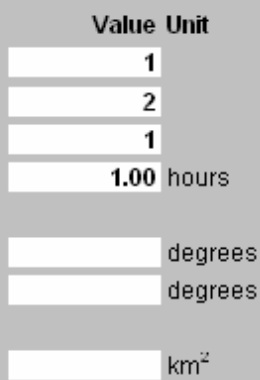

Comments Enter 1 or 2 Enter 1 to 8 Enter 1 or 2 see comment

Note: Either enter terrain index or enter river and terrain inclines. Enter terrain index if no detailed information is available on the dam location. Enter inclines if you have site-specific information.

Note: The currently available terrain indeces are specific to 8 sites. Eventually, we will allow you to choose from different terrain settings (lowlands, mountains, etc.)

Note: If you don't know the inundated area, enter the terrain index and the model will estimate the inundated area. Otherwise enter the inundated area in square $\mathrm{km}$.

FIGURA 4.3 - Exibição da entrada do modelo para barragem e características do local

O modelo é desenvolvido de forma similar com respeito à informação do terreno. É possível escolher tanto os índices de uma série predefinida de terreno quanto especificar a informação do terreno. O usuário pode selecionar entre os oito índices de terreno pré-ajustados que são mostrados quando se move o cursor sobre esse campo e que são específicos para certas localizações de rios, como mostrado na FIG. 4.4. O modelo trará um conjunto de tipos de terreno disponíveis, como planícies, montanhas, desfiladeiros etc (IAEA, 2003a). 


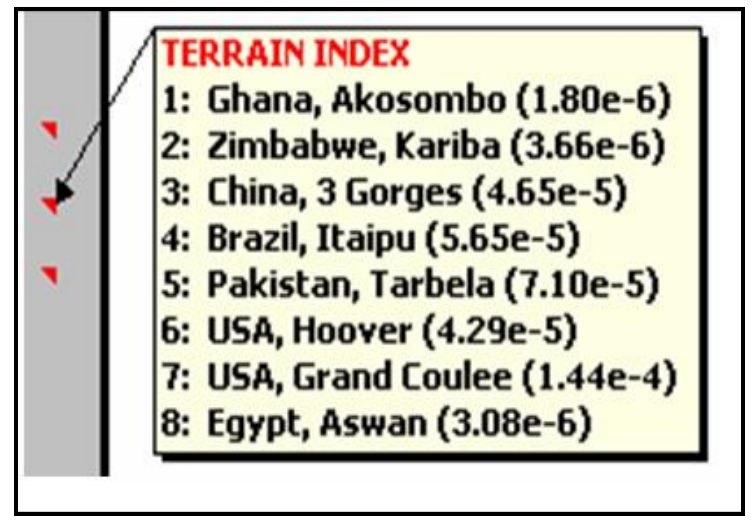

FIGURA 4.4 - Índices de Terreno Atuais Disponíveis no Modelo

A tela de entrada das características da população e da terra contém os parâmetros mostrados na FIG 4.5. A densidade populacional e a parcela de pessoas reinstaladas/ indenizadas são usadas nos cálculos de deslocamento. Esse valor deve ser o mais específico possível. A população com risco de acidente é um parâmetro de entrada para o cálculo de falha da barragem. O modelo leva três tipos de cobertura do solo em consideração (floresta, área de cultivo e outras), quando computa os dados econômicos da inundação. (IAEA, 2003a).

\begin{tabular}{|c|c|c|c|}
\hline \multicolumn{4}{|c|}{ POPULATION AND LANDUSE CHARACTERISTICS } \\
\hline Characteristic & Value Unit & Comments & \\
\hline Population density in river basin & 35 persons $i \mathrm{~km}^{2}$ & see comment & v \\
\hline Population at risk of accident & 250,000 persons & & \\
\hline Share of people resettledicompensated & $50.0 \%$ & & \\
\hline Land cover: Forest & $50.0 \%$ & & \\
\hline Land cover: Farmland & $30.0 \%$ & & \\
\hline Land cover: Other & $\begin{array}{r}\mathbf{2 0 . 0} \\
100.0\end{array}$ & & \\
\hline
\end{tabular}

FIGURA 4.5 - Tela de Entrada do Modelo para Características da População e da Terra

Os dados de entrada para os parâmetros econômicos são apresentados na FIG. 4.6. O PIB per capita para o ano 2000 é usado para determinar o custo de reassentamento per capita para o país analisado. Os danos econômicos totais da perda de terreno são calculados com base nos valores fornecidos para as três categorias de uso do terreno. Se parte desses custos seja internalizada, pode-se especificar quanto dos custos totais são tipicamente incluídos nos custos do projeto, na forma de pagamentos de indenizações (IAEA, 2003a). 


\section{COST CHARACTERISTICS}

Characteristic

2000 GDP per capita

1995 GDP per capita

Cost of forest

Cost of farmland

Cost of other land

Fraction of costs internalized

Economic lifetime of project

Interest Rate for Cost Levelization
Value Unit

Comments

$\mathbf{1 , 6 0 0}$ US $\$ 2000$ per capita

$\mathbf{1 , 5 0 0}$ US $\$ 1995$ per capita

2,000 US $\$ 2000$ per hectare

2,500 US $\$ 2000$ per hectare

$\mathbf{1 , 0 0 0}$ US $\$ 2000$ per hectare

0.750 fraction

30 years

$0.0 \%$

FIGURA 4.6 - Tela de Entrada do Modelo para Características de Custo

As características das emissões são demonstradas na FIG. 4.7. Os campos para fatores de emissão de $\mathrm{CH}_{4}$ e $\mathrm{CO}_{2}$ podem ser usados para situações em que se tem uma informação específica disponível. Caso contrário, os campos podem ser deixados em branco, e o modelo estimará as emissões baseadas na identificação da região escolhida, conforme as características do local. O valor padrão para o Potencial de Aquecimento Global, Global Warm Potential (GWP), para o metano é 21, mas pode ser alterado pelo usuário. Os preços de carbono, $\mathrm{SO}_{2}$, e $\mathrm{NOx}$ são usados para calcular os custos externos das emissões (IAEA, 2003a).

\section{EMISSIONS CHARACTERISTICS}

Characteristic

$\mathrm{CH}_{4}$ Emissions low

$\mathrm{CH}_{4}$ Emissions high

$\mathrm{CH}_{4}$ Emissions mean

$\mathrm{CO}_{2}$ Emissions low

$\mathrm{CO}_{2}$ Emissions high

$\mathrm{CO}_{2}$ Emissions mean

GWP for Methane (GWP $\mathrm{CH}_{4}$ )

Price of Carbon

Price of $\mathrm{SO2}$

Price of NOX

Note: If you do not know the emission factors, leave the fields blank and the model will estimate them. If you DO know the emission factors, enter the values and your inputs will overwrite any model estimates.

FIGURA 4.7 - Tela de Entrada do Modelo para Características de Emissão

A tela de entrada para a perda de produção agrícola e de gado é apresentada na FIG 4.8. Similarmente, a tela de entrada para a perda de recursos naturais e culturais é 
apresentada na FIG. 4.9. A tela de entrada para o aumento de ocorrência de doenças mostrada na mesma figura segue a mesma lógica (IAEA, 2003a).

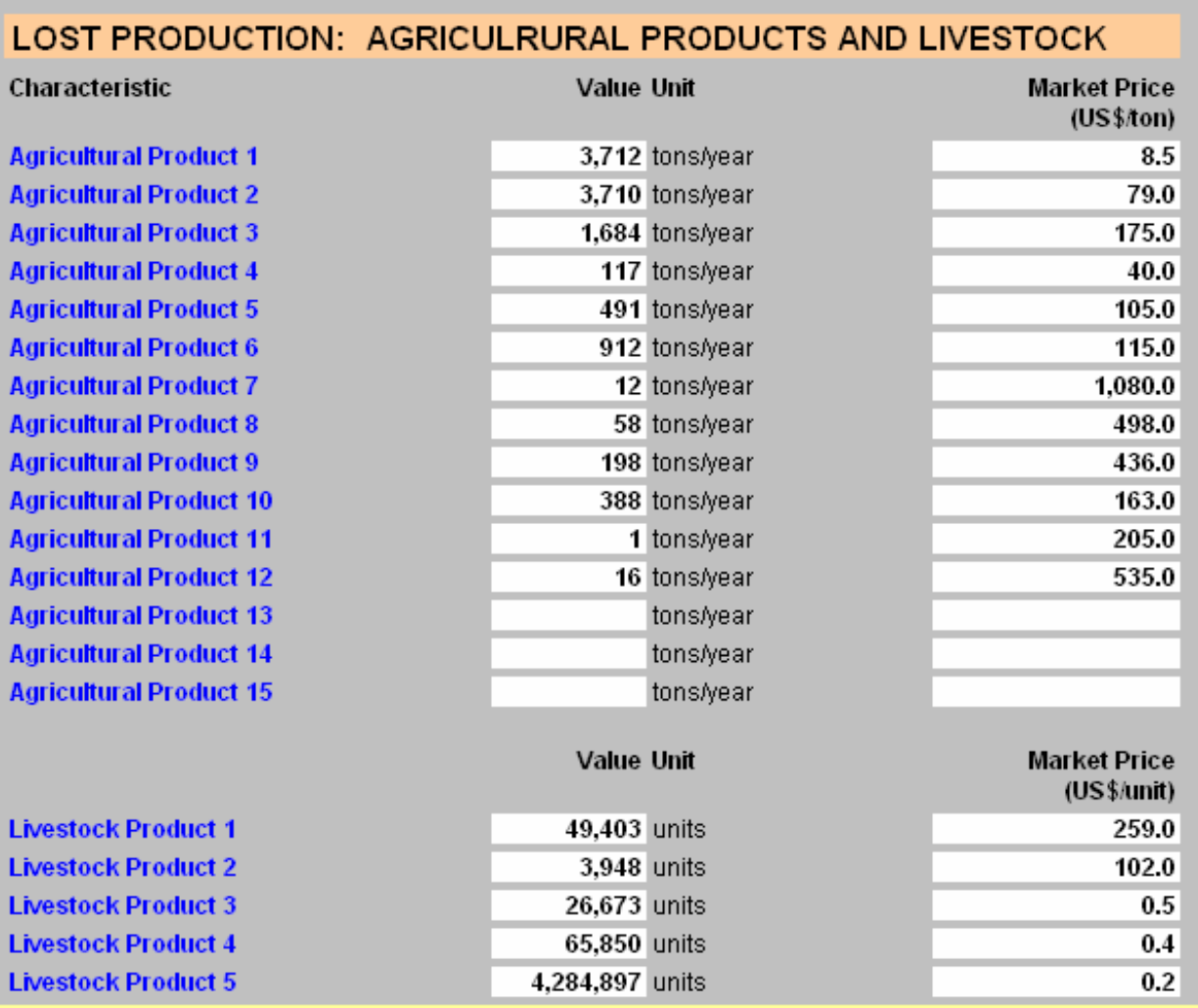

Note: Leave cells blank if you do not have any information on lost production and market prices

FIGURA 4.8 - Tela de Entrada do Modelo para Perda de Produção Agrícola e de Gado 

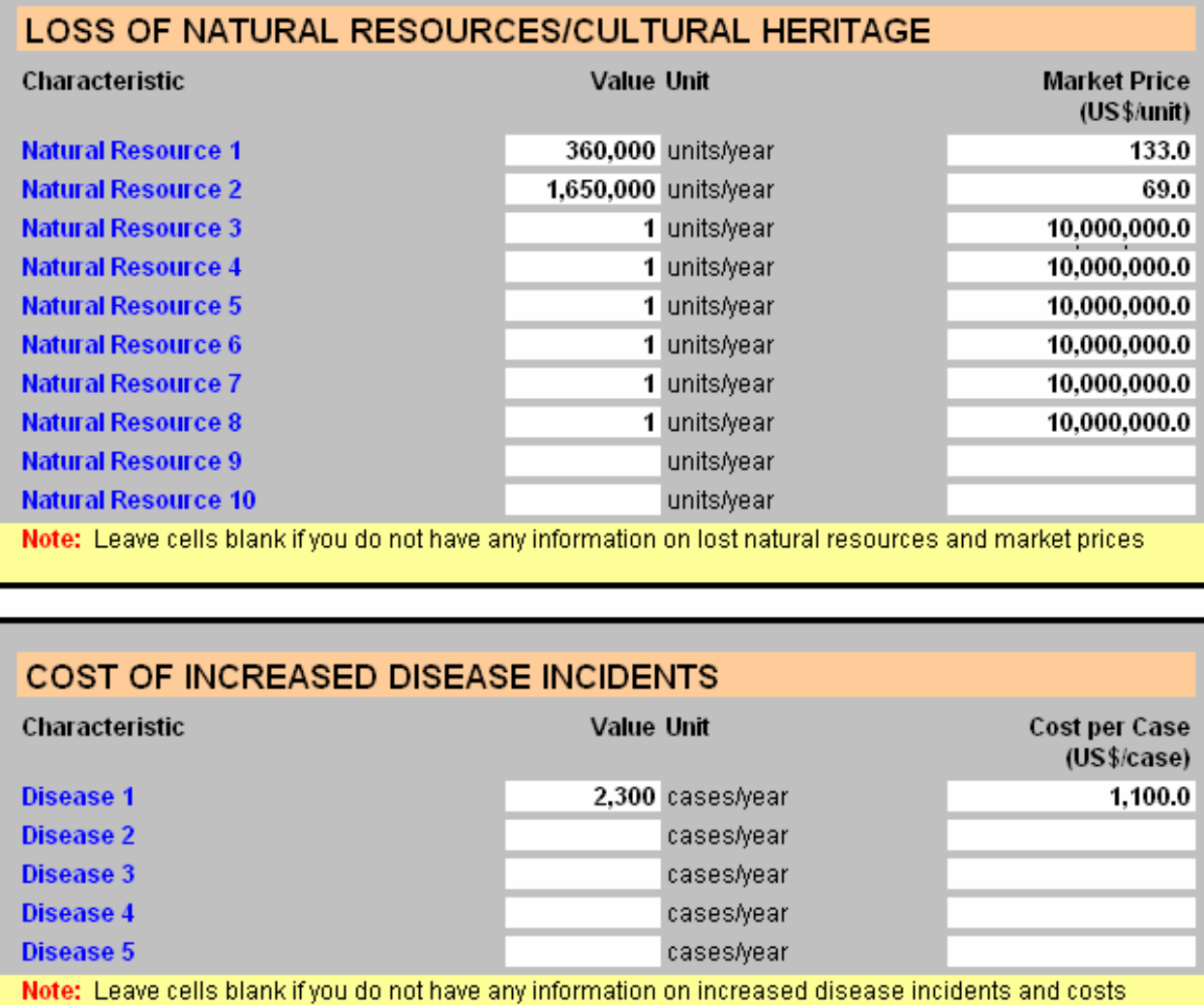

Note: Leave cells blank if you do not have any information on increased disease incidents and costs

FIGURA 4.9 - Tela de Entrada do Modelo para de Recursos Naturais e Culturais e Custo de Aumento de Ocorrência de Doença

Os resultados são apresentados nas FIG. 4.10 a 4.13. Os resultados do modelo são apresentados na forma de tabelas e gráficos. A área inundada estimada é apresentada como total e, da mesma forma, dividida por categoria de terra utilizada. Perdas de vidas relacionadas a acidentes são apresentadas em termos de casos por reservatório. As emissões são divididas em emissões relacionadas à construção e à operação. Para todos os poluentes, o modelo fornece um índice (alto/baixo) e emissões médias projetadas por ano (IAEA, 2003a). 


\begin{tabular}{|c|c|c|c|}
\hline Dam Height & \multicolumn{2}{|c|}{$128 \mathrm{~m}$} & \\
\hline \multicolumn{4}{|l|}{ LOSS OF LAND } \\
\hline Forest & \multicolumn{2}{|c|}{$4,477 \mathrm{~km}^{2}$} & \\
\hline Farmland & \multicolumn{2}{|c|}{$2,686 \mathrm{~km}^{2}$} & \\
\hline other & \multicolumn{2}{|c|}{$1,791 \mathrm{~km}^{2}$} & \\
\hline Total & \multicolumn{2}{|c|}{$8,953 \mathrm{~km}^{2}$} & \\
\hline \multicolumn{4}{|c|}{ DISPLACEMENT AND RESETTLEMENT } \\
\hline Displaced Persons & \multicolumn{3}{|c|}{313,356 persons } \\
\hline Resettled Persons & \multicolumn{3}{|c|}{156,678 persons } \\
\hline \multicolumn{4}{|l|}{ LOSS OF LIFE (ACCIDENTS) } \\
\hline Loss of Life per Failure & \multirow{2}{*}{\multicolumn{3}{|c|}{$\begin{array}{l}7,758 \text { cases per dam failure } \\
0.776 \text { cases per dam-year }\end{array}$}} \\
\hline Expected Loss of Life & & & \\
\hline \multicolumn{4}{|l|}{ EMISSIONS } \\
\hline Emissions during Construction & Low & Mean & High \\
\hline $\mathrm{SO}_{2}$ & 526 & 2,300 & 6,570 metric tonsiyear \\
\hline $\mathrm{NO}_{x}$ & 197 & 394 & 854 metric tonslyear \\
\hline $\mathrm{CO}_{2}$ & 65,700 & 179,580 & 387,630 metric tons/year \\
\hline Emissions during Operation & Low & Mean & High \\
\hline $\mathrm{CH}_{4}$ & 13,430 & 161,154 & 358,120 metric tons/year \\
\hline $\mathrm{CO}_{2}$ & $1,342,951$ & $16,097,504$ & $35,812,022$ metric tonslyear \\
\hline TOTAL Emissions & Low & Mean & High \\
\hline $\mathrm{SO}_{2}$ & 526 & 2,300 & 6,570 metric tonsiyear \\
\hline $\mathrm{NO}_{x}$ & 197 & 394 & 854 metric tons/year \\
\hline $\mathrm{CH}_{4}$ & 13,430 & 161,154 & 358,120 metric tonsiyear \\
\hline $\mathrm{CO}_{2}$ & $1,408,651$ & $16,277,084$ & $36,199,652$ metric tons/year \\
\hline GHG (in Carbon Equivalents) & 461,092 & $5,362,178$ & $11,923,684$ metric tons/year \\
\hline
\end{tabular}

FIGURA 4.10 - Tela de Entrada com Resultados Resumidos

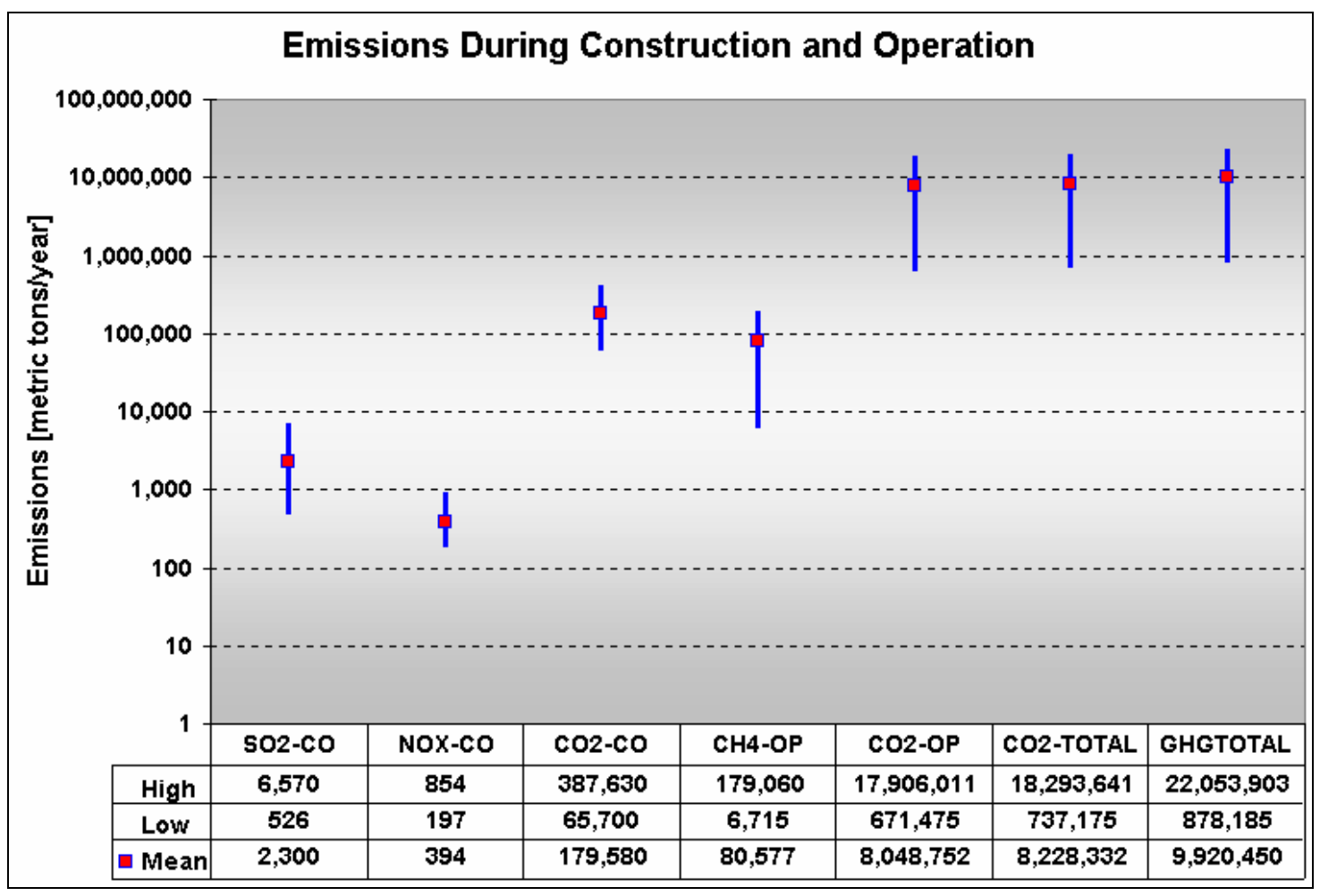

FIGURA 4.11 - Tela de Entrada com Gráficos dos Resultados das Emissões 


\section{SUMMARY OF ECONOMIC IMPACTS}

DISPLACEMENT OF PEOPLE

Total damage cost

External cost (displaced but not resettled/compensated)

Annual external cost of displacement

External cost of displacement per MWh

LOSS OF LAND

Forest

Farmland

Other

External cost of loss of land

Annual external cost of loss of land

External cost of loss of land per MWh

LOSS OF LIFE (ACCIDENTS)

Annual damage cost (external)

External cost of loss of life per MWh

666.82 million US $\$ 2000$

333.41 million US $\$ 2000$

11.11 million US $\$ 2000$ per year

1.69E-01 US\$2000 per MWh

$\mathbf{1 , 7 4 5 . 8 4}$ million US $\$ 2000$

895.30 million US $\$ 2000$

671.48 million US $\$ 2000$

$\mathbf{1 7 9 . 0 6}$ million US\$2000

436.46 million US $\$ 2000$

14.55 million US $\$ 2000$ per year

2.21E-01 US\$2000 per MWh

LOSS OF AGRICULTURAL AND LIVESTOCK PRODUCTION

Annual damage cost (external)

External cost of loss of agriculturalivestock production per MWh

0.21 million US $\$ 2000$ per year

3.22E-03 US\$2000 per MWh

LOSS OF NATURAL AND CULTURAL RESOURCES

Annual damage cost (external)

External cost of loss of natural/cultural resources per MWh

15.08 million US $\$ 2000$ per year

2.29E-01 US $\$ 2000$ per MWh

COST OF INCREASED DISEASE INCIDENTS

Annual damage cost (external)

External cost of increased disease incidents per MWh

7.39 million US $\$ 2000$ per year 1.12E-01 US\$2000 per MWh

COST OF EMISSIONS

Annual damage cost (external)

External cost of loss of life per MWh

2.53 million US $\$ 2000$ per year $2.53 \mathrm{E}+06$ US $\$ 2000$ per MWh

108.18 million US $\$ 2000$

1.65E+00 US $\$ 2000$ per MWh

2.42E+00 US\$2000 per MWh

FIGURA 4.12 - Tela de Entrada do Modelo para Características de Custo

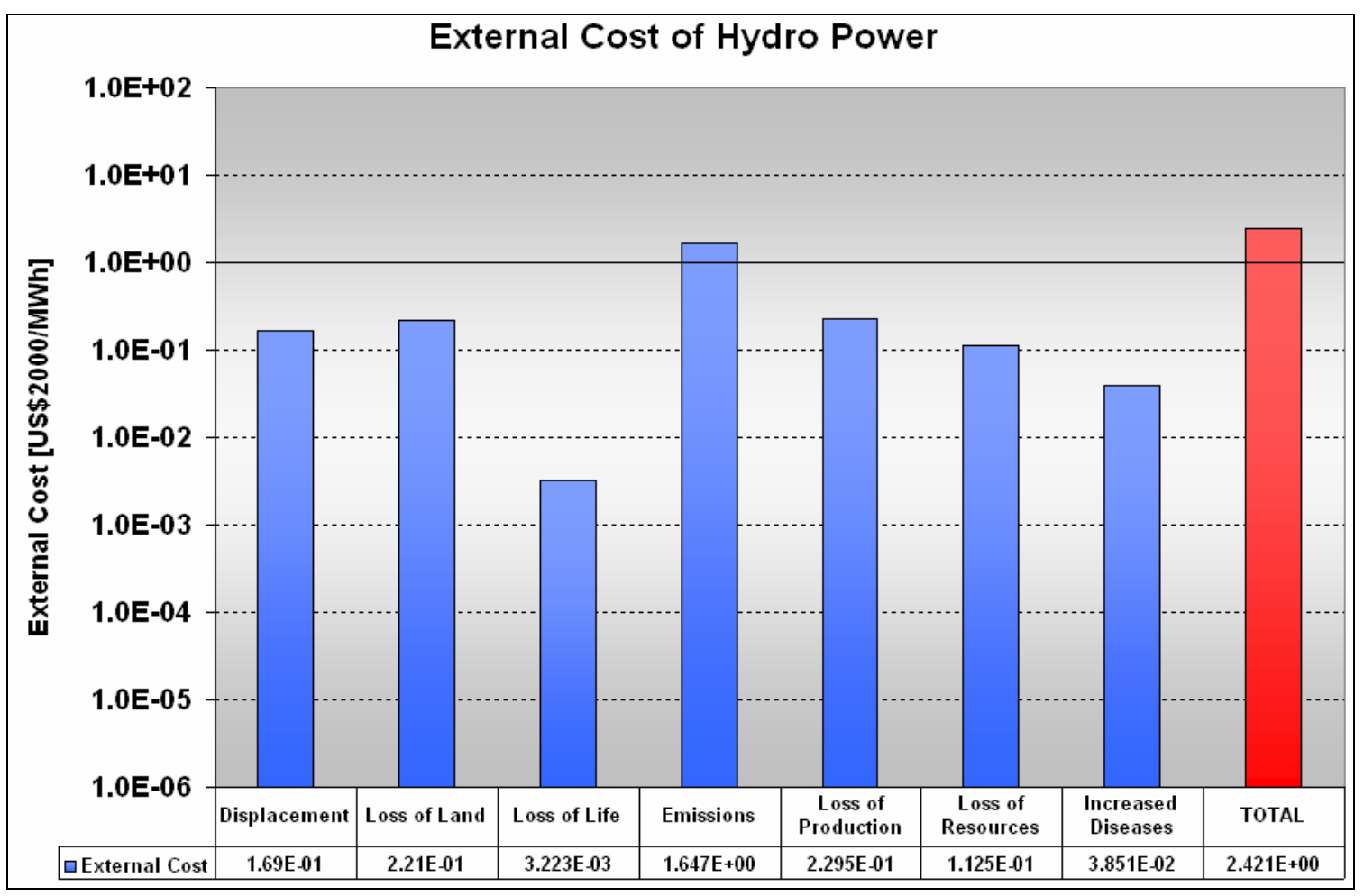

FIGURA 4.13 - Resultados do Programa

Os custos de danos são relatados pela categoria de impacto, isto é, deslocamento, perda de terra, perda de vida, perda de produção agrícola e de gado, perda 
de recursos naturais e culturais, custo do aumento de incidentes por doença e custo de emissões. Todos os custos são mostrados como anuais e por MWh gerado (IAEA, 2003a). A seguir, serão apresentadas as equações usadas no Módulo HYDROPACTS.

\subsubsection{Equações usadas no HYDROPACTS}

As equações usadas no HYDROPACTS são apresentadas e divididas em:

1. Estimativa da área inundada pelo reservatório;

2. Estimativa da altura da barragem;

3. Estimativa da população deslocada;

4. Emissões atmosféricas durante a construção e durante a operação da hidrelétrica;

5. Estimativa de impactos de acidentes;

6. Custo externo de perdas de recursos naturais;

7. Custo externo do aumento de incidentes por doenças;

8. Custos externos de emissões.

\subsubsection{Estimativa da área inundada pelo reservatório}

Os impactos dos reservatórios são extremamente específicos, conforme apontados na seção anterior. As tentativas iniciais de estimativas simplificadas de desenvolvimento de deslocamento foram baseadas em meta-análises que tentaram projetar o número de pessoas afetadas como uma função da potência da estação hidrelétrica (MARKANDYA, 2000). A seguir estão os três tipos de relação desenvolvidos (4.2):

$$
\begin{aligned}
& \text { Area }_{\text {Im outustad }}\left[\mathrm{km}^{2}\right]=0.57 \times \text { Capacity }[\mathrm{MW}] \quad \text { Coeff } \text { Comstation }=0.570
\end{aligned}
$$

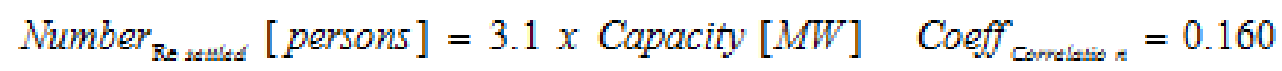

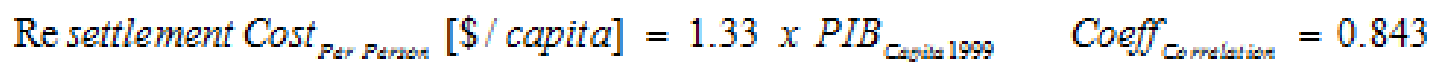


Onde:

- Area Impounded representa a área represada;

- Number Resettled representa o número de pessoas reassentadas;

- Resettlement Cost PerPerson é o custo de cada pessoa reassentada.

Em geral, acredita-se que, na mesma localidade, quanto mais alta a barragem, maior a área inundada pelo reservatório. Da mesma maneira, a mesma altura da barragem resulta em uma diferença acentuada do impacto medido em termos de área inundada, se construída em diferentes áreas com terrenos distintos (IAEA, 2003a).

O modelo 3-D, usado para estimar a área inundada pelo enchimento do reservatório (IARS), é mostrado na FIG. 4.14. É usado um cubo simples para modelar a forma e o tamanho do reservatório. O cubo pode ser descrito por diversos parâmetros, incluindo (IAEA, 2003a):

- $\quad$ Altura da barragem em metros $\left(H_{D}\right)$;

- $\quad$ Largura máxima do reservatório em quilômetros (WRS-max);

- $\quad$ Largura do reservatório em quilômetros $(L R S)$;

- $\quad$ Inclinação do terreno em graus $(\beta)$;

- $\quad$ Inclinação do rio em graus $(\alpha)$.

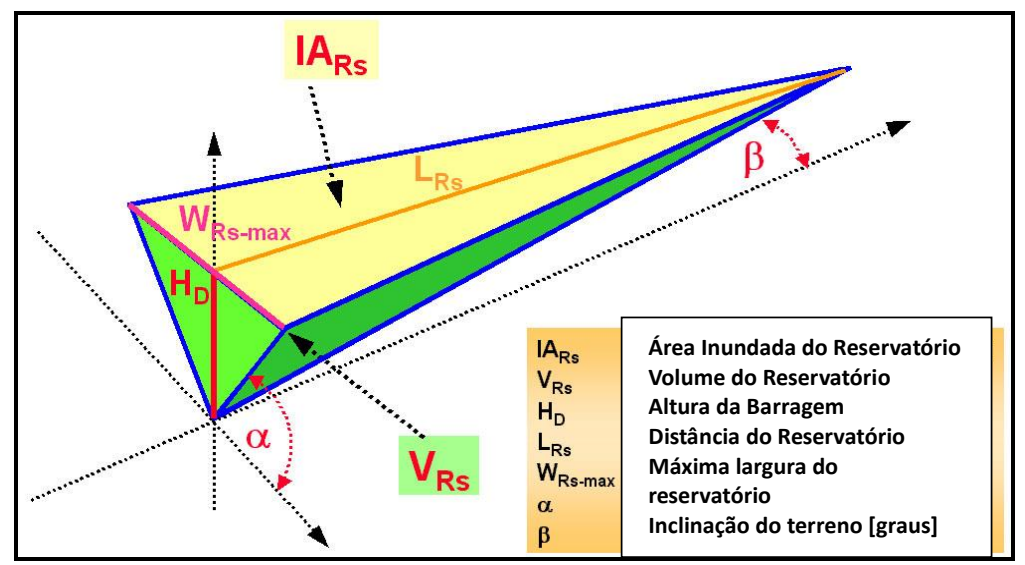

FIGURA 4.14 - Modelo 3D do Reservatório - Cubo Triangular

Para testar a validade dessa simplificação, foi utilizado um modelo aleatório de 130 barragens do registro da International Commission on Large Dams (ICOLD) e foi executado um teste simples no conjunto de dados. $O$ registro fornece algumas características muito básicas de barragens e reservatórios, incluindo a altura da barragem, 
o volume e o tamanho do reservatório. Se o reservatório pode ser descrito de forma simples, como um cubo, a razão da área de sua base pelo volume deve ser assim (4.3) (IAEA, 2003a).

$$
\text { AVRatio }_{\text {Cube }}=\frac{\text { Base Area }}{\text { Volume }}=\frac{\text { Base Area }}{\left(\frac{\text { Base Area } \times \text { Height }}{3}\right)}=\frac{3}{\text { Height }[\mathrm{m}]}
$$

Onde:

- Base Area é a área da base do cubo;

- Volume é o volume do cubo;

- Height representa a altura da barragem.

O modelo acima permite estimar a área inundada como uma função de altura do reservatório e informação do terreno. Com base na geometria do modelo, as seguintes equações trigonométricas (4.4) podem ser aplicadas para desenvolver a última relação para a área inundada pelo reservatório em $\mathrm{km}^{2}$ (IAEA, 2003a):

$$
\begin{aligned}
& \tan \alpha=\frac{H_{D}[\mathrm{~m}]}{0.5 \times 1,000 \times W_{R S-M e x}[\mathrm{~km}]} \\
& \tan \beta=\frac{H_{D}[\mathrm{~m}]}{1,000 \times L_{R S}[\mathrm{~km}]} \\
& I A_{R S}=\frac{\left(H_{D}[\mathrm{~m}]\right)^{2}}{\tan \alpha \times \tan \beta \times 10^{6}}
\end{aligned}
$$

\subsubsection{Estimativa da altura da barragem}

Para novas usinas hidrelétricas, o usuário pode obter a altura da barragem pela unidade hídrica se o processo de planejamento para a instalação já estiver em desenvolvimento. Entretanto, se for utilizada essa ferramenta em combinação com ferramentas de previsão do sistema de energia, pode-se apenas conhecer a capacidade 
planejada de cada projeto hídrico individual. Nessa situação, preferencialmente, o usuário deverá consultar a instituição ou os especialistas responsáveis para a avaliação de recursos hídricos da localização ou, alternativamente, tentar estimar a altura da barragem nas relações descritas abaixo (IAEA, 2003a).

Para simplificar, o programa adotou as perdas gerais do sistema, incluindo perdas hidráulicas, como sendo de $10 \%$. Se o fluxo da turbina for desconhecido, o valor padrão de $5.000 \mathrm{~m}^{3} / \mathrm{s}$ poderá ser usado e, então, se fará uma análise sensível usando valores altos e baixos (IAEA, 2003a). A equação demonstrada abaixo converte a energia cinética da água em energia elétrica (4.5).

$$
\text { Head }=\frac{P[M W] \times 1,000}{9.81\left[\frac{m}{s^{2}}\right] \times 0.9 \times Q_{\pi}\left[\frac{m^{3}}{s}\right]}
$$

Onde:

- $P$ é a potência em MW;

- $Q_{w}$ é o fluxo da turbina.

Em uma situação padrão, a central de energia com o gerador está localizada na base da barragem e a sua altura se iguala à principal. Entretanto, em alguns modelos, a central de energia está localizada bem mais longe da barragem a fim de melhorar a saída de energia da unidade. Nessa configuração, é necessário ajustar a equação acima, especificando a correção adicional em metros $(\Delta \mathrm{H})$. A relação para o ajuste é dada pela equação (4.6) (IAEA, 2003a).

$$
H_{D}=\operatorname{Head}[m]-\Delta H[m]
$$

Onde $\Delta H$ é a distância vertical entre a base da barragem e a localização da central de energia ou do gerador. Em alguns casos, o $H$ pode ser, várias vezes, o tamanho de $H_{D}$. Portanto é importante levá-lo em consideração quando se estima o tamanho da barragem com o uso do algoritmo acima. Caso contrário, o usuário poderá superestimar o tamanho atual da barragem (IAEA, 2003a). 


\subsubsection{Estimativa da população deslocada por causa do reservatório}

Ao saber da área inundada pelo reservatório, é possível estimar a população que foi deslocada fisicamente (POP ${ }_{\text {DIS }}$ ) pela terra inundada do upstream da barragem. Além de ser dependente do tamanho do reservatório (IARS), o deslocamento físico é também uma função da densidade populacional em pessoas $/ \mathrm{km}^{2}$ (POPDis) pela região afetada, como demonstra a equação (4.7) (IAEA, 2003a).

$$
P O P_{D I S}=I A_{R S}\left[\mathrm{~km}^{2}\right] \times P O P_{\text {Density }}\left[\frac{\text { persons }}{\mathrm{km}^{2}}\right]
$$

De maneira ideal, o usuário pode usar a informação demográfica específica do local ou região para onde deseja realizar o cálculo. Estes dados são facilmente encontrados na literatura.

\subsubsection{Estimativa das emissões atmosféricas}

As emissões atmosféricas provenientes das hidrelétricas ocorrem em duas etapas: na construção e na operação da barragem. Ambas serão discutidas nas seções abaixo (IAEA, 2003a).

\subsection{Emissões durante a construção de uma nova barragem}

Uma análise completa do ciclo de vida envolve, tipicamente, o material usado na construção da usina e depois quantifica a energia necessária e as emissões associadas. Isso pode variar para usinas hidrelétricas considerando o tipo e o tamanho da barragem. Há uma variedade de barragens, incluindo as preenchidas por terra e rocha, por concreto, por arco de concreto e suporte e outros tipos de barragens. Elas podem ser classificadas em duas categorias: (1) barragens de concreto e (2) barragens de entulho. As barragens de concreto são feitas de um concreto reforçado, ferro e outros materiais estruturais. As barragens de entulho são construídas com terra e brita com algumas seções que fornecem 
força na estrutura, enquanto outras são feitas para resistir à percolação de água. As barragens de rocha e terra representam cerca de $70 \%$ de todas as grandes barragens, enquanto que as que têm base em concreto representam aproximadamente 25\% (ICOLD, 1998). As necessidades de energia e materiais associados são muito diferentes nos diversos tipos de barragem e, tipicamente, incluem material, equipamento mecânico e elétrico, estradas de acesso etc. As barragens de rocha e terra exigem, normalmente, menos energia para a construção, mas têm emissões adicionais durante a extração e condução de rocha e terra. Os valores altos, médios e baixos de fatores de emissão usados no modelo para a fase de construção dos grandes projetos hídricos são apresentados na TAB. 4.1 (IAEA, 2003a).

TABELA 4.1 - Emissões durante a construção de uma nova barragem

\begin{tabular}{l|c|c|c|c}
\hline \multirow{2}{*}{ Emissões } & \multicolumn{2}{|c|}{$\mathbf{C O}_{\mathbf{2}}(\mathrm{g} / \mathbf{k W h})$} & \multirow{2}{*}{$\begin{array}{c}\mathbf{S O}_{2} \\
(\mathbf{g} / \mathbf{k W h})\end{array}$} & \multirow{2}{*}{$\begin{array}{c}\mathbf{N O}_{\mathbf{x}} \\
(\mathbf{g} / \mathbf{k W h})\end{array}$} \\
\cline { 2 - 3 } & Concreto & $\begin{array}{c}\text { Terra + Rocha } \\
\text { Preenchimento }\end{array}$ & & \\
\hline Baixas & 1.00 & 0.10 & 0.008 & 0.003 \\
\hline Altas & 5.90 & 1.00 & 0.100 & 0.013 \\
\hline Médias & 2.733 & 0.55 & 0.035 & 0.006 \\
\hline
\end{tabular}

Fonte: IEA, 1998

Os fatores de emissão da tabela acima estão baseados em 100 anos de vida. Para calcular a emissão anual em toneladas é preciso ter conhecimento da geração de eletricidade média por ano. O modelo realiza este cálculo, segundo a equação (4.8), utilizando valores para os fatores de emissão em $\mathrm{g} / \mathrm{kWh}\left(\mathrm{EF}_{\mathrm{Constr}}\right)$ da tabela acima. A capacidade da usina em MWe (P) e o fator de capacidade (CF) médio em \% também são considerados na equação (4.8) (IAEA, 2003a).

Emissions $_{\text {Const,Your }}=\frac{E F_{\text {Const }}\left[\frac{g}{k W h}\right] \times P[M W e] \times 8,760\left[\frac{h}{y e a r}\right] \times C F[\%]}{1,000}$

\subsection{Emissões de Gases do efeito estufa durante a operação da barragem}

Ao encher um reservatório e inundar uma grande quantidade de terra, em alguns casos, ocorre a submersão de uma quantidade acentuada de biomassa (vegetação e 
solo). Isso é comum em áreas tropicais de baixo relevo. A biomassa e a afluência de carbono da bacia de captação, quando inundadas, são decompostas por micróbios via processos biológicos anaeróbicos e aeróbicos. Os bioprodutos dessa decomposição são dióxido de carbono $\left(\mathrm{CO}_{2}\right)$, metano $\left(\mathrm{CH}_{4}\right)$ e, em menor escala, óxido nitroso $\left(\mathrm{N}_{2} \mathrm{O}\right)$. As dinâmicas desse processo bioquímico dependem, principalmente, do tipo e da quantidade de biomassa, da profundidade do reservatório, da temperatura ambiente e do conteúdo do oxigênio dissolvido na água. A decomposição também mostra uma variação ao longo do tempo das maiores emissões que ocorrem nos estágios iniciais da operação das barragens. Três fases podem ser distinguidas: (1) fase inicial, com duração de 1 a 3 anos após inundação; (2) fase de erosão, com duração até 7 ou 10 anos e (3) fase de balanceamento, com duração de 10 a 30 anos (IEA, 1998). Além disso, há evidências de uma forte variação sazonal e anual (WCD, 2000). As emissões também variam de acordo com a área geográfica. Normalmente, podemos distinguir três diferentes localizações geográficas: (1) áreas planas setentrionais de clima frio, como o Canadá; (2) regiões tropicais úmidas com alta densidade de biomassa, como o Brasil e (3) áreas alpinas de altas altitudes e baixa densidade relativa de biomassa, como a Áustria (IEA, 1998).

Os fatores de emissão da TAB. 4.2 são anuais e por unidade de área do reservatório.

TABELA 4.2 - Emissão de gases durante operação da reserva existente

\begin{tabular}{l|c|c|c|c}
\hline \multirow{2}{*}{ Emissões } & \multicolumn{2}{|c|}{ Tropical } & \multicolumn{2}{c}{ Boreal } \\
\cline { 2 - 5 } & $\mathbf{C O 2}$ & $\mathbf{C H}_{\mathbf{4}}$ & $\mathbf{C O} \mathbf{2}$ & $\mathbf{C H}_{\mathbf{4}}$ \\
\hline Baixas & 150 & 1.5 & 183 & 1.8 \\
\hline Altas & 4,000 & 40 & 1,350 & 13.5 \\
\hline Médias & 1,798 & 18 & 693 & 6.9 \\
\hline
\end{tabular}

Fontes: [CMB, 2000], [IEA, 1998D

Todos os valores estão em ton/ $/ \mathrm{km} / \mathrm{ano}$

Para estimar o total das emissões anuais em toneladas por ano para cada um dos dois gases estufa, o modelo utiliza a área inundada em $\mathrm{km}^{2}$ (IARS) e os fatores da emissão durante a operação em toneladas $/ \mathrm{km}^{2}$-ano $\left(\mathrm{EF}_{\text {Operat }}\right)$ com base na equação (4.9) (IAEA, 2003a).

$$
\text { Emissions }_{\text {Operat,Yoar }}=L A_{R S}\left[\mathrm{~km}^{2}\right] \times E F_{\text {Operat }}\left[\frac{\text { ton }}{\mathrm{km}^{2}-\text { year }}\right]
$$


O modelo também determina o total das emissões de gases estufa na forma de carbono equivalente, usando a potência de metano no aquecimento global, $\left(\mathrm{GWPCH}_{4}\right)$ e peso das moléculas de carbono e dióxido de carbono (4.10) (IAEA, 2003a).

$$
\mathrm{GHG}_{\mathrm{CE} \text {, Total,Year }}=\left(\mathrm{CO}_{2}, \text { Const }\left[\frac{\text { tons }}{\text { year }}\right]+\mathrm{CO}_{2, \text { operat }}\left[\frac{\text { tons }}{\text { year }}\right]+\left(G W P_{\mathrm{CH} 4} \times \mathrm{CH}_{4, \text { Operat }}\left[\frac{\text { tons }}{\text { year }}\right]\right)\right) \times \frac{12}{44}
$$

\subsubsection{Estimativa de impactos de acidentes}

Um dos maiores riscos potenciais à saúde humana está associado à falha acidental em barragem. As consequências dessa falha podem ser catastróficas e podem resultar em uma perda significativa de vidas e bens materiais.

As duas principais causas da falha são (a) estáticas, causadas pela tubulação e pela infiltração e (b) hidrológicas, causadas pelos vertedouros inadequados ou galgamentos (vide TAB. 4.3). Quando ocorre a tubulação ou infiltração (erosão interna), a velocidade da penetração de água pelo aterro ou mobilidade torna-se algo tão grande que partículas do solo passam a ser retiradas. O processo de erosão acelera e, eventualmente, leva a um canal ou "cano" tão grande, capaz de destruir a barragem. O galgamento descreve uma situação em que a quantidade de água que flui dentro do reservatório é maior do que a capacidade do mesmo. Nesse caso, a água tem que sair por algum lugar, e o resultado disso, normalmente, é o transbordamento. Para conter os galgamentos, muitas barragens são construídas com vertedouros, portões ou saídas trabalhadas para conter a saída excessiva de água (IAEA, 2003a).

TABELA 4.3 - Causas de Falha na Barragem

\begin{tabular}{l|c}
\hline Causas de Falha & Ocorrência \\
\hline $\begin{array}{l}\text { Galgamento ou inadequado } \\
\text { vertedouro }\end{array}$ & $23-38 \%$ \\
\hline Tubulação ou infiltração & $30-44 \%$ \\
\hline Deslizamentos & $2-15 \%$ \\
\hline Outros & $9-35 \%$ \\
\hline
\end{tabular}

Fonte: (CHRISTIAN; BAECHER, 1999) 
$\mathrm{O}$ risco de uma falha na barragem é estimado em aproximadamente 1.0E-04 por barragem a cada ano (BAECHER et al. 1980; BRANDESTEN et al., 1993). Entretanto, o risco não é uniforme durante toda a vida da barragem. De fato, a chance de acontecer uma falha é maior no começo, ou seja, na primeira vez que um reservatório tem sua capacidade preenchida. Registros demonstram que, aproximadamente, metade das falhas nas barragens ocorre durante o primeiro preenchimento do reservatório. $\mathrm{O}$ risco residual é mais ou menos distribuído uniformemente durante a vida restante da barragem (CHRISTIAN; BAECHER, 1999).

Uma vez que a barragem falha, o dano pode ser catastrófico em termos de vidas perdidas e de bens destruídos. Entretanto, o dano é específico para cada local. Ao analisarem falhas antigas das barragens, Brown e Graham (1988) identificaram os seguintes fatores que desempenham um papel fundamental na determinação do nível de danos:

- População (e propriedade) em risco;

- Tempo de aviso;

- Tipo de terreno.

Os autores desenvolveram uma relação que estima o número de vidas perdidas como uma função dos parâmetros acima. Enquanto discutem e fornecem informações no tempo de alarme e de terreno escolhidos, a população em risco não está bem definida, e os usuários do algoritmo podem selecionar o valor para esse parâmetro. Eles não incluem a propriedade em risco como a única aplicação para seu algoritmo de vidas perdidas. O tempo de alarme é aquele em número de horas entre o período em que a população é informada sobre a falha da barragem e o período em que a falha realmente ocorreu. Em outras palavras, esse é o tempo que a população tem para ser evacuada. Verificou-se que o terreno downstream da barragem influencia o número de falhas, já que isso afeta o tamanho e extensão da onda de inundação, como também a capacidade para evacuar e impedir o impacto dessa onda. A equação (4.11) mostra a relação das vidas perdidas por acidente (LIVES Lost.Acc) como função da população em risco ( $P O P$ Risk) e tempo de alarme (TIMEWarm) (IAEA, 2003a).

$$
\text { LIVES }_{\text {Lost }, \text { Acc }}=\frac{P O P_{\text {Risk }}[\text { persons }]}{(1+5.207) \times\left(5.838 \times T I M E_{\text {Wan }}[\text { hours }]-T E R\right)}
$$




\subsubsection{Custo externo de perda de recursos culturais e naturais}

Já para as perdas de produção agrícola e de gado, o modelo não quantifica a perda física dos recursos culturais e naturais. Em vez disso, as perdas atuais de recursos (AGLoss) e custos de unidade associados (LSLoss) devem ser fornecidos pelo usuário. O modelo apenas estima o valor econômico das perdas de forma simples. A perda econômica em US\$ por MWh gerado (CostLossAgLiv,MWh,EXT) é estimada usando a equação (4.12) (IAEA, 2003a):

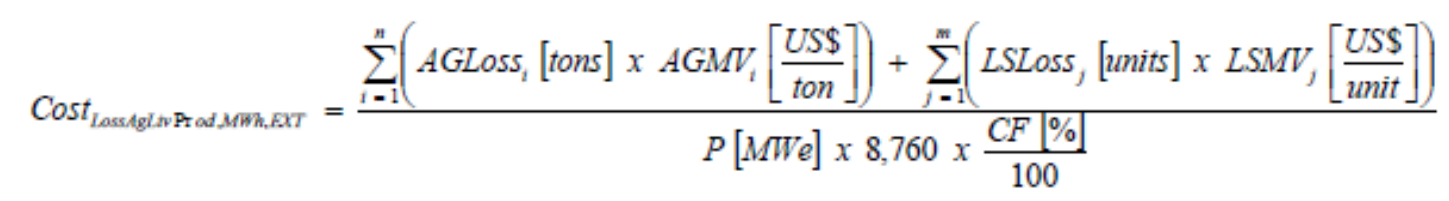

\subsubsection{Custo externo do aumento de incidentes por doenças}

O modelo não quantifica os aumentos atuais em incidentes por doenças. Ele apenas computa o custo econômico de tais aumentos baseando-se nos valores de entrada fornecidos pelos usuários para incidentes adicionais (DISInc) e custos por incidente (CostDISInc). Atualmente o modelo é estruturado para acomodar mais de cinco diferentes tipos de doenças. O custo econômico em US\$ por MWh gerado (CostDISInc,MWh,EXT) é estimado usando a equação (4.13) (IAEA, 2003a):

$$
\operatorname{Cost}_{\text {DISHC.MWh, EXT }}=\frac{\sum_{i=1}^{n}\left(\text { DISInc }_{i} \times \operatorname{Cost}_{\text {DISInc,i }}\right)}{P[M W e] \times 8,760 \times \frac{C F[\%]}{100}}
$$

\subsubsection{Custos externos de emissões}

Com base nas emissões anuais estimadas, o modelo permite que os custos externos relacionados à liberação de gases na atmosfera, como o $\mathrm{CO}_{2}, \mathrm{SO}_{2}$, e $\mathrm{NOx}$ sejam computados Para isso, utilizam-se as emissões anuais estimadas para cada um dos três poluentes multiplicadas pelo custo da unidade. Para o custo de unidade por carbono 
(CARVal), pode-se aplicar valores de carbono usados pelo Fundo Mundial para o Meio Ambiente ou o Prototype Carbon Fund do Banco Mundial. Os valores podem estar em uma média de US\$10-20 por toneladas de carbono. Para $\mathrm{SO}_{2}$, pode-se usar qualquer um dos valores do AIRPACTS ou, se houver um sulfúrico a venda no lugar, o preço de mercado de $\mathrm{SO}_{2}\left(\mathrm{SO}_{2} \mathrm{Val}\right)$ poderá ser considerado. $\mathrm{O}$ mesmo acontece para $\mathrm{NOx}\left(\mathrm{NO}_{\mathrm{X}} \mathrm{Val}\right)$. O custo econômico em US\$ por MWh gerado (CostEmis,MWh,EXT) é estimado usando a equação (4.14) (IAEA, 2003a):

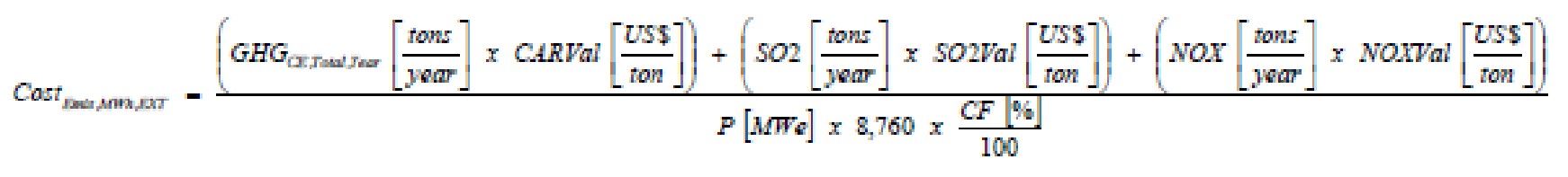

O somatório dos custos apresentados resulta no custo externo final por MWh gerado.

A seguir, será apresentada a metodologia do módulo NUKPACTS.

\subsection{NUKPACTS}

O principal módulo do SIMPACTS para o desenvolvimento desse trabalho é o NUKPACTS, que converte os impactos da liberação de radiação em operação normal e acidental de uma central nuclear em termos monetários, como descrito detalhadamente a seguir.

A avaliação nuclear do SIMPACTS inclui dois submódulos, um para emissões rotineiras e outro para emissões acidentais. No caso das emissões rotineiras, quatro vias para os radionuclídeos são incluídas: inalação direta no ar; irradiação externa imersa nas nuvens; irradiação externa da deposição e ingestão por meio de produtos agropecuários. As principais fases dessas vias são: emissão, transporte, contaminação, exposição humana e efeitos na saúde. O componente das emissões acidentais faz uso do julgamento de peritos sobre a probabilidade e a magnitude das consequências e utiliza a abordagem que leva em consideração o risco esperado. A valoração das consequências esperadas fornece os custos externos de um acidente (IAEA, 2001). 
O referido módulo aplica um método para valorar os potenciais efeitos adversos à saúde das pessoas, decorrentes de liberações atmosféricas rotineiras de radioatividade das instalações nucleares. O módulo é baseado em um quadro de meios de exposição, geralmente seguindo uma análise que considera as três principais categorias de emissão ao meio ambiente: emissões de ar, disposição de líquidos em um rio ou mar e de disposição de lixo no solo. São considerados índices de emissão de ar especificados pelo próprio usuário, seguindo um quadro de rotas de exposição que usa a dispersão atmosférica, deposição no solo e deposição na vegetação e produtos agrícolas para estimar as doses radiológicas em pessoas. As doses radiológicas são calculadas para populações locais (distância de $100 \mathrm{~km}$ ) e regionais (de 100 a $1000 \mathrm{~km}$ de distância). O modelo estima os efeitos estocásticos na saúde, baseados em cálculos de dose (IAEA, 2003b).

A radiação liberada tanto em operação normal quanto em caso de um acidente poderá afetar ambos, a atmosfera e o ambiente aquático, de acordo com os fluxogramas apresentados na FIG. 4.15 (a) e (b) (IAEA, 2003b). 


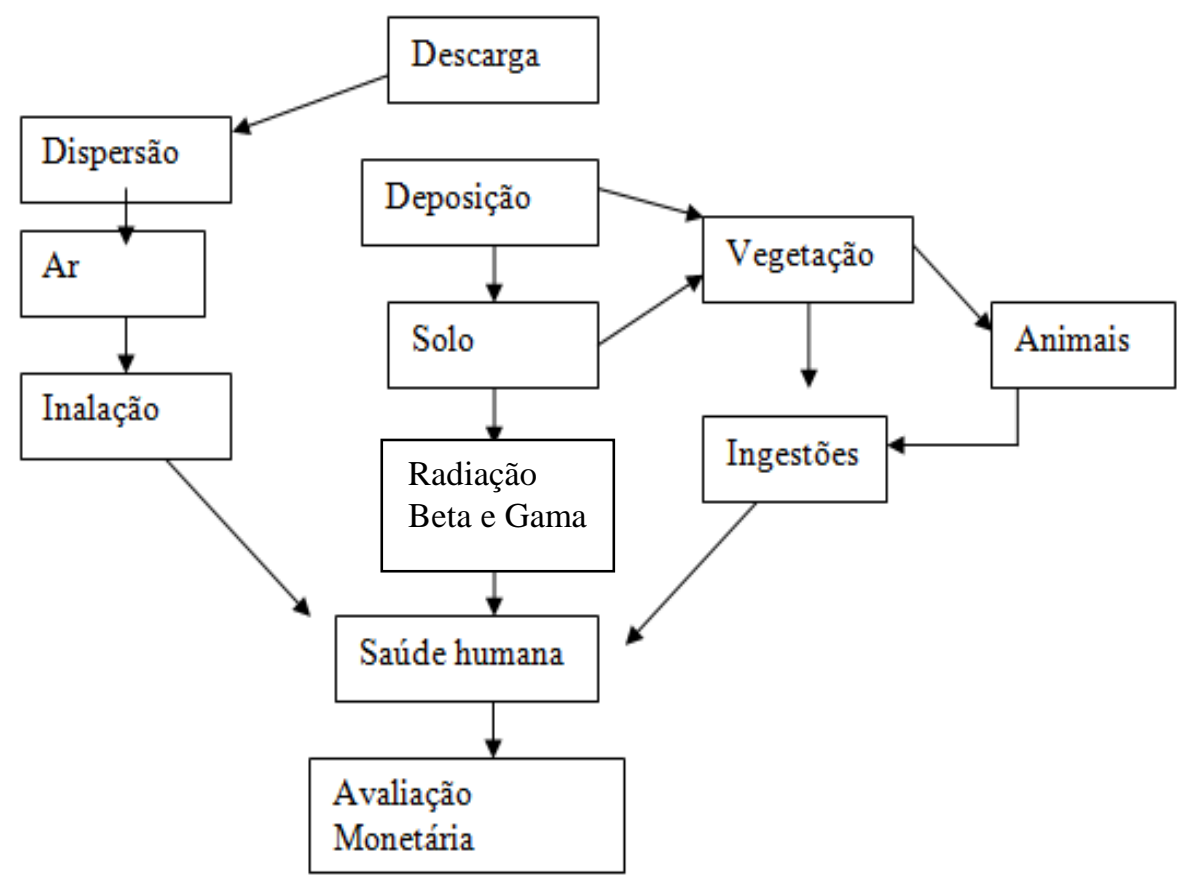

(a)

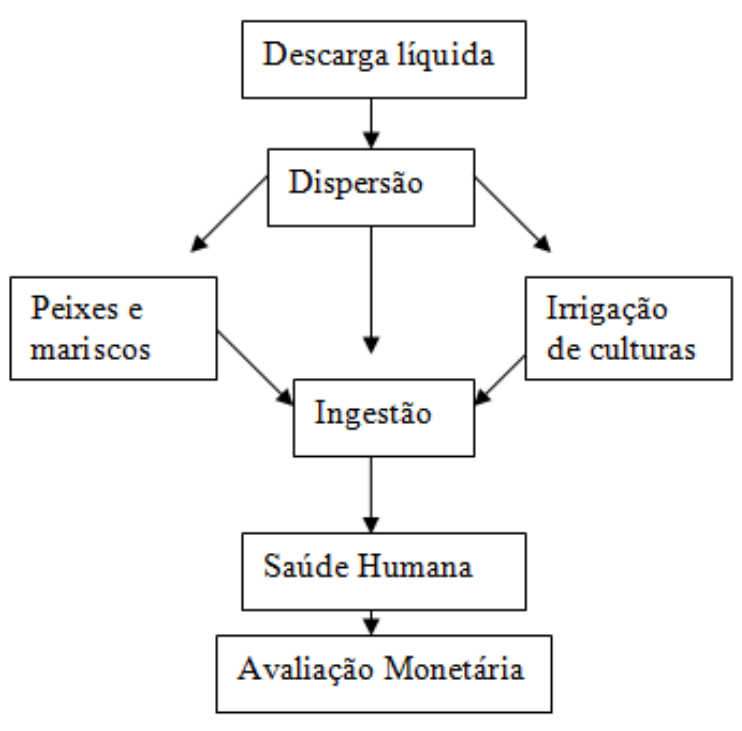

(b)

FIGURA 4.15 - Caminhos para as emissões atmosféricas de radionuclídeos (a) e Caminhos para a descarga líquida de radionuclídeos em ambiente aquático (b). 
A dispersão atmosférica é mais abrangente em relação à dispersão em meio aquático, pois a saúde da população é afetada não apenas pela ingestão como também pela inalação, conforme fluxograma mostrado na FIG. 4.15 (a). A descrição lógica de cada uma das fases da dispersão é tratada no NUKPACTS, conforme o fluxograma apresentado na FIG. 4.16 (ATHAR, 2003).

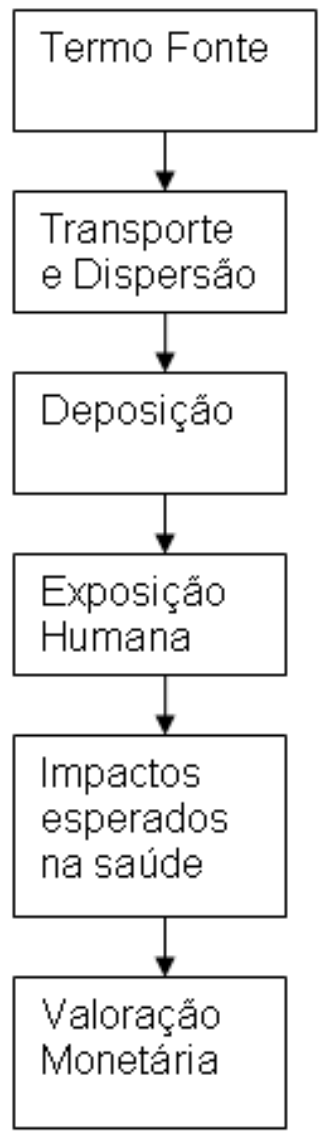

FIGURA 4.16 - Fluxograma demonstrativo da metodologia de cálculo do módulo NUKPACTS

A primeira etapa de cálculo leva em consideração o termo fonte, ou seja, a dispersão na atmosfera de radionuclídeos provenientes da operação normal ou anormal de reatores nucleares. Como exemplo, a TAB. 4.4 fornece os radionuclídeos liberados para o ar e suas respectivas meias-vidas, em um reator do tipo PWR (ATHAR, 2003). 
TABELA 4.4 - Principais radionuclídeos liberados para o ar e suas respectivas meias-vidas

\begin{tabular}{l|l|l|l}
\hline \multicolumn{1}{c|}{ Radionuclídeo } & Meia-vida & Radionuclídeo & Meia-vida \\
\hline $\mathrm{Kr}-85$ & 10.7 anos & $\mathrm{I}-134$ & 52.6 minutos \\
\hline $\mathrm{Kr}-87$ & 76.3 minutos & $\mathrm{I}-135$ & 6.6 horas \\
\hline $\mathrm{Kr}-88$ & 2.8 horas & $\mathrm{Cs}-134$ & 2.1 anos \\
\hline $\mathrm{Xe}-133$ & 5.2 dias & $\mathrm{Cs}-136$ & 13.1 dias \\
\hline $\mathrm{Xe}-135$ & 9.2 h oras & $\mathrm{Cs}-137$ & 30 anos \\
\hline $\mathrm{Xe}-138$ & 14 minutos & $\mathrm{Co}-58$ & 71 dias \\
\hline $\mathrm{I}-131$ & 8.1 dias & $\mathrm{Co}-60$ & 5.3 anos \\
\hline $\mathrm{I}-132$ & 2.3 horas & $\mathrm{C}-14$ & 5710 anos \\
\hline $\mathrm{I}-133$ & 21 horas & $\mathrm{H}-3$ & 13.3 anos \\
\hline
\end{tabular}

A segunda etapa de cálculo considera o transporte e a dispersão dos radionuclídeos. O cálculo da concentração de radiação média anual por unidade de volume $\left(\mathrm{Bq} / \mathrm{m}^{3}\right)$ é realizado utilizando-se o modelo de dispersão da pluma Gaussiana (SEINFELD \& PANDIS, 1988).

Os dados necessários para esse cálculo são: a emissão de cada radionuclídeo, a velocidade média anual dos ventos, a altura efetiva da liberação do radionuclídeo e a categoria de estabilidade correspondente de acordo como o modelo de "Pasquil-Gifford" (TURNER, 1970).

A equação (4.15) fornece a relação entre a velocidade do vento e a altura da liberação (BRODE \& WANG, 1992):

Velocidade do vento (altura da radiação liberada) $=V_{k} \times\left(\frac{h_{k}}{h_{r}}\right)^{p}$

Onde:

$V_{k}=$ velocidade do vento na altura conhecida $(\mathrm{m} / \mathrm{s})$;

$h_{k}=$ altura conhecida $(\mathrm{m})$;

$h_{r}=$ altura liberada $(\mathrm{m})$;

$p=$ expoente que varia com a estabilidade atmosférica. 
A estabilidade atmosférica é calculada a partir dos dados apresentados na TAB. 4.5.

TABELA 4.5 - Demonstração do cálculo do coeficiente de estabilidade da atmosfera

\begin{tabular}{l|c|c|l}
\hline \multicolumn{1}{c|}{ Classe de Estabilidade } & Coeficiente & $\begin{array}{c}\text { Velocidade do vento a } \\
\mathbf{1 0 m}\end{array}$ & \multicolumn{1}{|c}{ Tempo (clima) } \\
\hline A - muito instável & 0,15 & 1 a 2.5 & Muito ensolarado \\
\hline B - moderadamente instável & 0,15 & 1 a 5 & Ensolarado \\
\hline C - ligeiramente instável & 0,20 & 2 a 6 & $\begin{array}{l}\text { Parte do dia } \\
\text { nublado }\end{array}$ \\
\hline D - neutra & 0,25 & 2 a > 10 & $\begin{array}{l}\text { Nublado } \\
\text { nublada da noite }\end{array}$ \\
\hline E - estável & 0,40 & 2 a 5 & Noite clara \\
\hline F - muito estável & 0,60 & 2 a 3 & \\
\hline
\end{tabular}

A terceira etapa calcula a deposição dos radionuclídeos segundo a equação (4.16) (IAEA, 2003b).

$$
W_{i}=C_{i} \times V_{d}
$$

Onde:

$W_{i}=$ fluxo médio do radionuclídeo $\mathrm{i}\left(\mathrm{Bq} / \mathrm{m}^{2} . \mathrm{s}\right)$;

$C_{i}=$ concentração média anual do radionuclídeo no ar por unidade de volume $\left(\mathrm{Bq} / \mathrm{m}^{3}\right)$;

$V_{d}=$ velocidade média de deposição $(\mathrm{m} / \mathrm{s})$

A quarta etapa trata da exposição do público em geral aos radionuclídeos, podendo ser da seguinte forma (IAEA, 2003b):

- Inalação de radionuclídeos presentes no ar;

- Irradiação externa da exposição de nuvem;

- Irradiação externa da deposição no terreno;

- Ingestão de radionuclídeos presentes nos alimentos. 
Cada uma dessas formas de exposição é calculada por meio de equações matemáticas que serão descritas em um item separado (ANEXO A).

A quinta etapa, correspondente aos impactos esperados na saúde humana, considera basicamente os casos fatais de câncer, que podem ocorrer na população, causados pela radiação, os casos não fatais de câncer e os casos de efeitos severos nas próximas gerações das populações expostas (ATHAR, 2003).

A sexta e última etapa realiza a conversão dos impactos identificados em termos monetários (valoração monetária). O modelo possui dados relativos aos valores econômicos dos impactos da radiação na saúde da população de vários países, mas o usuário do programa poderá inserir seus próprios valores previamente calculados. Essas informações deverão ser fornecidas em unidades monetárias (US\$, €, etc.) e normalizadas nas unidades de moeda por energia (US\$/kWh, $€ / \mathrm{kWh}$, etc.) (ATHAR, 2003).

A utilização do módulo tratado nesse item será apresentada a seguir.

\subsubsection{Utilização do Módulo}

De forma esquemática, ao abrir o modelo SIMPACTS, o usuário poderá escolher entre a opção para avaliar os potenciais efeitos de emissões de ar de impactos radiológicos ou avaliar os efeitos de impactos não radiológicos. O usuário clicará na tabela radiológica e, em seguida, no botão que inicia, para executar o modelo NUKPACTS. Assim o usuário será levado a uma nova janela onde deverá digitar os parâmetros em quatro categorias gerais: Dispersão e Recepção, Emissões e Meteorologia, Consumo de alimentos e Efeitos à saúde e Valoração. A metodologia simplificada do NUKPACTS será demonstrada na FIG. 4.17. Logo abaixo, são demonstrados os parâmetros de entrada do módulo e como esses são representados no Programa, nas TAB. 4.6 e FIG. de 4.18 a 4.21 (IAEA, 2003b). 


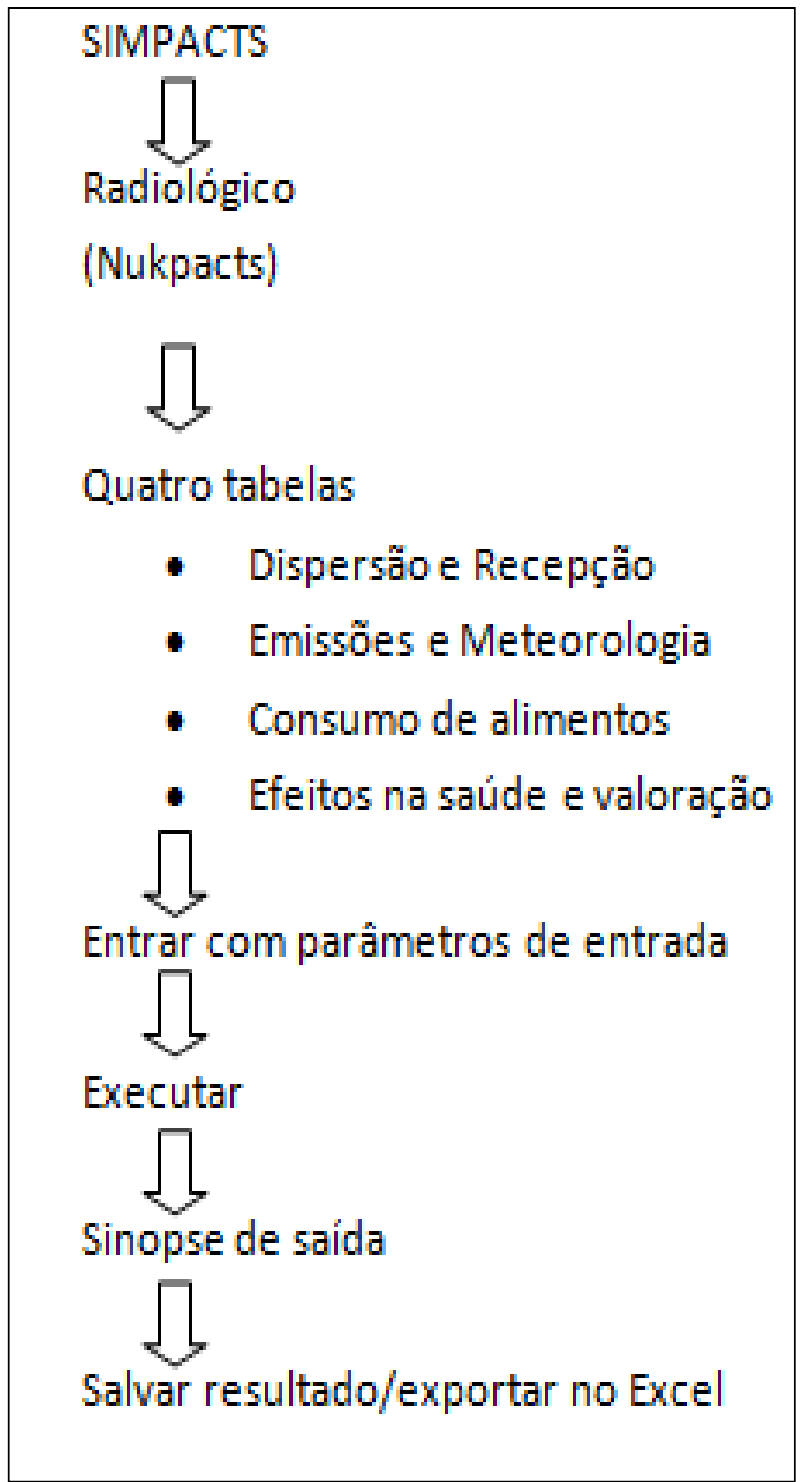

FIGURA 4.17 - Metodologia simplificada do NUKPACTS 
TABELA 4.6 - Parâmetros de entrada do NUKPACTS

\begin{tabular}{|c|c|}
\hline Dispersão e Recepção & Unidades \\
\hline Parâmetros de população e dispersão & População por $\mathrm{Km}^{2}$ \\
\hline Distribuição urbano-rural & $\%$ \\
\hline Velocidade média anual do vento & $\mathrm{m} / \mathrm{s}$ \\
\hline Altura de emissão efetiva & $\mathrm{M}$ \\
\hline Velocidade média de deposição molhada ou seca & $\mathrm{m} / \mathrm{s}$ \\
\hline Velocidade de deposição & $\mathrm{m} / \mathrm{s}$ \\
\hline Índice médio anual frequência respiratória adulta & $\mathrm{m}^{3} / \mathrm{ano}$ \\
\hline Emissões e Meteorologia & Unidades \\
\hline Índice de emissão de radionuclídeos & $\mathrm{Bq} / \mathrm{s}$ \\
\hline $\begin{array}{l}\text { Ocorrência de estabilidade para Classes de Estabilidade } \\
\text { Pasquill (A,B,C,D,E,F) (Muito instável } \rightarrow \text { muito } \\
\text { estável) }\end{array}$ & $\%$ \\
\hline Consumo de alimentos & Unidades \\
\hline $\begin{array}{l}\text { Índice de consumo médio de cada um dos seguintes } \\
\text { alimentos: carne bovina, porco, frango, ovelha, cereais, } \\
\text { verduras, tubérculos, leite fresco e outros tipos. }\end{array}$ & $\begin{array}{l}\mathrm{Kg} \text { por pessoa por } \\
\text { ano }\end{array}$ \\
\hline $\begin{array}{l}\text { Fração comestível para cada um dos seguintes } \\
\text { alimentos: carne bovina, porco, frango, ovelha, cereais, } \\
\text { verduras, tubérculos, leite fresco e outros tipos. }\end{array}$ & $\%$ \\
\hline Efeitos na saúde e Valoração & Unidades \\
\hline Fatores de risco aos efeitos na saúde & $\begin{array}{l}\text { Casos por pessoa } \\
\mathrm{Sv}\end{array}$ \\
\hline \multicolumn{2}{|l|}{$\begin{array}{l}3 \text { efeitos - Câncer fatal, câncer não fatal, efeitos } \\
\text { hereditários graves. }\end{array}$} \\
\hline $\begin{array}{l}\text { Valores de unidade econômica em câncer fatal (VOSL), } \\
\text { câncer fatal (VLYL), câncer não fatal. }\end{array}$ & US\$ por caso \\
\hline PIB per capita no PPC (Paridade de Poder de Compara) & US\$ \\
\hline
\end{tabular}




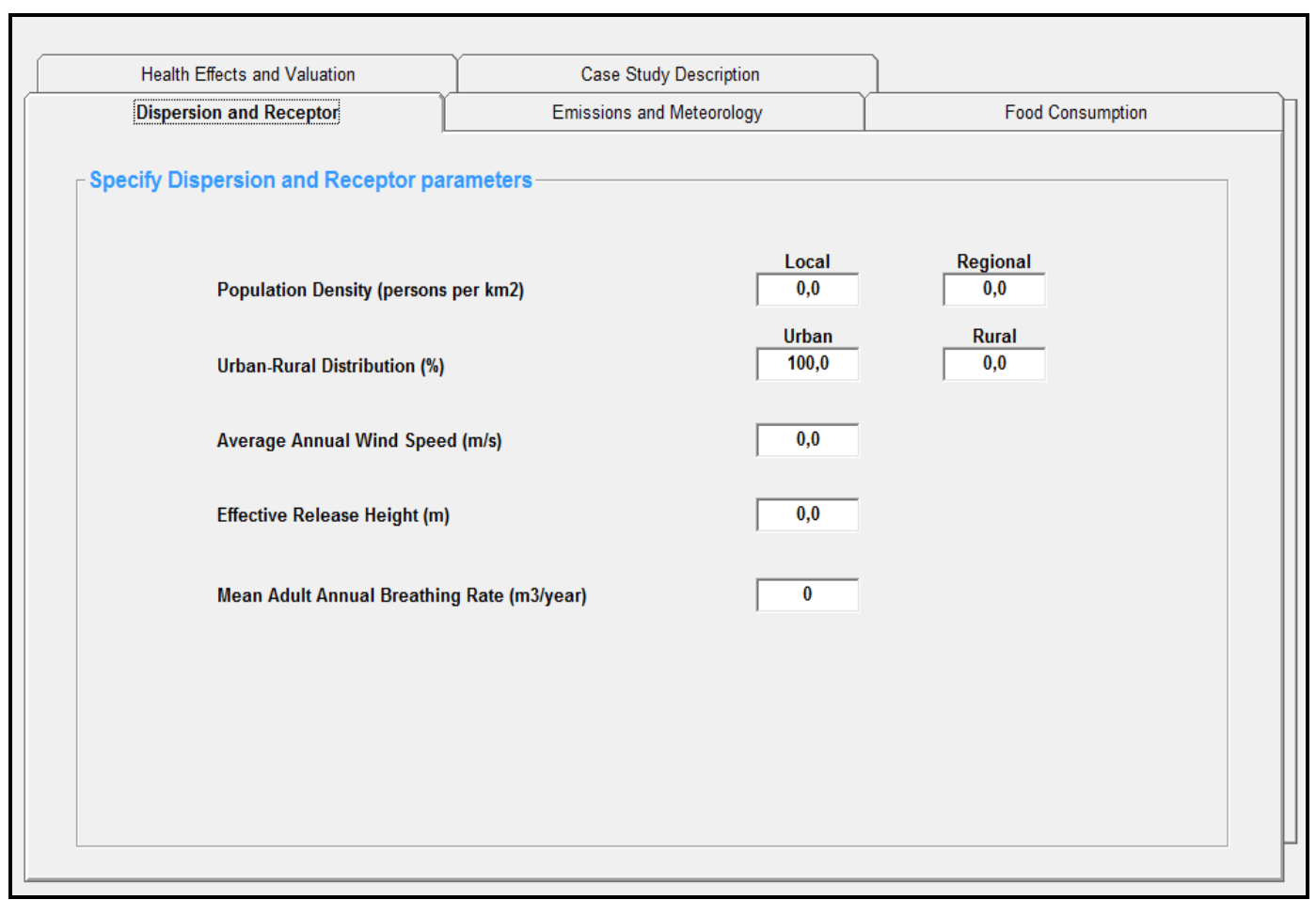

FIGURA 4.18 - Telas de entrada do modelo para Dispersão e Recepção

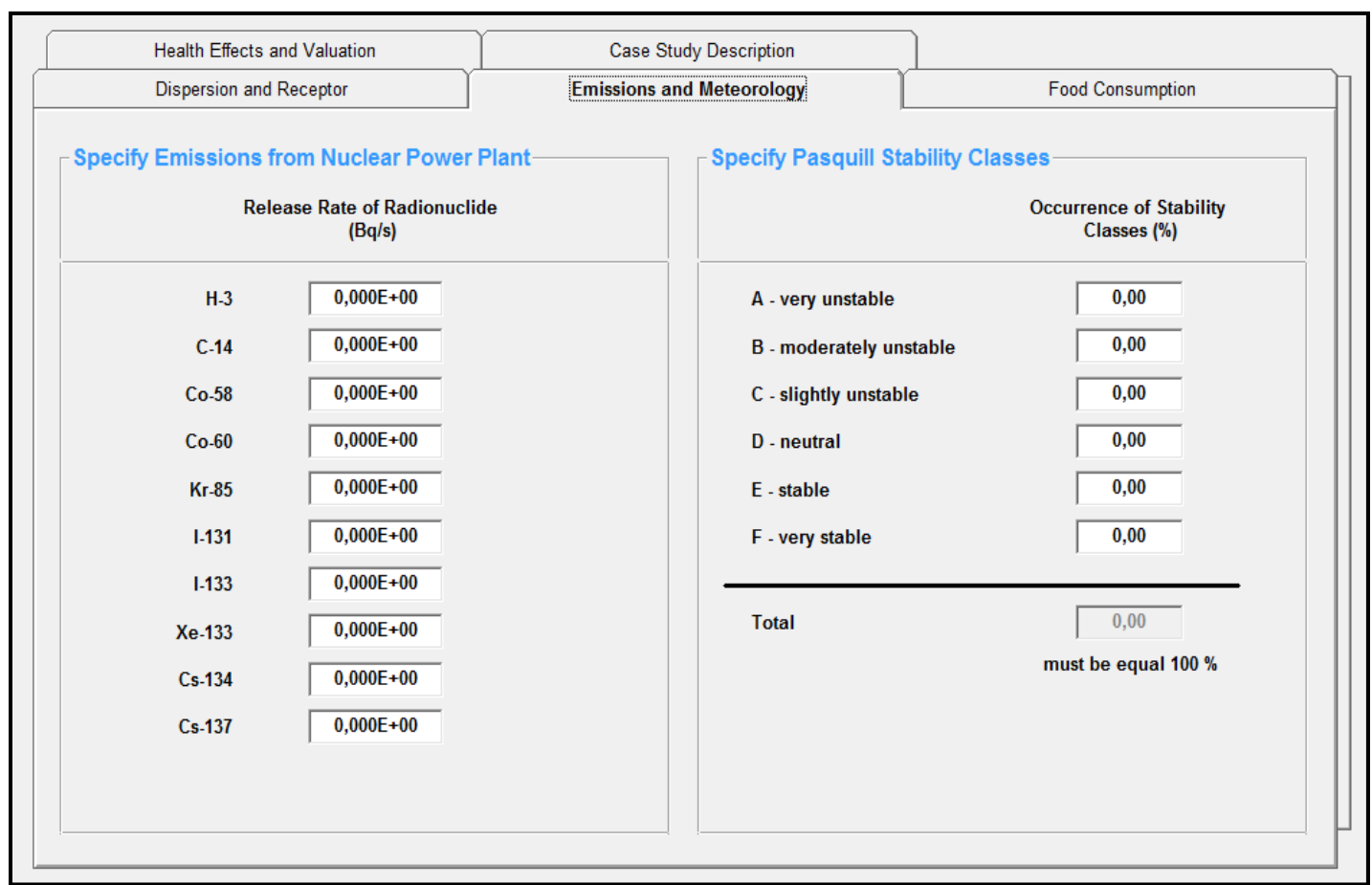

FIGURA 4.19 - Telas de entrada do modelo para Emissões e Meteorologia 


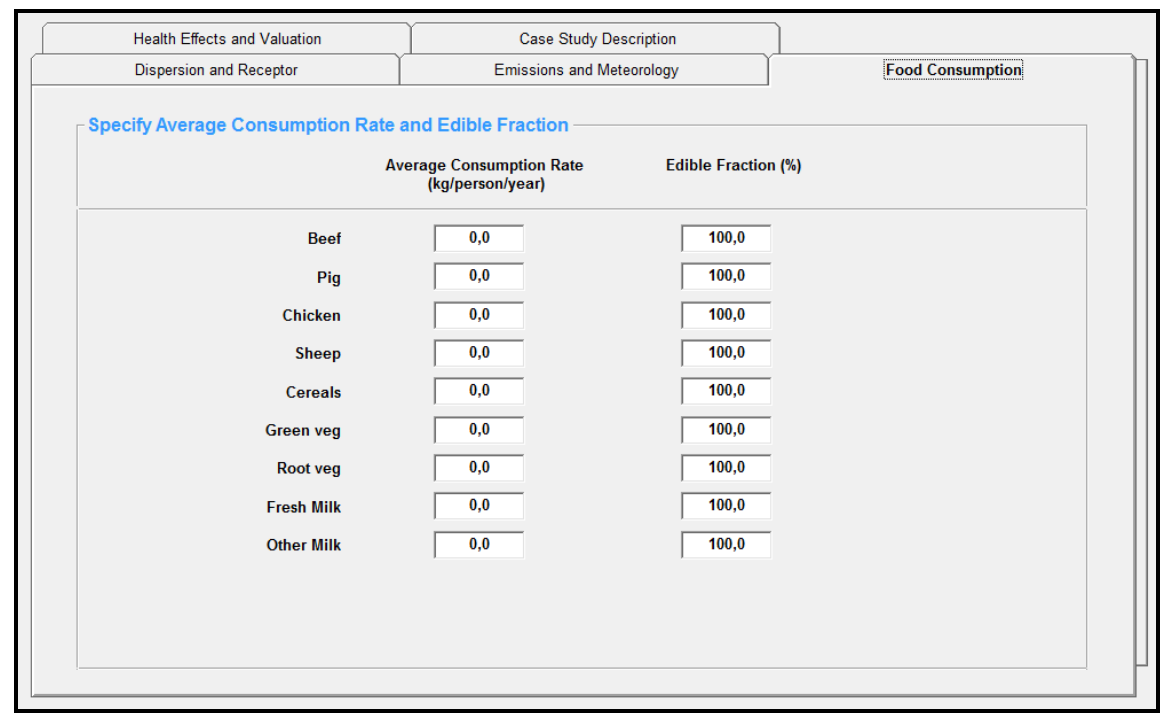

FIGURA 4.20 - Telas de entrada do modelo para Consumo de alimentos

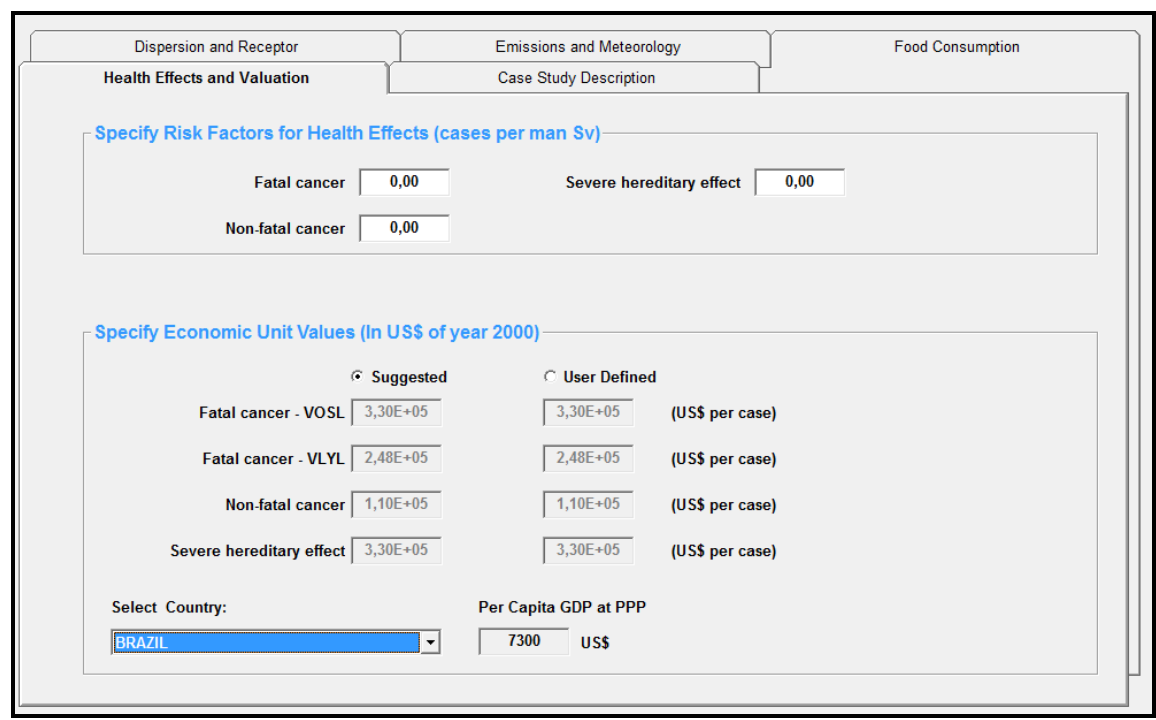

FIGURA 4.21 - Telas de entrada do modelo para Efeitos na saúde e Valoração

O próximo item descreverá algumas especificidades de como o NUKPACTS realiza o cálculo de custo ambiental para diferentes meios de exposição.

\subsubsection{Vias de transferências ambientais}

O NUKPACTS calcula a dose coletiva para todas as vias de transferência, nas áreas locais e regionais separadamente e, então, soma as duas estimativas para obter uma dose combinada total. O modelo calcula os potenciais riscos à saúde em casos por ano e atribui o valor de 1 (um) dólar aos potencias efeitos à saúde (IAEA, 2003b). 
A FIG. 4.22 demonstra cada um dos passos na análise das vias de transferências (IAEA, 2003a).

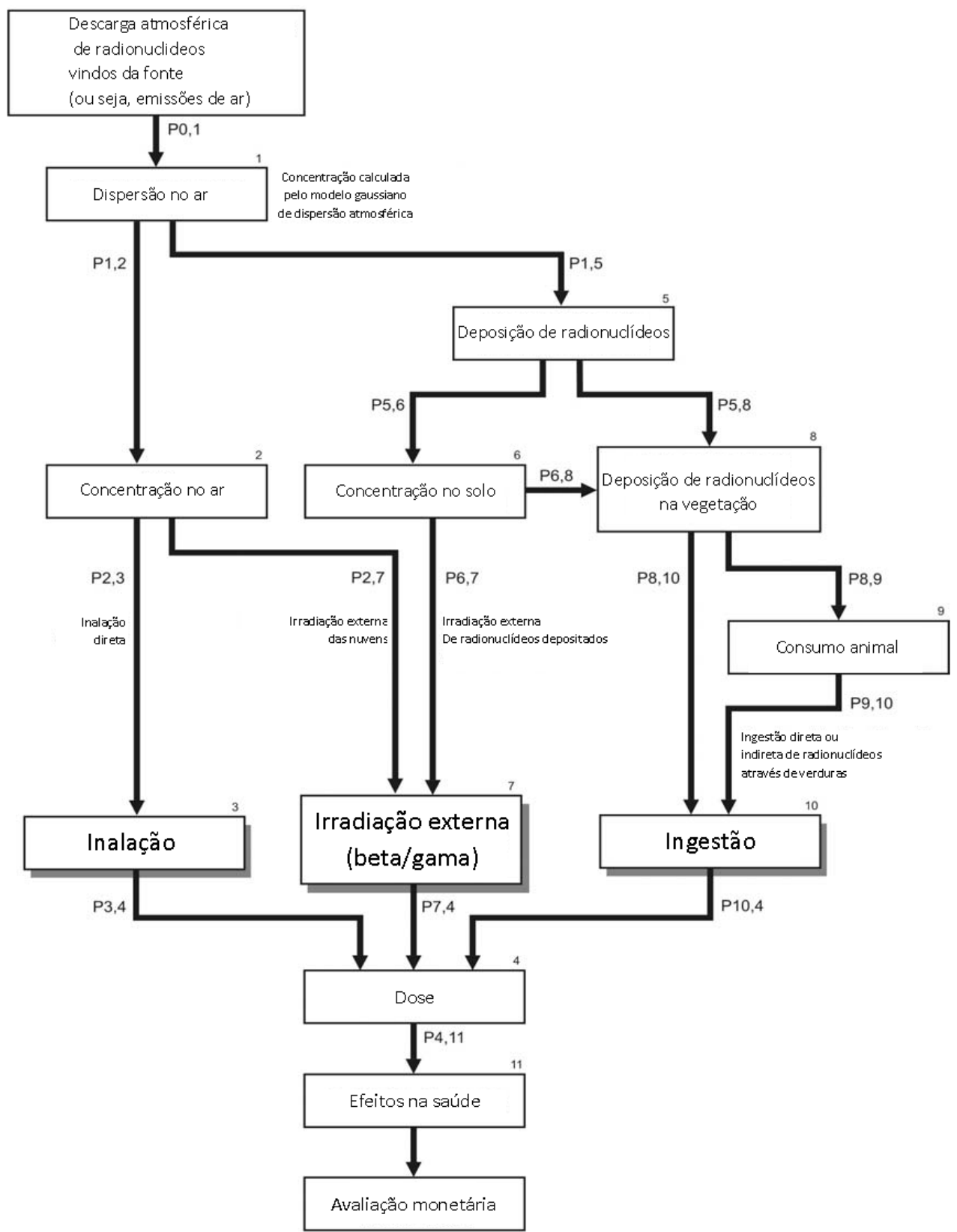

FIGURA 4.22 - Vias de transferência de exposição atmosférica usada no NUKPACTS. 


\subsubsection{Dispersão no ar}

As dispersões local e regional serão tratadas nesse item.

\subsection{Local}

O NUKPACTS avalia oito radionuclídeos lançados ao ar, vindos de estações de geração de energia. Dada as estimativas de emissões de ar para os vários radionuclídeos, a dispersão do ar é o primeiro passo nas análises de via de transferências de exposição; ela estimula o movimento dos poluentes através da atmosfera, da fonte para o receptor em uma distância (e em uma direção), como demonstrado na FIG. 4.23 (IAEA, 2003b).

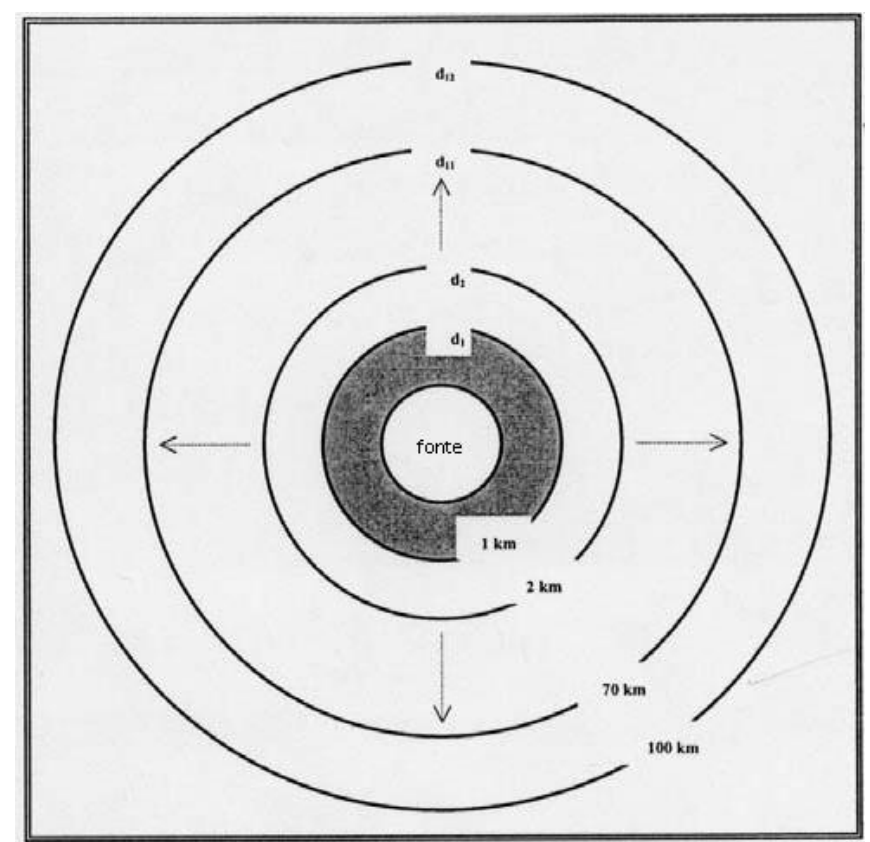

FIGURA 4.23 - Distribuição espacial local de radionuclídeos

O NUKPACTS utiliza o modelo de dispersão de pluma gaussiana para calcular as concentrações de radionuclídeos a favor do vento lançados ao ar. Admite-se no programa que os radionuclídeos são dispersos uniformemente em todas as direções e que as concentrações são uniformes em uma dada banda de distância radial vindo da fonte (IAEA, 2003b).

Salienta-se que alguns fatores afetam a estabilidade atmosférica, incluindo, por exemplo, velocidade do vento, aspereza do solo e intensidade de radiação solar. A velocidade do vento, direção do vento e turbulência atmosférica variam com a altura adicional, que pode posteriormente complicar as análises da dispersão atmosférica. Os 
efeitos desses não podem ser captados pelo modelo de pluma gaussiana no NUKPACTS (IAEA, 2003b).

\subsection{Regional}

Os modelos do NUKPACTS para concentrações atmosféricas médias no âmbito regional entre $100 \mathrm{~km}$ e $1000 \mathrm{~km}$ da fonte são dados pela equação (4.17) (IAEA, 2003b):

$\mathrm{C}_{\mathrm{R}}=\mathrm{Q}_{\mathrm{R}} / \mathrm{A}_{\mathrm{R}} / \mathrm{V}_{\mathrm{d}}^{\mathrm{w}, \mathrm{d}}$

Onde:

$\mathrm{C}_{\mathrm{R}}=$ Concentração de radionuclídeos médias i através do âmbito regional $\left(\mathrm{Bq}\right.$ por $\left.\mathrm{m}^{3}\right)$.

$\mathrm{Q}_{\mathrm{R}}=$ Índice de emissão de radionuclídeos i (Bq por segundo).

$\mathrm{A}_{\mathrm{R}}=$ Área regional $\left(\mathrm{m}^{2}\right)$.

$\mathrm{V}_{\mathrm{d}}^{\mathrm{w}, \mathrm{d}}=$ Índice médio de deposição úmida ou seca (m por segundo).

\subsubsection{Inalação}

Depois dos radionuclídeos serem dispersos no ar, as pessoas podem ser expostas a eles por meio de uma variedade de vias de transferências, incluindo a inalação. Com relação à inalação, é considerado o produto da concentração atmosférica dos radionuclídeos e do índice de frequência respiratória. A dose é, então, o produto da entrada, vias de inalação e o fator de conversão de dose apropriada. O índice médio anual de frequência respiratória de um adulto é de $7500 \mathrm{~m}^{3}$ por ano, sendo esse o valor usado para o cálculo no NUKPACTS (IAEA, 2003b).

\subsubsection{Irradiação externa}

A emissão de radiação gama ou beta por radionuclídeos no ar é considerada fonte potencial de exposição à irradiação externa. Outra fonte de irradiação externa é a exposição direta devido à contaminação no solo proveniente dos radionuclídeos que emitem gama e beta (IAEA, 2003b). 


\subsubsection{Ingestão}

A exposição pela ingestão ocorre quando o radionuclídeo no meio ambiente entra na cadeia alimentar. A via de transferência da ingestão envolve passos adicionais de transferência para plantas e animais, que são consumidos por humanos (IAEA, 2003b).

Uma vez que a concentração de radionuclídeos nas plantas e animais é conhecida, a quantidade de radioatividade consumida pelas pessoas pode ser estimada, multiplicando a concentração de radionuclídeo em um dado alimento pela quantidade de alimento consumido em um ano. Os fatores de conversão de doses para radionuclídeos consumidos estão listados na TAB. 4.7 (IAEA, 2003b), sendo que sievert (Sv) corresponde a medida de dose equivalente de radiação ionizante, assim como bequerel $(\mathrm{Bq})$, ambas unidades do Sistema Internacional (SI).

TABELA 4.7 - Fatores de conversão de dose do NUKPACTS para ingestão de radionuclídeos em produtos alimentícios

\begin{tabular}{c|c}
\hline Radionuclídeo & Fatores de conversão de dose (Sv/Bq) \\
\hline H-3 & $1.80 \mathrm{E}-11$ \\
\hline C-14 & $5.60 \mathrm{E}-10$ \\
\hline Co-58 & $1.00 \mathrm{E}-09$ \\
\hline Co-60 & $7.20 \mathrm{E}-09$ \\
\hline $\mathrm{I}-131$ & $2.20 \mathrm{E}-08$ \\
\hline $\mathrm{I}-133$ & $4.20 \mathrm{E}-09$ \\
\hline Cs-134 & $1.90 \mathrm{E}-08$ \\
\hline Cs-137 & $1.30 \mathrm{E}-08$ \\
\hline
\end{tabular}

A dose anual para um indivíduo é calculada como o produto do tempo exposto e do índice de exposição para todas as vias de transferências. As doses coletivas são, então, calculadas multiplicando a dose média para uma pessoa dentro de um círculo radial pelo número de pessoas que vivem no mesmo círculo semi-radial. Essa dose será incluída no cálculo do nível de dose coletiva (IAEA, 2003b).

\subsubsection{Efeitos na saúde}

A análise de potenciais efeitos à saúde é uma parte crucial da via de transferência de emissão atmosférica. Depois de estimar a dose coletiva, o modelo NUKPACTS estima os potenciais riscos à saúde multiplicando a dose por fatores que convertem dose para efeitos à saúde (riscos). Para doses nos níveis esperados de emissões 
crônicas de radioatividade no ar, o NUKPACTS usa a dose para fatores de risco de efeitos estocásticos à saúde, denominados: câncer fatal, câncer não fatal e efeitos severos hereditários, demonstrados na TAB. 4.8 (IAEA, 2003b).

TABELA 4.8 - Fatores de risco do NUKPACTS

\begin{tabular}{l|c}
\hline \multicolumn{1}{c|}{ Efeitos de saúde (Adulto) } & Fator de risco (casos por homem Sv) \\
\hline Câncer fatal & $5.00 \mathrm{E}-02$ \\
\hline Câncer não fatal & $1.20 \mathrm{E}-01$ \\
\hline Efeitos severos hereditários & $1.00 \mathrm{E}-02$ \\
\hline
\end{tabular}

A seguir, uma breve descrição de como o NUKPACTS realiza o cálculo de custo ambiental para termelétricas será apresentada.

\subsubsection{Termelétricas}

\subsubsection{Aspectos Radiológicos da combustão do carvão}

O NUKPACTS também pode ser aplicado em instalações termelétricas movidas a carvão. O principal componente do carvão é o carbono, e a porção inorgânica do carvão possui alguns elementos que podem ser radioativos. Nesses, estão inclusos o urânio e o tório, com sua alta quantidade de produtos de desintegração, incluindo o radio-226, radônio-222, chumbo-210 e polônio-210. Durante a combustão do carvão, muitos desses elementos radioativos são liberados e distribuídos na fase gasosa ou como produtos sólidos de combustão, dependendo da volatilidade de cada elemento radioativo. Quando esses elementos são dispersos por meio das várias vias de transferência, o resultado é a exposição da população às doses radiológicas (IAEA, 2003b).

Além das emissões de óxidos de enxofre, nitrogênio e partículas, as centrais movidas a carvão também lançam elementos radioativos, pois todos os tipos de combustão contêm baixos níveis de materiais radioativos ocorrendo naturalmente, como potássio-40, urânio, tório e seus produtos radioativos de vida longa (vide TAB. 4.9). Esses radionuclídeos são tipicamente concentrados nas cinzas da combustão, e uma pequena fração dela é lançada na atmosfera. As vias de transferências potenciais de exposições dos radionuclídeos lançados no ar pela combustão de carvão são similares àquelas para radionuclídeos lançados por centrais nucleares (IAEA, 2003b). 
TABELA 4.9 - Coeficientes de transferência para elementos radioativos envolvidos na combustão de carvão

\begin{tabular}{c|c|c|c|c|l|l}
\hline Elemento & $\begin{array}{l}\text { Cereais (a) } \\
\text { Bq/safra de } \\
\text { peso seco }\end{array}$ & $\begin{array}{l}\text { Vegetais verdes } \\
\text { Bq/solo de peso } \\
\text { seco }\end{array}$ & $\begin{array}{l}\text { Tubérculos } \\
\text { Bq/solo de } \\
\text { peso seco }\end{array}$ & $\begin{array}{l}\text { Carne bovina } \\
\mathbf{d} / \mathbf{K g}\end{array}$ & $\begin{array}{l}\text { Cordeiro } \\
\mathbf{d} / \mathbf{K g}\end{array}$ & $\begin{array}{l}\text { Leite } \\
\mathbf{d} / \mathbf{L}\end{array}$ \\
\hline $\mathrm{U}$ & $1.3 \mathrm{E}-03$ & $8.3 \mathrm{E}-03$ & $1.4 \mathrm{E}-02$ & $3.0 \mathrm{E}-04$ & $3.0 \mathrm{E}-04$ & $4.0 \mathrm{E}-04$ \\
\hline $\mathrm{Th}$ & $3.4 \mathrm{E}-05$ & $1.8 \mathrm{E}-03$ & $3.9 \mathrm{E}-02$ & $6.0 \mathrm{E}-06$ & $6.0 \mathrm{E}-06$ & $5.0 \mathrm{E}-06$ \\
\hline $\mathrm{Ra}$ & $1.2 \mathrm{E}-03$ & $4.9 \mathrm{E}-02$ & $1.1 \mathrm{E}-02$ & $9.0 \mathrm{E}-04$ & $9.0 \mathrm{E}-04$ & $1.3 \mathrm{E}-03$ \\
\hline $\mathrm{Pb}$ & $4.7 \mathrm{E}-03$ & $1.0 \mathrm{E}-02$ & $2.0 \mathrm{E}-02$ & $4.0 \mathrm{E}-04$ & $4.0 \mathrm{E}-04$ & $2.5 \mathrm{E}-04$ \\
\hline $\mathrm{Po}$ & $2.3 \mathrm{E}-03$ & $1.2 \mathrm{E}-03$ & $7.0 \mathrm{E}-03$ & $5.0 \mathrm{E}-03$ & $5.0 \mathrm{E}-03$ & $3.4 \mathrm{E}-04$ \\
\hline
\end{tabular}

Os potenciais Fatores de Conversão de Doses (Dose Conversion Factors, DCFs) para uso na avaliação de radionuclídeos da combustão de carvão incluem: DCFs externos para dose, devido à imersão na pluma, e exposição direta, devido à contaminação no solo; DCFs, para as vias de transferências de inalação e DCFs, para as vias de transferências de ingestão, demonstrados nas TAB. 4.10 a 4.12 (IAEA, 2003b). 
TABELA 4.10 - Fatores de conversão de doses para radionuclídeos envolvidos na combustão de carvão para exposição externa de nuvens passageiras e deposições no solo

\begin{tabular}{|c|c|c|}
\hline Radionuclídeo & Nuvem Sv/s / Bq/m 3 & $\begin{array}{c}\text { Solo Sv/s / } \\
\text { Bq/m } \mathbf{m}^{2}\end{array}$ \\
\hline $\mathrm{U}-238$ & $3.41 \mathrm{E}-18$ & $5.51 \mathrm{E}-19$ \\
\hline Th-234 & $3.38 \mathrm{E}-16$ & $8.32 \mathrm{E}-18$ \\
\hline $\mathrm{Pa}-234 \mathrm{~m}$ & $7.19 \mathrm{E}-16$ & $1.53 \mathrm{E}-17$ \\
\hline U-234 & 7.63E-18 & $7.48 \mathrm{E}-19$ \\
\hline Th-230 & $1.74 \mathrm{E}-17$ & $7.50 \mathrm{E}-19$ \\
\hline Ra-226 & $3.15 \mathrm{E}-16$ & $6.44 \mathrm{E}-18$ \\
\hline Rn-222 & $1.91 \mathrm{E}-17$ & $3.95 \mathrm{E}-19$ \\
\hline Po-218 & $4.48 \mathrm{E}-19$ & $8.88 \mathrm{E}-21$ \\
\hline $\mathrm{Pb}-214$ & $1.18 \mathrm{E}-14$ & $2.44 \mathrm{E}-16$ \\
\hline Bi-214 & $7.65 \mathrm{E}-14$ & $1.41 \mathrm{E}-15$ \\
\hline Po-214 & $4.08 \mathrm{E}-18$ & $8.13 \mathrm{E}-20$ \\
\hline $\mathrm{Pb}-210$ & $5.64 \mathrm{E}-17$ & $2.48 \mathrm{E}-18$ \\
\hline Bi-210 & $3.29 \mathrm{E}-17$ & $1.05 \mathrm{E}-18$ \\
\hline Po-210 & 4.16E-19 & 8.29E-21 \\
\hline U-235 & $7.20 \mathrm{E}-15$ & $1.48 \mathrm{E}-16$ \\
\hline Th-231 & $5.22 \mathrm{E}-16$ & $1.85 \mathrm{E}-17$ \\
\hline $\mathrm{Pa}-231$ & $1.72 \mathrm{E}-15$ & $4.07 \mathrm{E}-17$ \\
\hline Ac-227 & $5.82 \mathrm{E}-18$ & $1.57 \mathrm{E}-19$ \\
\hline Th-227 & $4.88 \mathrm{E}-15$ & $1.04 \mathrm{E}-16$ \\
\hline Fr-223 & $2.29 \mathrm{E}-15$ & $5.65 \mathrm{E}-17$ \\
\hline $\mathrm{Ra}-223$ & $6.09 \mathrm{E}-15$ & $1.28 \mathrm{E}-16$ \\
\hline Rn-219 & $2.68 \mathrm{E}-15$ & $5.49 \mathrm{E}-17$ \\
\hline Po-215 & $8.43 \mathrm{E}-18$ & $1.74 \mathrm{E}-19$ \\
\hline $\mathrm{Pb}-211$ & $2.49 \mathrm{E}-15$ & $5.08 \mathrm{E}-17$ \\
\hline Bi-211 & $2.22 \mathrm{E}-15$ & $4.58 \mathrm{E}-17$ \\
\hline Po-211 & $3.81 \mathrm{E}-16$ & 7.61E-18 \\
\hline Tl-207 & $1.62 \mathrm{E}-16$ & $3.76 \mathrm{E}-18$ \\
\hline
\end{tabular}




\begin{tabular}{|c|c|c|}
\hline Radionuclídeo & Nuvem Sv/s / Bq/m 3 & $\begin{array}{c}\text { Solo Sv/s/ } \\
\text { Bq/m }{ }^{2}\end{array}$ \\
\hline Th-232 & $8.72 \mathrm{E}-18$ & $5.51 \mathrm{E}-19$ \\
\hline Ra-228 & 0 & $0.00 \mathrm{E}+00$ \\
\hline Ac-228 & $4.78 \mathrm{E}-14$ & $9.28 \mathrm{E}-16$ \\
\hline Th-228 & $9.20 \mathrm{E}-17$ & $2.35 \mathrm{E}-18$ \\
\hline Ra-224 & $4.71 \mathrm{E}-16$ & $9.57 \mathrm{E}-18$ \\
\hline Rn-220 & $1.85 \mathrm{E}-17$ & $3.81 \mathrm{E}-19$ \\
\hline Po-216 & $8.29 \mathrm{E}-19$ & $1.65 \mathrm{E}-20$ \\
\hline $\mathrm{Pb}-212$ & $6.87 \mathrm{E}-15$ & $1.43 \mathrm{E}-16$ \\
\hline $\mathrm{Bi}-212$ & $9.24 \mathrm{E}-15$ & $1.79 \mathrm{E}-16$ \\
\hline Po-212 & 0 & $0.00 \mathrm{E}+00$ \\
\hline TL-208 & $1.77 \mathrm{E}-13$ & $2.98 \mathrm{E}-15$ \\
\hline $\mathrm{K}-40$ & $8.05 \mathrm{E}-15$ & $1.46 \mathrm{E}-16$ \\
\hline
\end{tabular}


TABELA 4.11 - Fatores de conversão de dose para radionuclídeos envolvidos na inalação de combustão de carvão

\begin{tabular}{|c|c|c|c|c|c|c|}
\hline \multirow[b]{2}{*}{ Radionuclídeo } & \multicolumn{5}{|c|}{ Inalação DCF (Sv/Bq). } & \multirow[b]{2}{*}{ F1 } \\
\hline & Adults & o 15 anos & 10 anos & 5 anos & 1 ano & \\
\hline $\mathrm{U}-238$ & $8.0 \mathrm{E}-06$ & 8.7E-06 & $1.0 \mathrm{E}-05$ & $1.6 \mathrm{E}-05$ & $2.5 \mathrm{E}-05$ & 0.002 \\
\hline U-234 & $9.4 \mathrm{E}-06$ & $1.0 \mathrm{E}-05$ & $1.2 \mathrm{E}-05$ & $1.9 \mathrm{E}-05$ & 2.9E-05 & 0.002 \\
\hline Th-230 & $1.4 \mathrm{E}-05$ & $1.5 \mathrm{E}-05$ & $1.6 \mathrm{E}-05$ & $2.4 \mathrm{E}-05$ & $3.5 \mathrm{E}-05$ & 0.0005 \\
\hline Ra-226 & $9.5 \mathrm{E}-06$ & $1.0 \mathrm{E}-05$ & $1.2 \mathrm{E}-05$ & $1.9 \mathrm{E}-05$ & 2.9E-05 & 0.01 \\
\hline $\mathrm{Pb}-210$ & $5.6 \mathrm{E}-06$ & 5.9E-06 & 7.2E-06 & $1.1 \mathrm{E}-05$ & $1.8 \mathrm{E}-05$ & 0.01 \\
\hline Po-210 & 4.3E-06 & $5.1 \mathrm{E}-06$ & 5.9E-06 & 8.6E-06 & $1.4 \mathrm{E}-05$ & 0.01 \\
\hline Series DCF por Bq U-238 & $5.08 \mathrm{E}-05$ & $5.47 \mathrm{E}-05$ & $6.31 \mathrm{E}-05$ & $9.76 \mathrm{E}-05$ & $1.50 \mathrm{E}-04$ & \\
\hline U-235 & $8.5 \mathrm{E}-06$ & $9.2 \mathrm{E}-06$ & $1.1 \mathrm{E}-05$ & $1.7 \mathrm{E}-05$ & $2.6 \mathrm{E}-05$ & 0.002 \\
\hline $\mathrm{Pa}-231$ & $3.4 \mathrm{E}-05$ & $3.6 \mathrm{E}-05$ & 3.9E-05 & $5.2 \mathrm{E}-05$ & $6.9 \mathrm{E}-05$ & 0.0005 \\
\hline Ac- 227 & $7.2 \mathrm{E}-05$ & $7.6 \mathrm{E}-05$ & 8.7E-05 & $1.3 \mathrm{E}-04$ & $2.0 \mathrm{E}-04$ & 0.0005 \\
\hline Th-227 & $1.0 \mathrm{E}-05$ & $1.3 \mathrm{E}-05$ & $1.4 \mathrm{E}-05$ & $1.9 \mathrm{E}-05$ & $3.0 \mathrm{E}-05$ & 0.0005 \\
\hline Ra-223 & 8.7E-06 & $1.1 \mathrm{E}-05$ & $1.1 \mathrm{E}-05$ & $1.5 \mathrm{E}-05$ & $2.4 \mathrm{E}-05$ & 0.01 \\
\hline Series DCF por Bq U-235 & $1.33 \mathrm{E}-04$ & $1.45 \mathrm{E}-04$ & 1.62E-04 2 & 2.33E-04 & $3.49 \mathrm{E}-04$ & \\
\hline Th-232 & $2.5 \mathrm{E}-05$ & $2.5 \mathrm{E}-05$ & $2.6 \mathrm{E}-05$ & $3.7 \mathrm{E}-05$ & $5.0 \mathrm{E}-05$ & 0.0005 \\
\hline Ra-228 & $1.6 \mathrm{E}-05$ & $1.6 \mathrm{E}-05$ & $2.0 \mathrm{E}-05$ & $3.2 \mathrm{E}-05$ & $4.8 \mathrm{E}-05$ & 0.01 \\
\hline Th-228 & $4.0 \mathrm{E}-05$ & 4.7E-05 & $5.5 \mathrm{E}-05$ & $8.2 \mathrm{E}-05$ & $1.3 \mathrm{E}-04$ & 0.0005 \\
\hline Ra-224 & $3.4 \mathrm{E}-06$ & $4.2 \mathrm{E}-06$ & 4.4E-06 & 5.9E-06 & $9.2 \mathrm{E}-06$ & 0.01 \\
\hline $\mathrm{Pb}-212$ & $1.9 \mathrm{E}-07$ & $2.4 \mathrm{E}-07$ & $2.5 \mathrm{E}-07$ & $3.3 \mathrm{E}-07$ & $5.0 \mathrm{E}-07$ & 0.01 \\
\hline Series DCF por Bq Th-232 & $8.46 \mathrm{E}-05$ & $9.24 \mathrm{E}-05$ & $1.06 \mathrm{E}-04$ & $1.57 \mathrm{E}-04$ & 2.38E-04 & \\
\hline
\end{tabular}


TABELA 4.12 - Fatores de conversão de risco para radionuclídeos envolvidos na ingestão de combustão de carvão

\begin{tabular}{|c|c|c|c|c|c|c|c|}
\hline \multirow[b]{2}{*}{ Radionuclídeo } & \multirow{2}{*}{\multicolumn{2}{|c|}{$\mathbf{f 1}^{\mathbf{b}}$}} & \multicolumn{5}{|c|}{ Ingestão DCF (Sv/Bq) } \\
\hline & & & Adulto & 15 anos & 10 anos & 5 anos & 1 ano \\
\hline $\mathrm{U}-238$ & & 0.02 & 4.5E-08 & 6.7E-08 & $6.8 \mathrm{E}-08$ & 8.0E-08 & $1.2 \mathrm{E}-07$ \\
\hline Th-234 & & 0.0005 & 3.4E-09 & 4.2E-09 & 7.4E-09 & $1.3 \mathrm{E}-08$ & $2.5 \mathrm{E}-08$ \\
\hline $\mathrm{U}-234$ & & 0.02 & 4.9E-08 & 7.4E-08 & 7.4E-08 & 8.8E-08 & $1.3 \mathrm{E}-07$ \\
\hline Th-230 & & 0.0005 & $2.1 \mathrm{E}-07$ & $2.2 \mathrm{E}-07$ & $2.4 \mathrm{E}-07$ & $3.1 \mathrm{E}-07$ & $4.1 \mathrm{E}-07$ \\
\hline Ra-226 & 0.2 adultos, & 0.3 outros & 2.8E-07 & $1.5 \mathrm{E}-06$ & 8.0E-07 & $6.2 \mathrm{E}-07$ & $9.6 \mathrm{E}-07$ \\
\hline $\mathrm{Pb}-210$ & 0.2 adultos, & 0.4 outros & 6.9E-07 & $1.9 \mathrm{E}-06$ & $1.9 \mathrm{E}-06$ & 2.2E-06 & $3.6 \mathrm{E}-06$ \\
\hline $\mathrm{Bi}-210$ & & 0.05 & $1.3 \mathrm{E}-09$ & $1.6 \mathrm{E}-09$ & 2.9E-09 & 4.8E-09 & 9.7E-09 \\
\hline Po-210 & & 0.5 & $1.2 \mathrm{E}-06$ & $1.6 \mathrm{E}-06$ & $2.6 \mathrm{E}-06$ & 4.4E-06 & 8.8E-06 \\
\hline Séries DCF por & $\mathrm{J}-238$ & & $2.48 \mathrm{E}-06$ & $5.37 \mathrm{E}-06$ & $5.69 \mathrm{E}-06$ & $7.72 \mathrm{E}-06$ & $1.41 \mathrm{E}-05$ \\
\hline
\end{tabular}

$\begin{array}{lrrrrrr}\text { U-235 } & 0.02 & 4.7 \mathrm{E}-08 & 7.0 \mathrm{E}-08 & 7.1 \mathrm{E}-08 & 8.5 \mathrm{E}-08 & 1.3 \mathrm{E}-07 \\ \text { Pa-231 } & 0.0005 & 7.1 \mathrm{E}-07 & 8.0 \mathrm{E}-07 & 9.2 \mathrm{E}-07 & 1.1 \mathrm{E}-06 & 1.3 \mathrm{E}-06 \\ \text { Ac-227 } & 0.0005 & 1.1 \mathrm{E}-06 & 1.2 \mathrm{E}-06 & 1.5 \mathrm{E}-06 & 2.2 \mathrm{E}-06 & 3.1 \mathrm{E}-06 \\ \text { Th-227 } & 0.0005 & 8.8 \mathrm{E}-09 & 1.5 \mathrm{E}-08 & 2.3 \mathrm{E}-08 & 3.6 \mathrm{E}-08 & 7.0 \mathrm{E}-08 \\ \text { Ra-223 } & 0.2 \text { adultos, } 0.3 \text { outros } & 1.0 \mathrm{E}-07 & 3.7 \mathrm{E}-07 & 4.5 \mathrm{E}-07 & 5.7 \mathrm{E}-07 & 1.1 \mathrm{E}-06\end{array}$


Ingestão DCF (Sv/Bq)

\begin{tabular}{lrrrrrrr} 
Radionuclídeo & $\mathbf{f 1}^{\mathbf{b}}$ & Adulto & $\mathbf{1 5}$ anos & $\mathbf{1 0}$ anos & $\mathbf{5}$ anos & $\mathbf{1}$ ano \\
& & & & & & & \\
\hline Th-232 & 0.0005 & $2.3 \mathrm{E}-07$ & $2.5 \mathrm{E}-07$ & $2.9 \mathrm{E}-07$ & $3.5 \mathrm{E}-07$ & $4.5 \mathrm{E}-07$ \\
$\mathrm{Ra}-228$ & 0.2 adultos, 0.3 outros & $6.9 \mathrm{E}-07$ & $5.3 \mathrm{E}-06$ & $3.9 \mathrm{E}-06$ & $3.4 \mathrm{E}-06$ & $5.7 \mathrm{E}-06$ \\
$\mathrm{Th}-228$ & 0.0005 & $7.2 \mathrm{E}-08$ & $9.4 \mathrm{E}-08$ & $1.5 \mathrm{E}-07$ & $2.2 \mathrm{E}-07$ & $3.7 \mathrm{E}-07$ \\
$\mathrm{Ra}-224$ & 0.2 adultos, 0.3 outros & $6.5 \mathrm{E}-08$ & $2.0 \mathrm{E}-07$ & $2.6 \mathrm{E}-07$ & $3.5 \mathrm{E}-07$ & $6.6 \mathrm{E}-07$ \\
$\mathrm{~Pb}-212$ & 0.2 & $6.0 \mathrm{E}-09$ & $1.3 \mathrm{E}-08$ & $2.0 \mathrm{E}-08$ & $3.3 \mathrm{E}-08$ & $6.3 \mathrm{E}-08$
\end{tabular}

Séries DCF por Bq Th-232

1.06E-06 5.86E-06 4.62E-06 4.35E-06 7.24E-06

Na próxima seção, serão demonstrados os dados de entrada utilizados para a realização do cálculo de custo ambiental para hidrelétricas, utilizando o HYDROPACTS bem como os dados de entrada referentes ao módulo NUKPACTS, para centrais nucleares e termoelétricas. 


\section{DESENVOLVIMENTO DO TRABALHO}

O programa SIMPACTS foi recebido pela CNEN por intermédio do Dr. Laércio Vinhas, representante brasileiro junto a AIEA. Inicialmente, o acesso ao programa se restringiu apenas ao módulo executável e às planilhas de entrada de dados. Após contato com a equipe de suporte técnico da AIEA, que forneceu os manuais e esclareceu as dúvidas, foi possível executar o programa utilizando os dados de entrada necessários para o cálculo do custo ambiental.

Neste capítulo serão apresentadas as planilhas de entrada do SIMPACTS para o cálculo do custo ambiental das centrais nucleares Angra 1, 2 e 3 e para o reator de pesquisas IEA-R1. A fim de proporcionar parâmetros de comparação desses custos ambientais com os de outras fontes de energia, também foram considerados os custos de uma hidrelétrica com potência elétrica similar a Angra 2 e, ainda, uma outra instalação nuclear e uma usina movida a carvão, ambas contidas no próprio programa como exemplo. Em todos os cálculos, foram utilizados os módulos correspondentes do SIMPACTS.

Cada uma das fontes de energia é apresentada a seguir.

\section{$5.1 \quad$ Reatores Nucleares}

As planilhas de cálculo de custo ambiental para cada uma das instalações nucleares serão apresentadas separadamente.

\subsubsection{Reator IEA-R1}

Embora o IEA-R1 seja um reator de pesquisas de baixa potência (5MW), ele foi utilizado para se obter uma capacitação do programa SIMPACTS. A instalação nuclear de pesquisa foi inicialmente utilizada devido à disponibilidade de dados e à facilidade de acesso, quando comparados com os reatores de potência.

Os dados de entrada do SIMPACTS para o IEA-R1 estão subdivididos nas seguintes categorias:

- Dispersão e Recepção;

- Emissões e Meteorologia; 
- Consumo de alimentos;

- Efeitos na saúde e Valoração.

Os dados de entrada, com as respectivas categorias, serão descritos a seguir.

\subsubsection{Descrição dos dados de entrada}

\section{Dispersão e Recepção}

A concentração populacional local $(100 \mathrm{~km})$ considerada foi a da cidade de São Paulo, sendo essa de 7387,69 pessoas por $\mathrm{km}^{2}$ (IBGE, 2010). A concentração populacional regional (100 a $1000 \mathrm{Km}$ ) foi a do Estado de São Paulo, sendo essa de 166,25 pessoas por $\mathrm{km}^{2}$ (IBGE, 2010).

Os dados relativos à distribuição urbano-rural do Estado de São Paulo também foram obtidos por meio do IBGE (2010), sendo que mais de $99 \%$ da população do estado é urbana.

A velocidade média anual do vento demonstra um comportamento variável, que influencia muito na estabilidade da atmosfera e no comportamento dos radionuclídeos na atmosfera (CETESB, 2012). A velocidade média anual do vento em São Paulo é de 1,63 m/s (CETESB, 2012).

A altura da liberação efetiva é um dado referente à altura da chaminé. No reator IEA-R1, esse valor corresponde a 15,92 metros.

\section{Emissões e Meteorologia}

Os dados referentes à taxa de liberação de radionuclídeos foram obtidos no Relatório de Análise de Segurança (RAS) do reator IEA/R1, desenvolvido pelo IPEN (IPEN, 1998). Alguns radionuclídeos apresentam uma taxa de emissão igual a zero, em razão de o objeto de estudo ser um reator de pesquisa de baixa potência.

A ocorrência de cada uma das classes de estabilidade de Pasquill foi determinada por meio da medição dos dados da torre meteorológica do IPEN e apresentada em um relatório interno divulgado em 2013 (MOLNARY, 2012).

\section{Consumo de alimentos}

Os valores relativos ao consumo de alguns alimentos no Brasil, em quilogramas por pessoa por ano, foram encontrados em publicações anuais relacionadas 
aos diferentes produtos e se referem ao Brasil, como um todo, não considerando as diferenças entre as regiões. A maior parte dos dados foi obtida nos respectivos Anuários Brasileiros de cada categoria. Segundo os Anuários, o brasileiro ingere $47 \mathrm{~kg}$ de carne bovina por ano (ANUÁRIO BRASILEIRO DA PECUÁRIA, 2011), 14,5 kg de carne suína e $44 \mathrm{~kg}$ de carne de frango (ANUÁRIO BRASILEIRO DE AVES E SUÍNOS, 2011). A carne de ovelha é pouco consumida no país, sendo seu valor de 0,5 kg por ano para cada habitante (ANUÁRIO BRASILEIRO DA PECUÁRIA, 2011).

O valor de consumo dos cereais, como um todo, não foi encontrado na literatura, porém considerou-se o somatório dos cereais mais consumidos no Brasil, sendo estes o arroz, o milho e o trigo (IBGE, 2007). O consumo de milho é de $12 \mathrm{~kg}$ (EMBRAPAa, 2011), o de trigo é de $80 \mathrm{~kg}$ (EMBRAPAb, 2011) e o de arroz é de $43 \mathrm{~kg}$ por pessoa por ano (ANUÁRIO BRASILEIRO DO ARROZ, 2011). Assim, o valor encontrado e utilizado foi de $135 \mathrm{~kg}$ de cereais por habitante por ano.

Em relação aos vegetais verdes e de raiz, não há na literatura brasileira esta divisão, e os dados referentes ao consumo de cada tipo de produto não foram encontrados. Por isso, o valor considerado foi o do consumo das hortaliças como um todo, ou seja, 27,08 $\mathrm{kg}$ por pessoa por ano (ANUÁRIO BRASILEIRO DAS HORTALIÇAS, 2011).

Finalmente, o consumo de leite no Brasil, considerado nos parâmetros de entrada do SIMPACTS, foi de 161 litros por pessoa por ano (EMBRAPA, 2010).

Para fins de estudo, foi considerada a fração comestível de cada alimento como de $100 \%$.

\section{Efeitos na saúde e valoração}

A paridade de poder aquisitivo é um valor fornecido automaticamente pelo próprio programa SIMPACTS, quando o país para o qual a análise será feita é selecionado. Ao selecionar o país, o programa também oferece os valores econômicos unitários por câncer fatal, câncer não fatal e efeitos severos hereditários por ano. Esses valores são referentes ao ano de 2000 e, por esta razão o resultado final do cálculo de custo ambiental é dado em US\$ no ano 2000.

Os valores referentes aos efeitos na saúde representam a porcentagem da população afetada por câncer fatal, câncer não fatal e por efeitos hereditários. Esses valores são de $0,05 \%, 0,01 \%$ e $0,013 \%$, respectivamente (MECCA, 2012).

Esses dados podem ser vistos na TAB. 5.1. 
TABELA 5.1 - Dados de entrada do SIMPACTS para o IEA-R1

\begin{tabular}{|c|c|}
\hline \multicolumn{2}{|l|}{ DISPERSÃO E RECEPÇÃO } \\
\hline $\begin{array}{l}\text { Parâmetros populacionais e de } \\
\text { dispersão }\end{array}$ & $\begin{array}{l}\text { Regional: } 166,25 \text { pessoas por } \mathrm{km}^{2} \\
\text { (Estado de São Paulo) } \\
\text { Local: } 7387,69 \text { pessoas por } \mathrm{km}^{2} \\
\text { (Cidade de São Paulo) }\end{array}$ \\
\hline Distribuição urbano-rural & $\begin{array}{l}\text { 99,1\% (urbana) 0,99\% (rural) São } \\
\text { Paulo }\end{array}$ \\
\hline Velocidade média anual do vento & $1,63 \mathrm{~m} / \mathrm{s}$ \\
\hline Altura da liberação efetiva & 15,92 metros \\
\hline $\begin{array}{l}\text { Taxa de respiração anual média de } \\
\text { adultos }\end{array}$ & $7500 \mathrm{~m}^{3} /$ ano \\
\hline \multicolumn{2}{|l|}{ EMISSÕES E METEREOLOGIA } \\
\hline $\begin{array}{l}\text { Taxa de liberação de radionuclídeos } \\
\text { H-3 } \\
\text { C-14 } \\
\text { Co-58 } \\
\text { Co-60 } \\
\text { Kr-85 } \\
\text { I-131 } \\
\text { I-133 } \\
\text { Xe-133 } \\
\text { Cs-134 } \\
\text { Cs-137 }\end{array}$ & $\begin{array}{l}\mathrm{Bq} / \mathrm{s} \\
0 \\
0 \\
0 \\
0 \\
0 \\
2,03 \mathrm{E}-08 \\
3,35 \mathrm{E}-07 \\
4,18 \mathrm{E}-03 \\
0 \\
0\end{array}$ \\
\hline $\begin{array}{l}\text { Ocorrência de estabilidade das classes } \\
\text { de estabilidade de Pasquill (A, B, C, D, } \\
\text { E, F) }\end{array}$ & $\begin{array}{l}\text { A } 16,1 \% \\
\text { B } 2,2 \% \\
\text { C } 7,1 \% \\
\text { D } 35 \% \\
\text { E } 29,8 \% \\
\text { F } 9,8 \%\end{array}$ \\
\hline
\end{tabular}

CONSUMO DE ALIMENTOS

Taxa de consumo médio pra cada um dos seguintes alimentos: carne vermelha, porco, frango, ovelha, cereais, verduras, tubérculos, leite fresco e outros tipos de leite

Kg/hab/ano

Carne vermelha $=$ bovinos: 46,7

Porco: 14,5

Frango: 44

Ovelha: 0,5

Cereais: 135

Arroz: 43

Milho: 12

Trigo: 80

Hortaliças: 27,08

Leite: $161 \mathrm{~L}$

Fração comestível para cada um dos $100,00 \%$ alimentos acima. 


\begin{tabular}{l|l}
\hline \multicolumn{2}{l}{ EFEITOS NA SAÚDE E VALORAÇÃO } \\
\hline Fatores de risco para efeitos na saúde & Casos por Sv pessoa \\
\hline $\begin{array}{l}\text { Efeitos - câncer fatal, câncer não fatal, } \\
\text { graves efeitos hereditários }\end{array}$ & $\begin{array}{l}\text { Câncer fatal: 0,05\% } \\
\text { Câncer não fatal: 0,01\% } \\
\text { Efeito hereditário: 0,013\% }\end{array}$ \\
\hline $\begin{array}{l}\text { Valores econômicos unitários por } \\
\text { câncer fatal }\end{array}$ & $\begin{array}{l}\text { Câncer fatal: VOSL 3,30E+0,5; VLYL } \\
2,48 E+0,5\end{array}$ \\
& Câncer não fatal: 1,10E+0,5 \\
& Efeitos severos hereditários: 3,30E+0,5 \\
\hline Paridade de poder aquisitivo & 7330 Dólares \\
\hline
\end{tabular}

\subsubsection{Angra 1, 2 e 3}

Assim como no reator de pesquisa IEA-R1, o custo ambiental das usinas nucleares de Angra 1, 2 e 3 também foi calculado. A capacitação inicial do programa SIMPACTS facilitou o desenvolvimento do cálculo para as instalações de potência, como as mencionadas acima.

\subsubsection{Angra 2 e 3}

Os reatores de Angra 2 e 3 são similares no que diz respeito à potência (1350 e 1405 MW, respectivamente). Dessa forma, para fins de estudo, os dados relativos à Angra 2 serão os mesmos relativos à Angra 3 e, por isso serão, a seguir, apresentados de forma conjunta.

\subsubsection{Descrição dos dados de entrada}

\section{Dispersão e Recepção}

Os valores das densidades demográficas local e regional de Angra 2 são de 246,02 e 365,23 pessoas por $\mathrm{km}^{2}$, respectivamente (IBGE, 2010). Foi utilizado o valor de densidade demográfica local da cidade de Angra dos Reis, juntamente com a cidade de Parati $(100 \mathrm{~km})$. O valor de densidade demográfica regional está associado ao Estado do Rio de Janeiro. O Relatório Final de Análise de Segurança (FSAR - Final Safety Analysis Report) da usina de Angra 2 fornece dados da densidade demográfica da população residente em um raio de $50 \mathrm{~km}$ da usina, sendo essa densidade de 30 pessoas por $\mathrm{km}^{2}$ (ELETRONUCLEAR, 2006). 
Os dados relativos à distribuição urbano-rural do Estado do Rio de Janeiro também foram obtidos por meio do IBGE (2010), sendo que quase $97 \%$ da população do estado é urbana.

A velocidade média anual do vento encontrada para o estado do Rio de Janeiro foi de $7,5 \mathrm{~m} / \mathrm{s}$ (CEPEL, 2001).

\section{Emissões e Meteorologia}

Os dados referentes à taxa de liberação de radionuclídeos foram obtidos no FSAR da Usina Nuclear de Angra 2 (ELETRONUCLEAR, 2006). Para este reator, apenas um radionuclídeo apresenta taxa de emissão zero, sendo este o C14. O mesmo só é liberado em caso de acidente, por isso não entra na análise do programa.

A ocorrência das classes de estabilidade foi obtida também no FSAR de Angra 1. Porém, nele são apresentadas as taxas de estabilidade incluindo a classe $G$, que não é especificada no programa. Sendo assim, para totalizar 100\%, atribui-se à classe F o valor de $16,4 \%$ (1,15\% a mais - valor da parcela da classe de estabilidade G).

\section{Consumo de alimentos e Efeitos na saúde e valoração}

Nos itens referentes ao consumo de alimentos, os dados utilizados foram os mesmos do reator de pesquisa IEA/R1, uma vez que os mesmos são referentes ao país como um todo.

O mesmo ocorre com os dados referentes aos efeitos na saúde e valoração. $\mathrm{O}$ Programa considera dados referentes ao Brasil, por isso os dados encontrados anteriormente foram repetidos.

Esses dados estão resumidos na TAB. 5.2. 
TABELA 5.2 - Dados de entrada do SIMPACTS para Angra 2 e Angra 3

\begin{tabular}{|c|c|}
\hline \multicolumn{2}{|l|}{ DISPERSÃO E RECEPÇÃO } \\
\hline $\begin{array}{l}\text { Parâmetros populacionais e de } \\
\text { dispersão }\end{array}$ & $\begin{array}{l}\text { Regional: } 365,23 \text { pessoas por } \mathrm{km}^{2} \\
\text { (Estado do Rio de Janeiro) } \\
\text { Local: } 246,02 \text { pessoas por } \mathrm{km}^{2} \text { (Angra } \\
\text { dos Reis e Parati) }\end{array}$ \\
\hline Distribuição urbano-rural & $96,71 \%$ (urbana) 3,29\% (rural) \\
\hline Velocidade média anual do vento & $7,5 \mathrm{~m} / \mathrm{s}$ \\
\hline Altura da liberação efetiva & 150 metros \\
\hline $\begin{array}{l}\text { Taxa de respiração anual média de } \\
\text { adultos }\end{array}$ & $7500 \mathrm{~m}^{3} / \mathrm{ano}$ \\
\hline \multicolumn{2}{|l|}{ EMISSÕES E METEOROLOGIA } \\
\hline $\begin{array}{l}\text { Taxa de liberação de radionuclídeos } \\
\text { H-3 } \\
\text { C-14 } \\
\text { Co-58 } \\
\text { Co-60 } \\
\text { Kr-85 } \\
\text { I-131 } \\
\text { I-133 } \\
\text { Xe-133 } \\
\text { Cs-134 } \\
\text { Cs-137 }\end{array}$ & $\begin{array}{l}\mathrm{Bq} / \mathrm{s} \\
8,1 \mathrm{E}+05 \\
0 \\
0,66 \\
0,19 \\
2,55 \\
2,81 \mathrm{E}+02 \\
1,4 \mathrm{E}+03 \\
1,7 \mathrm{E}+03 \\
5,85 \\
1,7 \mathrm{E}+01\end{array}$ \\
\hline $\begin{array}{l}\text { Ocorrência de estabilidade das classes } \\
\text { de estabilidade de Pasquill (A, B, C, D, } \\
\text { E, F) }\end{array}$ & $\begin{array}{l}\text { A 10,60\% } \\
\text { B 7,48\% } \\
\text { C 7,20\% } \\
\text { D 24,16\% } \\
\text { E 34,16\% } \\
\text { F 15,24\% } \\
\text { G 1,15\% }\end{array}$ \\
\hline
\end{tabular}




\section{CONSUMO DE ALIMENTOS}

Taxa de consumo médio pra cada um dos seguintes alimentos: carne vermelha, porco, frango, ovelha, cereais, verduras, tubérculos, leite freso e outros tipos de leite

$\mathrm{Kg} / \mathrm{hab} / \mathrm{ano}$

Carne vermelha $=$ bovinos: 46,7

Porco: 14,5

Frango: 44

Ovelha: 0,5

Cereais: 135

Arroz: 43

Milho: 12

Trigo: 80

Hortaliças: 27,08

Leite: $161 \mathrm{~L}$

Fração comestível para cada um dos alimentos acima.

$100,00 \%$

EFEITOS NA SAÚDE E VALORAÇÃO

Fatores de risco para efeitos na saúde

Efeitos - câncer fatal, câncer não fatal, graves efeitos hereditários

Casos por $\mathrm{Sv}$ pessoa

Câncer fatal: $5(0,05 \%)$

Câncer não fatal: $1(0,01 \%)$

Efeito hereditário: 1,3 (0,013\%)

INCA (2012)

Valores econômicos unitários por

câncer fatal

Câncer fatal: VOSL 3,30E+0,5; VLYL

$2,48 \mathrm{E}+0,5$

Câncer não fatal: $1,10 \mathrm{E}+0,5$

Efeitos severos hereditários: 3,30E+0,5

Paridade de poder aquisitivo

7330 Dólares

\subsubsection{Angra 1}

O reator nuclear de Angra 1 tem potência menor, por isso apresenta uma variação em relação aos dados de Emissões e Meteorologia, sendo esses apresentados a seguir, juntamente com os outros dados de entrada.

\subsubsection{Descrição dos dados de entrada}

Os dados de entrada relativos à Dispersão e Recepção, Consumo de alimentos e Efeitos na saúde e Valoração são semelhantes à Angra 2 e 3. O que difere em Angra 1 são os dados relativos à Emissões e Meteorologia. 
Os dados referentes à altura da chaminé e taxa de liberação de radionuclídeos foram obtidos no Relatório de Análise de Segurança da Usina Nuclear Angra 1, desenvolvido pela Eletronuclear (ELETRONUCLEAR, 2005).

Os dados serão apresentados na TAB. 5.3.

TABELA 5.3 - Dados de entrada do SIMPACTS para Angra 1

\begin{tabular}{|c|c|}
\hline \multicolumn{2}{|l|}{ DISPERSÃO E RECEPÇÃO } \\
\hline $\begin{array}{l}\text { Parâmetros populacionais e de } \\
\text { dispersão }\end{array}$ & $\begin{array}{l}\text { Regional: } 365,23 \text { pessoas por } \mathrm{km}^{2} \\
\text { (Estado do Rio de Janeiro) } \\
\text { Local: } 246,02 \text { pessoas por } \mathrm{km}^{2} \text { (Angra } \\
\text { dos Reis e Parati) }\end{array}$ \\
\hline Distribuição urbano-rural & $96,71 \%$ (urbana) 3,29\% (rural) \\
\hline Velocidade média anual do vento & $7,5 \mathrm{~m} / \mathrm{s}$ \\
\hline Altura da liberação efetiva & 44,68 metros \\
\hline $\begin{array}{l}\text { Taxa de respiração anual média de } \\
\text { adultos }\end{array}$ & $7500 \mathrm{~m}^{3} /$ ano \\
\hline \multicolumn{2}{|l|}{ EMISSÕES E METEOROLOGIA } \\
\hline $\begin{array}{l}\text { Taxa de liberação de radionuclídeos } \\
\text { H-3 } \\
\text { C-14 } \\
\text { Co-58 } \\
\text { Co-60 } \\
\text { Kr-85 } \\
\text { I-131 } \\
\text { I-133 } \\
\text { Xe-133 } \\
\text { Cs-134 } \\
\text { Cs-137 }\end{array}$ & $\begin{array}{l}7,65 \mathrm{E}+04 \\
1,41 \\
1,03 \\
1,09 \mathrm{E}+05\end{array}$ \\
\hline $\begin{array}{l}\text { Ocorrência de estabilidade das classes } \\
\text { de estabilidade de Pasquill (A, B, C, D, } \\
\text { E, F) }\end{array}$ & $\begin{array}{l}\text { A } 10,60 \% \\
\text { B } 7,48 \% \\
\text { C } 7,20 \% \\
\text { D 24,16\% } \\
\text { E 34,16\% } \\
\text { F } 15,24 \% \\
\text { G } 1,15 \%\end{array}$ \\
\hline
\end{tabular}




\section{CONSUMO DE ALIMENTOS}

Taxa de consumo médio para cada um dos seguintes alimentos: carne vermelha, porco, frango, ovelha, cereais, verduras, tubérculos, leite freso e outros tipos de leite

$\mathrm{Kg} / \mathrm{hab} / \mathrm{ano}$

Carne vermelha $=$ bovinos: 46,7

Porco: 14,5

Frango: 44

Ovelha: 0,5

Cereais: 135

Arroz: 43

Milho: 12

Trigo: 80

Hortaliças: 27,08

Leite: $161 \mathrm{~L}$

Fração comestível para cada um dos $100,00 \%$ alimentos acima.

\begin{tabular}{l|l}
\hline \multicolumn{2}{l}{ EFEITOS NA SAÚDE E VALORAÇÃO } \\
\hline Fatores de risco para efeitos na saúde & Casos por Sv pessoa \\
\hline $\begin{array}{l}\text { Efeitos - câncer fatal, câncer não fatal, } \\
\text { graves efeitos hereditários }\end{array}$ & $\begin{array}{l}\text { Câncer fatal: } 5(0,05 \%) \\
\text { Câncer não fatal: } 1(0,01 \%) \\
\text { Efeito hereditário: } 1,3(0,013 \%) \\
\text { INCA (2012) }\end{array}$ \\
\hline Valores econômicos unitários por & Câncer fatal: VOSL 3,30E+0,5; VLYL \\
câncer fatal & 2,48E+0,5 \\
& Câncer não fatal: $1,10 \mathrm{E}+0,5$ \\
\hline Paridade de poder aquisitivo & Efeitos severos hereditários: 3,30E+0,5 \\
\hline
\end{tabular}

\subsubsection{Reator de Balakovo}

Os dados de entrada do SIMPACTS para o reator de Balakovo encontram-se no próprio Programa e serão apresentados na TAB 5.4.

TABELA 5.4 - Dados de entrada do SIMPACTS para Balakovo DISPERSÃO E RECEPÇÃO

\begin{tabular}{l|l}
\hline $\begin{array}{l}\text { Parâmetros populacionais e de } \\
\text { dispersão }\end{array}$ & $\begin{array}{l}\text { Densidade Populacional Regional: 35,2 } \\
\text { pessoas por } \mathrm{km}^{2} \\
\text { Local: } 82,3 \text { pessoas por } \mathrm{km}^{2}\end{array}$ \\
\hline Distribuição urbano-rural & $70 \%$ (urbana) $30 \%$ (rural) \\
\hline Velocidade média anual do vento & $3,1 \mathrm{~m} / \mathrm{s}$ \\
\hline Altura da liberação efetiva & $36 \mathrm{metros}$ \\
\hline $\begin{array}{l}\text { Taxa de respiração anual média de } \\
\text { adultos }\end{array}$ & $7500 \mathrm{~m}^{3} / \mathrm{ano}$ \\
\hline
\end{tabular}




\begin{tabular}{|c|c|c|}
\hline \multicolumn{3}{|l|}{ EMISSÕES E METEOROLOGIA } \\
\hline $\begin{array}{l}\text { Taxa de liberação de radionuclídeos } \\
\text { H-3 } \\
\text { C-14 } \\
\text { Co-58 } \\
\text { Co-60 } \\
\text { Kr-85 } \\
\text { I-131 } \\
\text { I-133 } \\
\text { Xe-133 } \\
\text { Cs-134 } \\
\text { Cs-137 }\end{array}$ & \multicolumn{2}{|l|}{$\begin{array}{l}\mathrm{Bq} / \mathrm{s} \\
1,11 \mathrm{E}+05 \\
9,54 \mathrm{E}+03 \\
3,57 \mathrm{E}-01 \\
3,57 \mathrm{E}-01 \\
2,17 \mathrm{E}+06 \\
9,69 \mathrm{E}+01 \\
4,85 \mathrm{E}+00 \\
2,61 \mathrm{E}+07 \\
3,57 \mathrm{E}-01 \\
3,57 \mathrm{E}-01\end{array}$} \\
\hline $\begin{array}{l}\text { Ocorrência de estabilidade das classes } \\
\text { de estabilidade de Pasquill (A, B, C, D, } \\
\text { E, F) }\end{array}$ & \multicolumn{2}{|l|}{$\begin{array}{l}\text { A } 2 \% \\
\text { B } 6 \% \\
\text { C } 10 \% \\
\text { D } 19 \% \\
\text { E 27\% } \\
\text { F 36\% }\end{array}$} \\
\hline \multicolumn{3}{|l|}{ CONSUMO DE ALIMENTOS } \\
\hline Taxa de consumo médio & $\begin{array}{l}\text { Kg/hab/ano } \\
\text { Bovinos: } 18 \\
\text { Porco: } 20 \\
\text { Frango: } 08 \\
\text { Ovelha: } 07 \\
\text { Cereais: } 67 \\
\text { Hortaliças: } 40 \\
\text { Tubérculos:50 } \\
\text { Leite fresco: } 150 \\
\text { Outros tipos: } 13\end{array}$ & $\begin{array}{l}\text { Fração comestível (\%) } \\
80 \\
70 \\
55 \\
80 \\
100 \\
70 \\
70 \\
100 \\
100\end{array}$ \\
\hline \multicolumn{3}{|l|}{ EFEITOS NA SAÚDE E VALORAÇÃO } \\
\hline Fatores de risco para efeitos na saúde & \multicolumn{2}{|c|}{ Casos por Sv pessoa } \\
\hline $\begin{array}{l}\text { Efeitos - câncer fatal, câncer não fatal, } \\
\text { graves efeitos hereditários }\end{array}$ & \multicolumn{2}{|c|}{$\begin{array}{l}\text { Câncer fatal: } 0,05 \% \\
\text { Câncer não fatal: } 0,12 \% \\
\text { Efeito hereditário: } 0,01 \%\end{array}$} \\
\hline $\begin{array}{l}\text { Valores econômicos unitários por } \\
\text { câncer fatal } \\
\text { (Rússia) }\end{array}$ & \multicolumn{2}{|c|}{$\begin{array}{l}\text { Câncer fatal: VOSL 3,63E+05; VLYL } \\
\text { 2,72E+05 } \\
\text { Câncer não fatal: 1,21E+05 } \\
\text { Efeitos severos hereditários: 3,63E+05 }\end{array}$} \\
\hline Paridade de poder aquisitivo & \multicolumn{2}{|c|}{8110 dólares } \\
\hline
\end{tabular}




\subsubsection{Usinas a carvão na França}

Dados de usinas a carvão na França, fornecidos pelo próprio Programa SIMPACTS, foram utilizados a fim de comparar os resultados de uma fonte fóssil com as outras fontes.

É possível observar que a abordagem de cálculo do programa em relação às usinas a carvão considera a emissão de radionuclídeos, em partes por milhão e porcentagem liberada. A emissão de gases do efeito estufa, como $\mathrm{CH}_{4} \mathrm{e} \mathrm{CO}_{2}$ não é incluída nos dados de entrada. Esses dados de entrada serão apresentados na TAB. 5.5.

TABELA 5.5 - Dados de entrada do SIMPACTS para termelétrica

\begin{tabular}{|c|c|c|}
\hline \multicolumn{3}{|l|}{ DISPERSÃO E RECEPÇÃO } \\
\hline Parâmetros populacionais e de dispersão & \multicolumn{2}{|c|}{$\begin{array}{l}\text { Regional: } 80 \text { pessoas por } \mathrm{km}^{2} \text {; } \\
\text { Local: } 74,8 \text { pessoas por } \mathrm{km}^{2}\end{array}$} \\
\hline Distribuição urbano-rural & \multicolumn{2}{|c|}{$20 \%$ (urbana) $80 \%$ (rural) } \\
\hline Velocidade média anual do vento & \multicolumn{2}{|l|}{$5 \mathrm{~m} / \mathrm{s}$} \\
\hline Altura da liberação efetiva & \multicolumn{2}{|l|}{150 metros } \\
\hline Taxa de respiração anual média de adultos & \multicolumn{2}{|l|}{$7500 \mathrm{~m}^{3} /$ ano } \\
\hline \multicolumn{3}{|l|}{ EMISSÕES E METEOROLOGIA } \\
\hline \multirow[t]{2}{*}{ Consumo anual de combustíveis fósseis } & \multicolumn{2}{|c|}{$\begin{array}{l}\text { 7,8 milhões de toneladas equivalentes de } \\
\text { petróleo }\end{array}$} \\
\hline & Partes por Milhão & $\%$ liberada \\
\hline $\mathrm{U}-238$ & $2,00 \mathrm{E}+00$ & $5,00 \mathrm{E}-01$ \\
\hline Th-234 & $2,00 \mathrm{E}+00$ & $5,00 \mathrm{E}-01$ \\
\hline Ra-226 & $5,00 \mathrm{E}-01$ & $5,00 \mathrm{E}-01$ \\
\hline C-14 & $1,00 \mathrm{E}-03$ & $9,90 \mathrm{E}+01$ \\
\hline $\begin{array}{l}\text { Ocorrência de estabilidade das classes de } \\
\text { estabilidade de Pasquill (A, B, C, D, E, F) }\end{array}$ & \multicolumn{2}{|l|}{$\begin{array}{l}\text { A } 1 \% \\
\text { B 5\% } \\
\text { C } 15 \% \\
\text { D } 65 \% \\
\text { E } 6 \% \\
\text { F } 8 \%\end{array}$} \\
\hline
\end{tabular}




\begin{tabular}{|c|c|c|}
\hline \multicolumn{3}{|l|}{ CONSUMO DE ALIMENTOS } \\
\hline Taxa de consumo médio & $\begin{array}{l}\text { Kg/hab/ano } \\
\text { Carne vermelha = } \\
\text { bovinos: } 18 \\
\text { Porco: } 20 \\
\text { Frango: } 08 \\
\text { Ovelha: } 07 \\
\text { Cereais: } 67 \\
\text { Hortaliças: } 40 \\
\text { Tubérculos: } 50 \\
\text { Leite: } 13 \text { L } \\
\text { Leite fresco } 150 \mathrm{~L}\end{array}$ & $\begin{array}{c}\text { Fração comestível (\%) } \\
\text { 80 } \\
75 \\
70 \\
75 \\
100 \\
70 \\
70 \\
100 \\
100\end{array}$ \\
\hline \multicolumn{3}{|l|}{ EFEITOS NA SAÚDE E VALORAÇÃO } \\
\hline Fatores de risco para efeitos na saúde & \multicolumn{2}{|l|}{ Casos por Sv pessoa } \\
\hline $\begin{array}{l}\text { Efeitos - câncer fatal, câncer não fatal, graves } \\
\text { efeitos hereditários }\end{array}$ & \multicolumn{2}{|l|}{$\begin{array}{l}\text { Câncer fatal: } 0,05 \\
\text { Câncer não fatal: } 0,12 \\
\text { Efeito hereditário: } 0,01\end{array}$} \\
\hline $\begin{array}{l}\text { Valores econômicos unitários por câncer fatal } \\
\text { (França) }\end{array}$ & \multicolumn{2}{|c|}{$\begin{array}{l}\text { Câncer fatal: VOSL 1,11E+06; VLYL } \\
8,29 \mathrm{E}+0,5 \\
\text { Câncer não fatal: 3,68E+0,5 } \\
\text { Efeitos severos hereditários: 1,11E+0,5 }\end{array}$} \\
\hline Paridade de poder aquisitivo & \multicolumn{2}{|c|}{24420 US\$ } \\
\hline
\end{tabular}

\subsubsection{Hidrelétrica Serra da Mesa}

Para comparar com outras fontes de energia, foi calculado o custo ambiental da hidrelétrica Serra da Mesa, localizada no estado de Goiás, com potência semelhante às usinas de Angra 2 e 3.

Os dados de entrada do SIMPACTS para hidrelétricas estão subdivididos nas seguintes categorias:

- $\quad$ Características da barragem;

- $\quad$ Características do local;

- Características da população e uso da terra;

- $\quad$ Perda de produção: produtos agrícolas e pecuários;

- $\quad$ Características de emissão;

- $\quad$ Características de custo. 
Os dados referentes a essa hidrelétrica vieram com o próprio programa, possibilitando o acesso a importantes informações que dificilmente seriam encontradas na literatura. Os dados serão apresentados na TAB. 5.6.

TABELA 5.6 - Dados de entrada do SIMPACTS para hidrelétricas

\begin{tabular}{|c|c|c|}
\hline \multicolumn{3}{|l|}{ CARACTERÍSTICAS DA BARRAGEM } \\
\hline Nome da Unidade & \multicolumn{2}{|c|}{ Serra da Mesa } \\
\hline Localização/Descrição & \multicolumn{2}{|c|}{$\begin{array}{l}\text { Localizada em Goiás, no Brasil. } \\
\text { Latitude }-13.833749 \text { e Longitude }-48.302809\end{array}$} \\
\hline Altura da barragem $\left(\mathrm{H}_{\mathrm{D}}\right)$ & \multicolumn{2}{|l|}{$150 \mathrm{~m}$} \\
\hline Queda líquida nominal & \multicolumn{2}{|l|}{$125,8 \mathrm{~m}$} \\
\hline Correção de queda adicional $\left(\Delta_{\mathrm{H}}\right)$ & \multicolumn{2}{|l|}{$-24,2 \mathrm{~m}$} \\
\hline Capacidade da planta $(\mathrm{P})$ & \multicolumn{2}{|l|}{$1.275 \mathrm{MW}$} \\
\hline Fator de capacidade media da planta (CF) & \multicolumn{2}{|l|}{$58 \%$} \\
\hline Fluxo de turbina $\left(\mathrm{Q}_{\mathrm{W}}\right)$ todas as turbinas & \multicolumn{2}{|l|}{$668,0 \mathrm{~m}^{3} / \mathrm{s}$} \\
\hline \multicolumn{3}{|l|}{ CARACTERÍSTICAS DO LOCAL } \\
\hline Características & Valor unitário & Comentários \\
\hline Região ID & 1 ou 2 & $\begin{array}{l}1 \text { para tropical e } 2 \\
\text { para boreal }\end{array}$ \\
\hline Índice de Terreno & 4 & $\begin{array}{l}4 \text { é o valor atribuído } \\
\text { pelo programa para a } \\
\text { região do Brasil, } \\
\text { sendo esse valor de } \\
5.65 \mathrm{E}-05\end{array}$ \\
\hline Tipo de terreno & 1 & $\begin{array}{l}\text { Valor atribuído pelo } \\
\text { programa para } \\
\text { cânions, desfiladeiros } \\
\text { e montanhas } \\
\text { íngremes. }\end{array}$ \\
\hline \multicolumn{3}{|l|}{ Inclinação média do terreno } \\
\hline \multicolumn{3}{|l|}{ Inclinação média do rio } \\
\hline Reservatório de área inundada & & $\begin{array}{l}\text { Se o valor não for } \\
\text { conhecido, o modelo } \\
\text { estimará }\end{array}$ \\
\hline Taxa de falha média & $1,00 \mathrm{E}-04$ & \\
\hline Tempo médio de aviso de acidente & 1,5 horas & \\
\hline
\end{tabular}




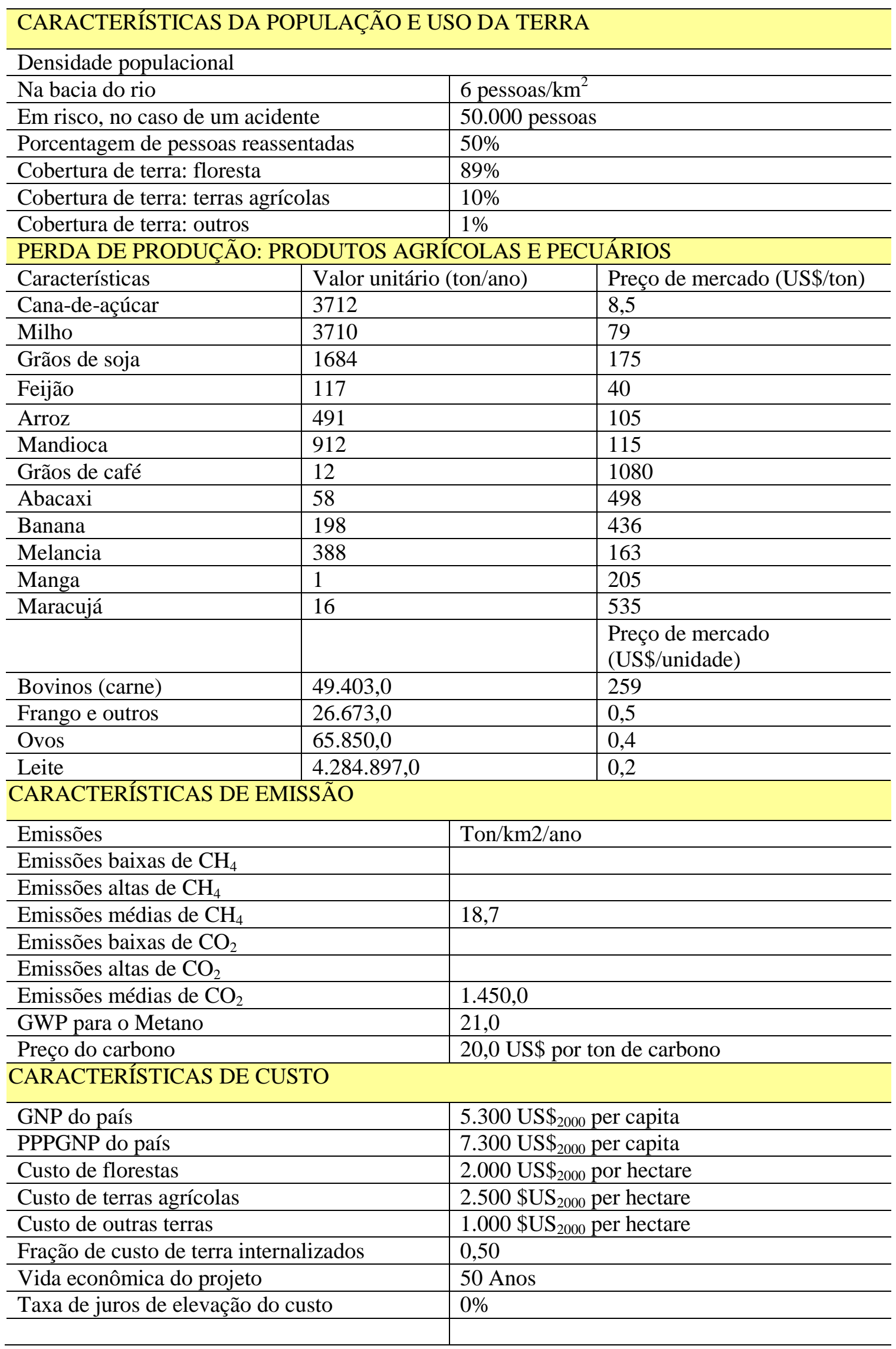


Para mensurar como cada variável de entrada influencia o resultado final, foi feito um Teste de Sensibilidade para os módulos do Programa SIMPACTS utilizados nesse trabalho. O Teste está demonstrado no ANEXO B. 


\section{ANÁLISE DOS RESULTADOS}

\subsection{NUKPACTS}

A partir do módulo NUKPACTS, foi realizado o cálculo de custo ambiental do reator de pesquisas IEA-R1, das usinas nucleares de Angra 1, 2 e 3 e do reator de Balakovo. Os custos ambientais e outros resultados parciais obtidos por meio do programa serão demonstrados e discutidos a seguir.

\subsubsection{IEA-R1}

Um dos resultados parciais apresentados pelo módulo NUKPACTS foi obtido a partir dos dados de entrada e dos cálculos associados, sendo relativos aos impactos locais e regionais de emissões atmosféricas. O cálculo do custo ambiental foi realizado a partir dos seguintes resultados parciais: ingestão de produtos agrícolas, inalação, exposição externa pela nuvem e irradiação externa pela atividade de deposição.

Todos os resultados obtidos com o SIMPACTS para o reator de pesquisas IEAR1 estão resumidos na TAB. 6.1 . 
TABELA 6.1 - Impactos de emissões atmosféricas do IEA-R1

\begin{tabular}{|c|c|c|}
\hline $\begin{array}{l}\text { Impactos locais de } \\
\text { emissões } \\
\text { atmosféricas }\end{array}$ & & $\begin{array}{l}\text { Sv homem } \\
\text { ano }\end{array}$ \\
\hline Inalação & & $1,34 \mathrm{E}-12$ \\
\hline Exposição externa pela nuvem & & $9,51 \mathrm{E}-11$ \\
\hline \multirow[t]{4}{*}{$\begin{array}{l}\text { Irradiação externa pela } \\
\text { atividade de deposição }\end{array}$} & & $4,00 \mathrm{E}-13$ \\
\hline & Carne de vaca & $1,72 \mathrm{E}-13$ \\
\hline & Carne de porco & $5,35 \mathrm{E}-14$ \\
\hline & Carne de frango & $1,62 \mathrm{E}-13$ \\
\hline \multirow[t]{5}{*}{$\begin{array}{l}\text { Ingestão de produtos } \\
\text { agropecuários }\end{array}$} & Carne de ovelha & $2,37 \mathrm{E}-15$ \\
\hline & Cereais & $0,00 \mathrm{E}+00$ \\
\hline & Vegetais verdes & $1,11 \mathrm{E}-13$ \\
\hline & Leite & $1,05 \mathrm{E}-12$ \\
\hline & Subtotal & $1,55 \mathrm{E}-12$ \\
\hline \multicolumn{3}{|l|}{ Ingestão: casos especiais } \\
\hline $\mathrm{H}-3$ & & 0 \\
\hline \multirow[t]{2}{*}{$\mathrm{C}-14$} & & 0 \\
\hline & Total & 9,84E-11 \\
\hline $\begin{array}{l}\text { Impactos regionais de } \\
\text { emissões atmosféricas }\end{array}$ & & $\begin{array}{l}\text { Sv homem } \\
\text { ano }\end{array}$ \\
\hline Inalação & & $3,47 \mathrm{E}-13$ \\
\hline Exposição externa pela nuvem & & $5,52 \mathrm{E}-12$ \\
\hline \multirow[t]{4}{*}{$\begin{array}{l}\text { Irradiação externa pela } \\
\text { atividade de deposição }\end{array}$} & & $1,04 \mathrm{E}-13$ \\
\hline & Carne de vaca & $4,30 \mathrm{E}-14$ \\
\hline & Carne de porco & $1,34 \mathrm{E}-14$ \\
\hline & Carne de frango & $4,05 \mathrm{E}-14$ \\
\hline \multirow[t]{5}{*}{$\begin{array}{l}\text { Ingestão de produtos } \\
\text { agropecuários }\end{array}$} & Carne de ovelha & $5,93 \mathrm{E}-16$ \\
\hline & Cereais & $0,00 \mathrm{E}+00$ \\
\hline & Hortaliças & $2,77 \mathrm{E}-14$ \\
\hline & Leite & $2,62 \mathrm{E}-13$ \\
\hline & Subtotal & $3,87 \mathrm{E}-13$ \\
\hline \multicolumn{3}{|l|}{ Ingestão: casos especiais } \\
\hline $\mathrm{H}-3$ & & 0 \\
\hline \multirow[t]{2}{*}{$\mathrm{C}-14$} & & 0 \\
\hline & Total & 6,35E-12 \\
\hline
\end{tabular}




\begin{tabular}{l|l|l}
\hline $\begin{array}{l}\text { Impactos locais e regionais } \\
\text { de emissões atmosféricas }\end{array}$ & & $\begin{array}{l}\text { Sv homem } \\
\text { ano }\end{array}$ \\
\hline Inalação & & $1,68 \mathrm{E}-12$ \\
\hline Exposição externa pela nuvem & & $1,01 \mathrm{E}-10$ \\
\hline $\begin{array}{l}\text { Irradiação externa pela } \\
\text { atividade de deposição }\end{array}$ & & $5,03 \mathrm{E}-13$ \\
\hline & Carne de vaca & $2,15 \mathrm{E}-13$ \\
\hline & Carne de porco & $6,69 \mathrm{E}-14$ \\
\hline & Carne de frango & $2,03 \mathrm{E}-13$ \\
\hline Ingestão de produtos & Carne de ovelha & \\
\hline & & $2,97 \mathrm{E}-15$ \\
\hline & Cereais & $0,00 \mathrm{E}+00$ \\
\hline & Hortaliças & $1,38 \mathrm{E}-13$ \\
\hline Ingestão: casos especiais & Leite & $1,31 \mathrm{E}-12$ \\
\hline H-3 & Subtotal & $1,94 \mathrm{E}-12$ \\
\hline C-14 & & \\
\hline & & 0 \\
\hline & & 0 \\
\hline & Total & $\mathbf{1 , 0 5 E}-10$ \\
\hline
\end{tabular}

Os valores obtidos com o NUKPACTS para os casos de câncer fatal, câncer não fatal e efeitos severos hereditários estão listados na TAB. 6.2.

TABELA 6.2 - Efeitos na saúde da população

\begin{tabular}{l|c|c|c}
\hline $\begin{array}{l}\text { Efeitos na saúde da } \\
\text { população }\end{array}$ & $\begin{array}{c}\text { Local } \\
\text { (casos/ano) }\end{array}$ & $\begin{array}{c}\text { Regional } \\
\text { (casos/ano) }\end{array}$ & $\begin{array}{c}\text { Total } \\
\text { (casos/ano) }\end{array}$ \\
\hline Câncer fatal & $4,92 \mathrm{E}-12$ & $3,18 \mathrm{E}-13$ & $\mathbf{5 , 2 4 E - 1 2}$ \\
\hline Câncer não fatal & $9,84 \mathrm{E}-13$ & $6,35 \mathrm{E}-14$ & $\mathbf{1 , 0 5 E - 1 2}$ \\
\hline $\begin{array}{l}\text { Efeitos severos } \\
\text { hereditários }\end{array}$ & $9,84 \mathrm{E}-13$ & $6,35 \mathrm{E}-14$ & $\mathbf{1 , 0 5 E - 1 2}$ \\
\hline
\end{tabular}

A maior parte dos custos está associada a mortes por câncer. O programa considera duas abordagens diferentes de valoração para o câncer fatal. Uma delas, a Value of Statistic Life (VOSL) leva em consideração o valor estatístico da vida. A outra, a Value of a Life Year Lost (VLYL) leva em consideração os anos perdidos pela pessoa que faleceu em decorrência do câncer.

Em nível local, embora os impactos e o custo associado a eles sejam baixos, são significativos, quando comparados aos regionais, e a maior parte deles está associada ao Câncer Fatal na abordagem VOSL. O valor encontrado para o Custo Total dos efeitos na saúde devido à liberação de radionuclídeos do reator de pesquisas IEA-R1 foi de US\$ 
3,49E-06. Os resultados para os custos ambientais do reator de pesquisas IEA-R1 são apresentados na FIG. 6.1 e na TAB. 6.3.

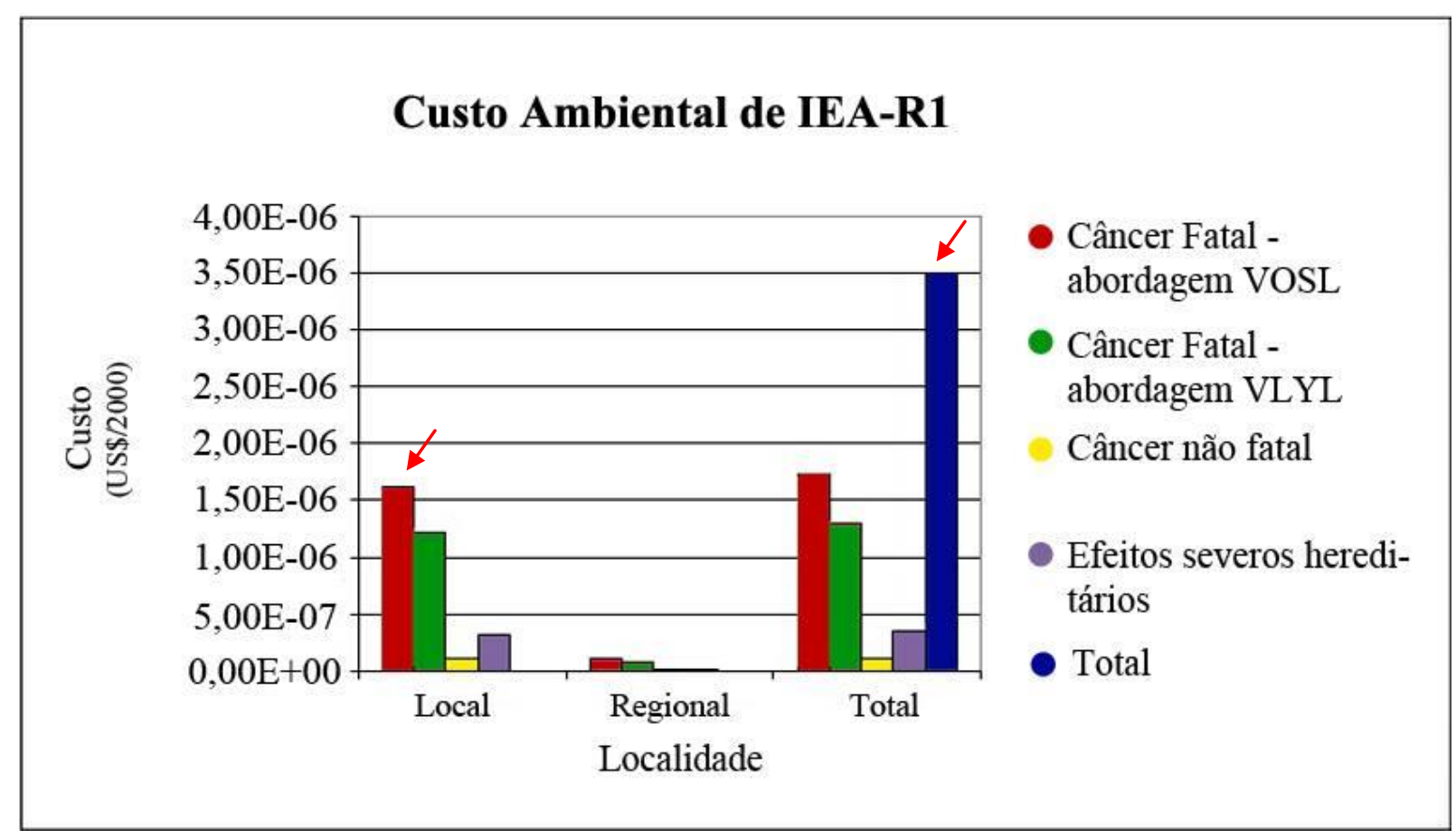

FIGURA 6.1 - Custo ambiental do IEA-R1

TABELA 6.3 - Resultados parciais do custo ambiental do reator IEA-R1

\begin{tabular}{l|c|c|c}
\hline Parâmetro & $\begin{array}{c}\text { Local } \\
(\mathbf{U S} \mathbf{\$ 2 0 0 0})\end{array}$ & $\begin{array}{c}\text { Regional } \\
(\mathbf{U S} \mathbf{2 0 0 0})\end{array}$ & $\begin{array}{c}\text { Total } \\
(\mathbf{U S} \mathbf{2 0 0 0} \mathbf{2 0 0})\end{array}$ \\
\hline Câncer fatal - abordagem VOSL & $1,62 \mathrm{E}-06$ & $1,05 \mathrm{E}-07$ & $1,73 \mathrm{E}-06$ \\
\hline Câncer fatal - abordagem VLYL & $1,22 \mathrm{E}-06$ & $7,88 \mathrm{E}-08$ & $1,30 \mathrm{E}-06$ \\
\hline Câncer não fatal & $1,08 \mathrm{E}-07$ & $6,99 \mathrm{E}-09$ & $1,15 \mathrm{E}-07$ \\
\hline Efeitos severos hereditários & $3,25 \mathrm{E}-07$ & $2,10 \mathrm{E}-08$ & $3,46 \mathrm{E}-07$ \\
\hline TOTAL & & & $3,49 \mathrm{E}-06$ \\
\hline
\end{tabular}

É possível perceber que a maior parte do custo ambiental do reator de pesquisa IEA-R1 está associada ao impacto local, sendo o regional quase desprezível. Isto pode ser explicado pela alta densidade populacional local, considerando-se a cidade de São Paulo.

\subsubsection{Angra 2 e 3}

O mesmo procedimento de cálculo feito para o reator de pesquisas IEA-R1 foi utilizado no cálculo de custo ambiental do reator de potência de Angra 2. Por ser similar ao reator de Angra 2, o de Angra 3 tem o seu cálculo de custo ambiental realizado da mesma 
maneira. Assim, os resultados apresentados referem-se aos dois reatores, ainda que os cálculos tenham sido feitos somente para Angra 2.

De forma análoga aos resultados anteriores, o módulo NUKPACTS apresenta como resultados parciais os impactos locais e regionais do reator, sendo estes calculados da mesma forma como no caso do IEA-R1. Os impactos locais totalizaram 7,36E-01 Sv homem por ano, e os regionais, 8,19E-02 Sv homem por ano. A partir desses resultados, foi possível calcular o impacto total das emissões atmosféricas, sendo esse obtido pelo somatório dos impactos locais e impactos regionais. O impacto total é de 8,38E-02 Sv homem por ano. Os valores parciais considerados para alcançar esses resultados estão listados na TAB 6.4.

TABELA 6.4 - Impactos das emissões atmosféricas de Angra 2 e 3

\begin{tabular}{l|l|l}
\hline $\begin{array}{l}\text { Impactos locais de emissões } \\
\text { atmosféricas }\end{array}$ & & Sv homem ano \\
\hline Inalação & & $3,71 \mathrm{E}-04$ \\
\hline Exposição externa pela nuvem & & $2,72 \mathrm{E}-06$ \\
\hline $\begin{array}{l}\text { Irradiação externa pela } \\
\text { atividade de deposição }\end{array}$ & & $7,18 \mathrm{E}-04$ \\
\hline & Carne de vaca & $1,41 \mathrm{E}-04$ \\
\hline & Carne de porco & $4,37 \mathrm{E}-05$ \\
\hline & Carne de frango & $1,33 \mathrm{E}-04$ \\
\hline Ingestão de produtos & Carne de ovelha & \\
\hline agropecuários & & $2,72 \mathrm{E}-06$ \\
\hline & Cereais & $1,69 \mathrm{E}-04$ \\
\hline & Vegetais verdes & $3,00 \mathrm{E}-05$ \\
\hline Ingestão: casos especiais & Leite & $2,59 \mathrm{E}-04$ \\
\hline H-3 & Subtotal & $7,78 \mathrm{E}-04$ \\
\hline C-14 & & \\
\hline & & $1,91 \mathrm{E}-08$ \\
\hline & & 0 \\
\hline & Subtotal & $1,91 \mathrm{E}-08$ \\
\hline & Total & $\mathbf{7 , 3 6 E - 0 1}$ \\
\hline
\end{tabular}




\begin{tabular}{|c|c|c|}
\hline $\begin{array}{l}\text { Impactos regionais de } \\
\text { emissões atmosféricas }\end{array}$ & & Sv homem ano \\
\hline Inalação & & $1,63 \mathrm{E}-02$ \\
\hline $\begin{array}{l}\text { Exposição externa pela } \\
\text { nuvem }\end{array}$ & & $1,18 \mathrm{E}-04$ \\
\hline \multirow[t]{4}{*}{$\begin{array}{l}\text { Irradiação externa pela } \\
\text { atividade de deposição }\end{array}$} & & $3,14 \mathrm{E}-02$ \\
\hline & Carne de vaca & $6,16 \mathrm{E}-03$ \\
\hline & Carne de porco & $1,91 \mathrm{E}-03$ \\
\hline & Carne de frango & $5,80 \mathrm{E}-03$ \\
\hline \multirow[t]{5}{*}{$\begin{array}{l}\text { Ingestão de produtos } \\
\text { agropecuários }\end{array}$} & Carne de ovelha & $1,19 \mathrm{E}-04$ \\
\hline & Cereais & $7,40 \mathrm{E}-03$ \\
\hline & Vegetais verdes & $1,31 \mathrm{E}-03$ \\
\hline & Leite & $1,14 \mathrm{E}-02$ \\
\hline & Subtotal & $3,41 \mathrm{E}-02$ \\
\hline \multicolumn{3}{|l|}{ Ingestão: casos especiais } \\
\hline $\mathrm{H}-3$ & & $8,34 \mathrm{E}-07$ \\
\hline \multirow[t]{3}{*}{$\mathrm{C}-14$} & & $0,00 \mathrm{E}+00$ \\
\hline & Subtotal & $8,34 \mathrm{E}-07$ \\
\hline & Total & 8,19E-02 \\
\hline $\begin{array}{l}\text { Impactos locais e regionais } \\
\text { de emissões atmosféricas }\end{array}$ & & Sv homem ano \\
\hline Inalação & & $1,67 \mathrm{E}-02$ \\
\hline Exposição externa pela nuvem & & $1,21 \mathrm{E}-04$ \\
\hline \multirow[t]{4}{*}{$\begin{array}{l}\text { Irradiação externa pela } \\
\text { atividade de deposição }\end{array}$} & & $3,21 \mathrm{E}-02$ \\
\hline & Carne de vaca & $6,30 \mathrm{E}-03$ \\
\hline & Carne de porco & $1,96 \mathrm{E}-03$ \\
\hline & Carne de frango & $5,93 \mathrm{E}-03$ \\
\hline \multirow[t]{5}{*}{$\begin{array}{l}\text { Ingestão de produtos } \\
\text { agropecuários }\end{array}$} & Carne de ovelha & $1,22 \mathrm{E}-04$ \\
\hline & Cereais & $7,57 \mathrm{E}-03$ \\
\hline & Hortaliças & $1,34 \mathrm{E}-03$ \\
\hline & Leite & $1,16 \mathrm{E}-02$ \\
\hline & Subtotal & $3,48 \mathrm{E}-02$ \\
\hline \multicolumn{3}{|l|}{$\begin{array}{l}\text { Ingestão: casos } \\
\text { especiais }\end{array}$} \\
\hline $\mathrm{H}-3$ & & $8,53 \mathrm{E}-07$ \\
\hline \multirow[t]{3}{*}{$\mathrm{C}-14$} & & $0,00 \mathrm{E}+00$ \\
\hline & Subtotal & $8,53 \mathrm{E}-07$ \\
\hline & Total & 8,38E-02 \\
\hline
\end{tabular}

Outro resultado do programa refere-se ao número de casos de câncer fatal, câncer não fatal e efeitos severos hereditários por ano na população, associados à atividade 
do reator em questão. Esses valores, apresentados na TAB. 6.5, são de 4,19E-03, 8,38E-04 e 8,38E-04 casos por ano, respectivamente.

TABELA 6.5 - Efeitos na saúde da população

\begin{tabular}{l|c|c|c}
\hline Parâmetro & $\begin{array}{c}\text { Local } \\
\text { (casos/ano) }\end{array}$ & $\begin{array}{c}\text { Regional } \\
\text { (casos/ano) }\end{array}$ & $\begin{array}{c}\text { Total } \\
\text { (casos/ano) }\end{array}$ \\
\hline Câncer fatal & $9,35 \mathrm{E}-05$ & $4,10 \mathrm{E}-03$ & $\mathbf{4 , 1 9 E - 0 3}$ \\
\hline Câncer não fatal & $1,87 \mathrm{E}-05$ & $8,19 \mathrm{E}-04$ & $\mathbf{8 , 3 8 E - 0 4}$ \\
\hline $\begin{array}{l}\text { Efeitos severos } \\
\text { hereditários }\end{array}$ & $1,87 \mathrm{E}-05$ & $8,19 \mathrm{E}-04$ & $\mathbf{8 , 3 8 E - 0 4}$ \\
\hline
\end{tabular}

Assim como para os outros reatores estudados, são considerados os impactos a nível local e regional. Sendo assim, o custo total corresponde ao somatório dos custos em nível local e regional, e são eles: Câncer Fatal na abordagem VOSL e VLYL, Câncer Não Fatal e Efeitos Severos Hereditários. O valor encontrado para o Custo Total dos efeitos na saúde da liberação de radionuclídeos pelos reatores de Angra 2 e de Angra 3 foi de US\$ 2.790 no ano 2000 .

Em nível regional, os impactos e o custo associado a eles são significativos, sendo que a maior parte deles está ligada ao Câncer Fatal na abordagem VOSL. Os resultados para o custo ambiental dos reatores de Angra 2 e 3 são apresentados na FIG. 6.2 e TAB 6.6.

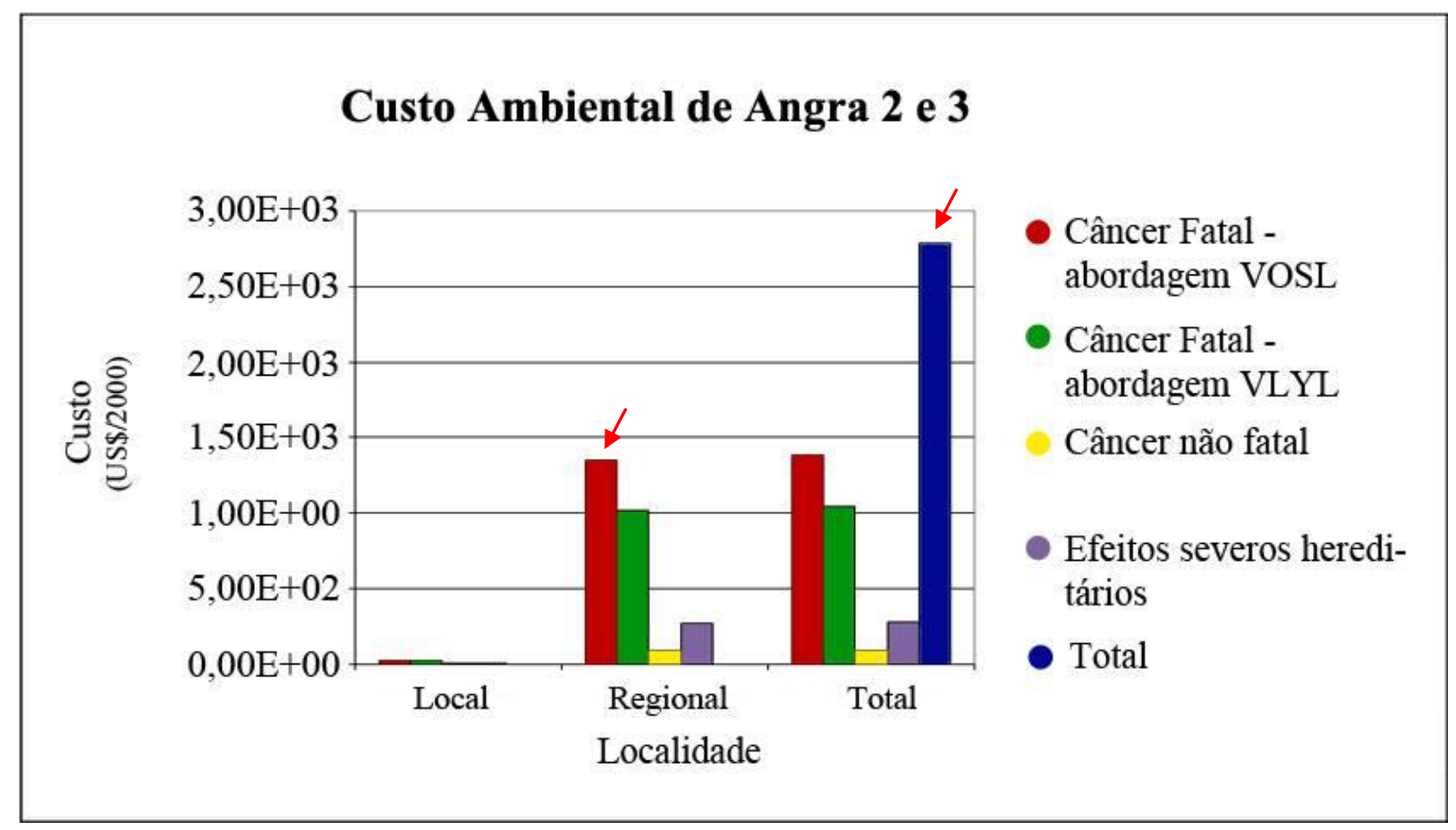

FIGURA 6.2 - Custo ambiental de Angra 2 e 3 
TABELA 6.6 - Resultados parciais do custo ambiental dos reatores de Angra 2 e 3

\begin{tabular}{l|c|c|c}
\hline Parâmetro & $\begin{array}{c}\text { Local } \\
(\mathbf{U S} \mathbf{\$ 2 0 0 0})\end{array}$ & $\begin{array}{c}\text { Regional } \\
(\mathbf{U S} \mathbf{2 0 0 0})\end{array}$ & $\begin{array}{c}\text { Total } \\
(\mathbf{U S} \mathbf{2 0 0 0})\end{array}$ \\
\hline Câncer fatal - abordagem VOSL & $3,09 \mathrm{E}+01$ & $1,35 \mathrm{E}+03$ & $1,38 \mathrm{E}+03$ \\
\hline Câncer fatal - abordagem VLYL & $2,32 \mathrm{E}+01$ & $1,02 \mathrm{E}+03$ & $1,04 \mathrm{E}+03$ \\
\hline Câncer não fatal & $2,06 \mathrm{E}+00$ & $9,01 \mathrm{E}+01$ & $9,22 \mathrm{E}+01$ \\
\hline Efeitos severos hereditários & $6,17 \mathrm{E}+00$ & $2,70 \mathrm{E}+02$ & $2,77 \mathrm{E}+02$ \\
\hline TOTAL & & & $2,79 \mathrm{E}+03$ \\
\hline
\end{tabular}

Ao contrário dos resultados do reator IEA-R1, o custo ambiental local dos reatores de Angra 2 e 3 não foi significativo, em parte pela baixa densidade populacional local, quando comparada à regional, e em parte pela velocidade do vento, que ajuda a propagar os radionuclídeos emitidos.

\subsubsection{Angra 1}

O Reator de potência de Angra 1 teve seu cálculo realizado de forma independente, e seus resultados serão apresentados a seguir. Assim como Angra 2 e 3, Angra 1 possui impactos das emissões atmosféricas em nível local e regional, apresentados na TAB 6.7.

TABELA 6.7 - Impactos de emissões atmosféricas de Angra 1

\begin{tabular}{l|l|c}
\hline $\begin{array}{l}\text { Impactos locais de } \\
\text { emissões atmosféricas }\end{array}$ & & Sv homem ano \\
\hline Inalação & & $5,03 \mathrm{E}-07$ \\
\hline $\begin{array}{l}\text { Exposição externa pela } \\
\text { nuvem }\end{array}$ & & $2,30 \mathrm{E}-05$ \\
\hline $\begin{array}{l}\text { Irradiação externa pela } \\
\text { atividade de deposição }\end{array}$ & & $1,52 \mathrm{E}-07$ \\
\hline & Carne de vaca & $2,18 \mathrm{E}-07$ \\
\hline & Carne de porco & $6,77 \mathrm{E}-08$ \\
\hline & Carne de frango & $2,05 \mathrm{E}-07$ \\
\hline Ingestão de produtos & Carne de ovelha & $3,00 \mathrm{E}-09$ \\
\hline agropecuários & Cereais & $0,00 \mathrm{E}-00$ \\
\hline & Vegetais verdes & $1,37 \mathrm{E}-07$ \\
\hline & Leite & $1,29 \mathrm{E}-06$ \\
\hline Ingestão: casos especiais & Subtotal & $1,92 \mathrm{E}-06$ \\
\hline H-3 & & $0,00 \mathrm{E}+00$ \\
\hline C-14 & & $0,00 \mathrm{E}+00$ \\
\hline & & $0,00 \mathrm{E}+00$ \\
\hline & Subtotal & $\mathbf{2 , 5 6 E - 0 5}$ \\
\hline & Total & \\
\hline & & \\
\hline & & \\
\hline & & \\
\hline & & \\
\hline & & \\
\hline
\end{tabular}




\begin{tabular}{|c|c|c|}
\hline \multicolumn{3}{|l|}{$\begin{array}{l}\text { Impactos regionais de } \\
\text { emissões atmosféricas }\end{array}$} \\
\hline Inalação & & $1,58 \mathrm{E}-05$ \\
\hline $\begin{array}{l}\text { Exposição externa pela } \\
\text { nuvem }\end{array}$ & & 4,28E-04 \\
\hline \multirow[t]{4}{*}{$\begin{array}{l}\text { Irradiação externa pela } \\
\text { atividade de deposição }\end{array}$} & & 4,77E-06 \\
\hline & Carne de vaca & $6,82 \mathrm{E}-06$ \\
\hline & Carne de porco & $2,12 \mathrm{E}-06$ \\
\hline & Carne de frango & $6,43 \mathrm{E}-06$ \\
\hline \multirow[t]{5}{*}{$\begin{array}{l}\text { Ingestão de produtos } \\
\text { agropecuários }\end{array}$} & Carne de ovelha & 9,38E-08 \\
\hline & Cereais & $0,00 \mathrm{E}+00$ \\
\hline & Vegetais verdes & $4,28 \mathrm{E}-06$ \\
\hline & Leite & $4,02 \mathrm{E}-05$ \\
\hline & Subtotal & $6,00 \mathrm{E}-05$ \\
\hline \multicolumn{3}{|l|}{ Ingestão: casos especiais } \\
\hline $\mathrm{H}-3$ & & $0,00 \mathrm{E}+00$ \\
\hline \multirow[t]{3}{*}{$\mathrm{C}-14$} & & $0,00 \mathrm{E}+00$ \\
\hline & Subtotal & $0,00 \mathrm{E}+00$ \\
\hline & Total & 5,09E-04 \\
\hline \multicolumn{3}{|l|}{$\begin{array}{l}\text { Impactos locais e } \\
\text { regionais de emissões } \\
\text { atmosféricas }\end{array}$} \\
\hline Inalação & & $1,63 \mathrm{E}-05$ \\
\hline $\begin{array}{l}\text { Exposição externa pela } \\
\text { nuvem }\end{array}$ & & $4,51 \mathrm{E}-04$ \\
\hline \multirow[t]{4}{*}{$\begin{array}{l}\text { Irradiação externa pela } \\
\text { atividade de deposição }\end{array}$} & & 4,92E-06 \\
\hline & Carne de vaca & 7,04E-06 \\
\hline & Carne de porco & $2,19 \mathrm{E}-06$ \\
\hline & Carne de frango & 6,64E-06 \\
\hline \multirow[t]{5}{*}{$\begin{array}{l}\text { Ingestão de produtos } \\
\text { agropecuários }\end{array}$} & Carne de ovelha & $9,68 \mathrm{E}-08$ \\
\hline & Cereais & $0,00 \mathrm{E}+00$ \\
\hline & Hortaliças & 4,42E-06 \\
\hline & Leite & $4,15 \mathrm{E}-05$ \\
\hline & Subtotal & $6,19 \mathrm{E}-05$ \\
\hline \multicolumn{3}{|l|}{ Ingestão: casos especiais } \\
\hline $\mathrm{H}-3$ & & $0,00 \mathrm{E}+00$ \\
\hline \multirow[t]{3}{*}{$\mathrm{C}-14$} & & $0,00 \mathrm{E}+00$ \\
\hline & Subtotal & $0,00 \mathrm{E}+00$ \\
\hline & Total & 5,35E-04 \\
\hline
\end{tabular}


A TAB. 6.8 resume os efeitos na saúde da população, referentes ao número de casos de câncer fatal, câncer não fatal e efeitos severos hereditários por ano na população associados à atividade do reator de Angra 1.

TABELA 6.8 - Efeitos na saúde da população

\begin{tabular}{l|c|c|c}
\hline Parâmetro & $\begin{array}{c}\text { Local } \\
\text { (casos/ano) }\end{array}$ & $\begin{array}{c}\text { Regional } \\
\text { (casos/ano) }\end{array}$ & $\begin{array}{c}\text { Total } \\
\text { (casos/ano) }\end{array}$ \\
\hline Câncer fatal & $1,28 \mathrm{E}-06$ & $2,55 \mathrm{E}-05$ & $\mathbf{2 , 6 7 E - 0 5}$ \\
\hline Câncer não fatal & $2,56 \mathrm{E}-07$ & $5,09 \mathrm{E}-06$ & $\mathbf{5 , 3 5 E - 0 6}$ \\
\hline $\begin{array}{l}\text { Efeitos severos } \\
\text { hereditários }\end{array}$ & $2,56 \mathrm{E}-07$ & $5,09 \mathrm{E}-06$ & $\mathbf{5 , 3 5 E - 0 6}$ \\
\hline
\end{tabular}

A FIG. 6.3 e a TAB. 6.9 apresentam os resultados do custo ambiental do reator de Angra 1, que foi de US\$ 17,8 em 2000.

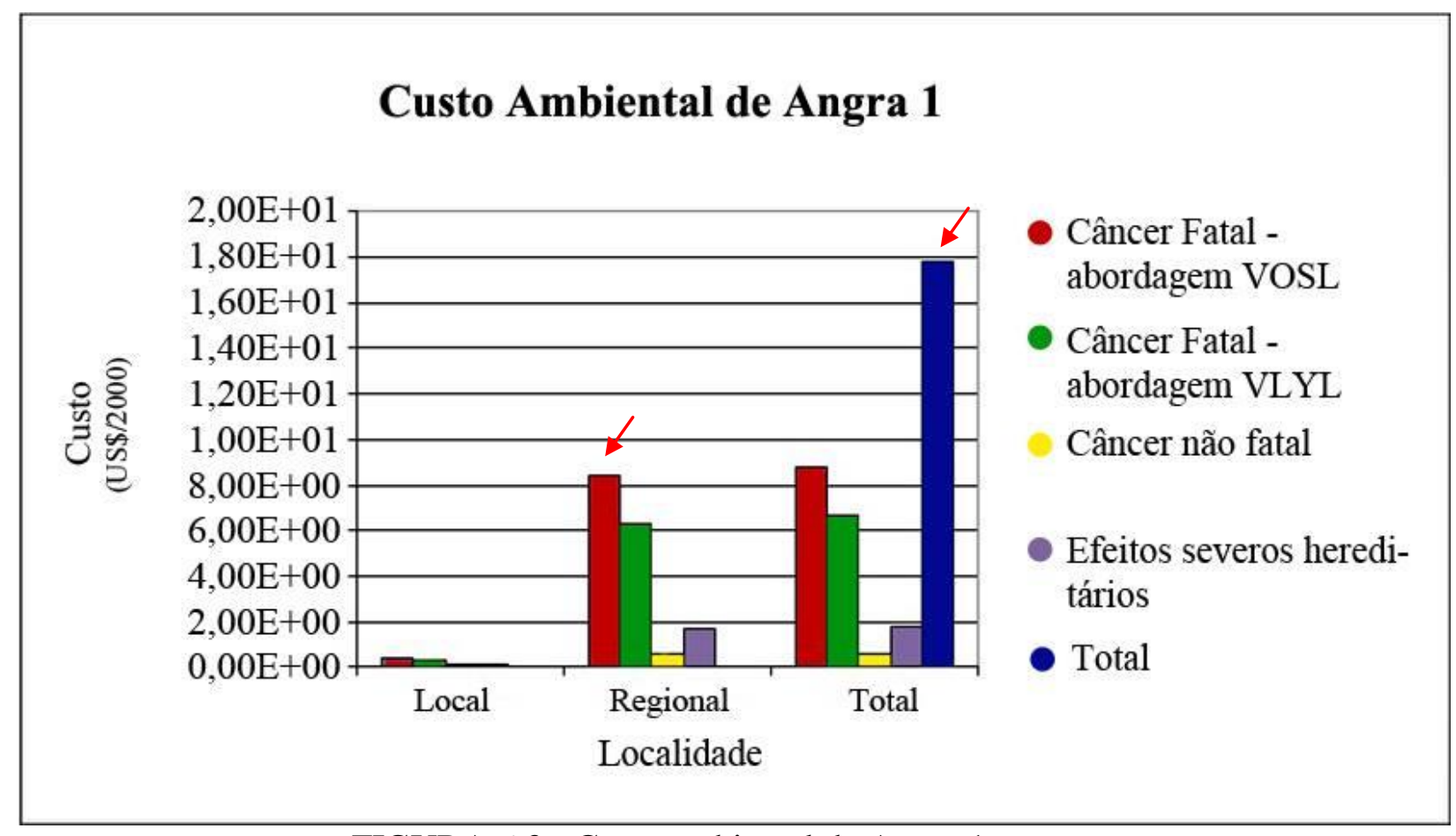

FIGURA 6.3 - Custo ambiental de Angra 1

TABELA 6.9 - Resultados parciais do custo ambiental do reator de Angra 1

\begin{tabular}{l|c|c|c}
\hline Parâmetro & $\begin{array}{c}\text { Local } \\
(\mathbf{U S \$ / 2 0 0 0})\end{array}$ & $\begin{array}{c}\text { Regional } \\
(\mathbf{U S} \mathbf{\$ 2 0 0 0})\end{array}$ & $\begin{array}{c}\text { Total } \\
(\mathbf{U S} \mathbf{\$ 2 0 0 0})\end{array}$ \\
\hline $\begin{array}{l}\text { Câncer fatal - abordagem } \\
\text { VOSL }\end{array}$ & $4,22 \mathrm{E}-01$ & $8,40 \mathrm{E}+00$ & $8,82 \mathrm{E}+00$ \\
\hline $\begin{array}{l}\text { Câncer fatal - abordagem } \\
\text { VLYL }\end{array}$ & $3,17 \mathrm{E}-01$ & $6,31 \mathrm{E}+00$ & $6,63 \mathrm{E}+00$ \\
\hline Câncer não fatal & $2,82 \mathrm{E}-02$ & $5,60 \mathrm{E}-01$ & $5,88 \mathrm{E}-01$ \\
\hline Efeitos severos hereditários & $8,45 \mathrm{E}-02$ & $1,68 \mathrm{E}+00$ & $1,76 \mathrm{E}+00$ \\
\hline TOTAL & & & $1,78 \mathrm{E}+01$ \\
\hline
\end{tabular}


Neste caso, os impactos regionais foram mais significativos do que os locais. As densidades populacionais consideradas para Angra 1 são as mesmas consideradas para Angra 2 e 3, e portanto, da mesma forma que para estes reatores, o impacto regional, em função da maior densidade demográfica, é maior.

\subsubsection{Reator de Balakovo}

Os resultados para o reator de Balakovo, que tratam, respectivamente, dos impactos locais de emissões atmosféricas, regionais e o somatório dos dois primeiros, foram obtidos no programa SIMPACTS e são apresentados na TAB. 6.10 a 6.12 .

TABELA 6.10 - Impactos locais de emissões atmosféricas de Balakovo

\begin{tabular}{l|l|c}
\hline $\begin{array}{l}\text { Impactos locais de emissões } \\
\text { atmosféricas }\end{array}$ & Sv homem ano \\
\hline Inalação & & $1,42 \mathrm{E}-04$ \\
\hline Exposição externa pela nuvem & & $9,98 \mathrm{E}-03$ \\
\hline $\begin{array}{l}\text { Irradiação externa pela atividade } \\
\text { de deposição }\end{array}$ & Carne de vaca & $6,20 \mathrm{E}-05$ \\
\hline $\begin{array}{l}\text { Ingestão de produtos } \\
\text { agropecuários }\end{array}$ & Carne de porco & $6,08 \mathrm{E}-06$ \\
\hline & Carne de frango & $5,91 \mathrm{E}-06$ \\
\hline & Carne de ovelha & $1,86 \mathrm{E}-06$ \\
\hline & Cereais & $4,03 \mathrm{E}-06$ \\
\hline & Vegetais verdes & $3,75 \mathrm{E}-06$ \\
\hline & Vegetais de raiz & $1,01 \mathrm{E}-05$ \\
\hline & Leite fresco & $2,63 \mathrm{E}-06$ \\
\hline & Outros tipos de & $8,69 \mathrm{E}-05$ \\
\hline leite & $4,89 \mathrm{E}-07$ \\
\hline H-3 & Subtotal & $1,22 \mathrm{E}-04$ \\
\hline C-14 & & $3,57 \mathrm{E}-09$ \\
\hline & & $6,86 \mathrm{E}-03$ \\
\hline & & $6,86 \mathrm{E}-03$ \\
\hline & Subtotal & $\mathbf{1 , 7 2 E - 0 2}$ \\
\hline
\end{tabular}


TABELA 6.11 - Impactos regionais de emissões atmosféricas de Balakovo

\begin{tabular}{l|l|c}
\hline $\begin{array}{l}\text { Impactos regionais de emissões } \\
\text { atmosféricas }\end{array}$ & & Sv homem ano \\
\hline Inalação & & $3,91 \mathrm{E}-04$ \\
\hline $\begin{array}{l}\text { Exposição externa pela nuvem } \\
\text { Ie deposição }\end{array}$ & & $5,91 \mathrm{E}-03$ \\
\hline $\begin{array}{l}\text { Ingestão de produtos } \\
\text { agropecuários }\end{array}$ & Carne de vaca & $1,71 \mathrm{E}-04$ \\
\hline & Carne de porco & $1,69 \mathrm{E}-05$ \\
\hline & Carne de frango & $1,64 \mathrm{E}-05$ \\
\hline & Carne de ovelha & $5,16 \mathrm{E}-06$ \\
\hline & Cereais & $1,12 \mathrm{E}-05$ \\
\hline & Vegetais verdes & $1,03 \mathrm{E}-05$ \\
\hline & Vegetais de raiz & $2,81 \mathrm{E}-05$ \\
\hline & Leite fresco & $7,32 \mathrm{E}-06$ \\
\hline & $\begin{array}{l}\text { Outros tipos de } \\
\text { leite }\end{array}$ & $2,42 \mathrm{E}-04$ \\
\hline Ingestão: casos especiais & Subtotal & $1,35 \mathrm{E}-06$ \\
\hline C-3 & & $3,39 \mathrm{E}-04$ \\
\hline & & $9,86 \mathrm{E}-09$ \\
\hline & & $1,89 \mathrm{E}-02$ \\
\hline & Subtotal & $1,89 \mathrm{E}-02$ \\
\hline & Total & $\mathbf{2 , 5 7 E - 0 2}$ \\
\hline
\end{tabular}


TABELA 6.12 - Impactos locais e regionais de emissões atmosféricas de Balakovo

\begin{tabular}{l|l|c}
\hline $\begin{array}{l}\text { Impactos locais e regionais } \\
\text { de emissões atmosféricas }\end{array}$ & & Sv homem ano \\
\hline Inalação & & $5,33 \mathrm{E}-04$ \\
\hline $\begin{array}{l}\text { Exposição externa pela } \\
\text { nuvem }\end{array}$ & & $1,59 \mathrm{E}-02$ \\
\hline $\begin{array}{l}\text { Irradiação externa pela } \\
\text { atividade de deposição }\end{array}$ & Carne de vaca & $2,33 \mathrm{E}-04$ \\
\hline $\begin{array}{l}\text { Ingestão de produtos } \\
\text { agropecuários }\end{array}$ & Carne de porco & $2,30 \mathrm{E}-05$ \\
\hline & Carne de frango & $2,23 \mathrm{E}-05$ \\
\hline & Carne de ovelha & $7,02 \mathrm{E}-06$ \\
\hline & Cereais & $1,52 \mathrm{E}-05$ \\
\hline & Vegetais verdes & $1,41 \mathrm{E}-05$ \\
\hline & Vegetais de raiz & $3,82 \mathrm{E}-05$ \\
\hline & Leite fresco & $9,96 \mathrm{E}-06$ \\
\hline & Outros tipos de & $3,29 \mathrm{E}-04$ \\
\hline leite & $1,84 \mathrm{E}-06$ \\
\hline H-3 & Subtotal & $4,61 \mathrm{E}-04$ \\
\hline & \multicolumn{2}{|c|}{} \\
\hline & Subtotal & $1,34 \mathrm{E}-08$ \\
\hline & Total & $2,58 \mathrm{E}-02$ \\
\hline & $\mathbf{4 , 2 9 E - 0 2}$ \\
\hline
\end{tabular}

Outros resultados parciais do Programa são os efeitos na saúde da população, divididos em: câncer fatal, câncer não fatal e efeitos severos hereditários, em casos por ano. Os resultados desses parâmetros para o reator de Balakovo, representados na TAB. 6.13, são 2,14E-03, 5,15E-03 e 4,29E-04, respectivamente.

TABELA 6.13 - Efeitos na saúde da população

\begin{tabular}{l|c|c|c}
\hline \multicolumn{1}{c|}{ Parâmetro } & $\begin{array}{c}\text { Local } \\
\text { (casos/ano) }\end{array}$ & $\begin{array}{c}\text { Regional } \\
\text { (casos/ano) }\end{array}$ & $\begin{array}{c}\text { Total } \\
\text { (casos/ano) }\end{array}$ \\
\hline Câncer fatal & $8,58 \mathrm{E}-04$ & $1,29 \mathrm{E}-03$ & $\mathbf{2 , 1 4 E - 0 3}$ \\
\hline Câncer não fatal & $2,06 \mathrm{E}-03$ & $3,09 \mathrm{E}-03$ & $\mathbf{5 , 1 5 E - 0 3}$ \\
\hline $\begin{array}{l}\text { Efeitos severos } \\
\text { hereditários }\end{array}$ & $1,72 \mathrm{E}-04$ & $2,57 \mathrm{E}-04$ & $\mathbf{4 , 2 9 E - 0 4}$ \\
\hline
\end{tabular}

O custo total corresponde ao somatório dos custos em nível local e nível regional, sendo eles: câncer fatal na abordagem VOSL e VLYL, câncer não fatal e efeitos severos hereditários. Para o reator de Balakovo, esse custo foi de US\$ 2.140 por ano, como 
é demonstrado na FIG. 6.4 e na TAB 6.14. A maior parte do custo está associada ao câncer fatal na abordagem VOSL, em torno de US\$ 778 por ano.

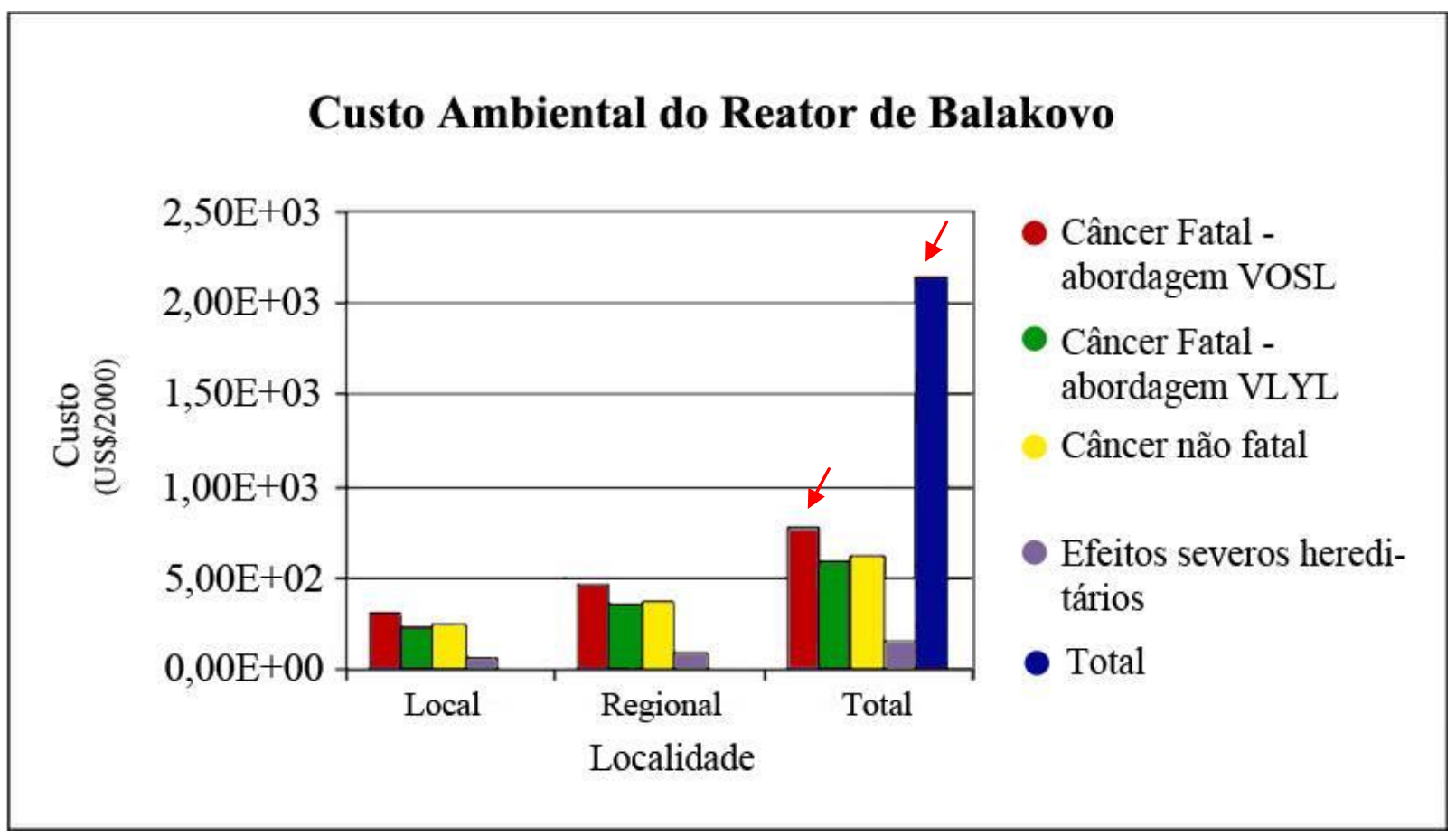

FIGURA 6.4 - Custo ambiental do reator de Balakovo

TABELA 6.14 - Resultados parciais do custo ambiental do reator de Balakovo

\begin{tabular}{l|c|c|c}
\hline Parâmetro & $\begin{array}{c}\text { Local } \\
(\mathbf{U S \$} / \mathbf{2 0 0 0})\end{array}$ & $\begin{array}{c}\text { Regional } \\
(\mathbf{U S \$} / \mathbf{2 0 0 0})\end{array}$ & $\begin{array}{c}\text { Total } \\
(\mathbf{U S \$} / \mathbf{2 0 0 0})\end{array}$ \\
\hline Câncer fatal - abordagem VOSL & $3,12 \mathrm{E}+02$ & $4,67 \mathrm{E}+02$ & $7,78 \mathrm{E}+02$ \\
\hline Câncer fatal - abordagem VLYL & $2,33 \mathrm{E}+02$ & $3,50 \mathrm{E}+02$ & $5,83 \mathrm{E}+02$ \\
\hline Câncer não fatal & $2,49 \mathrm{E}+02$ & $3,74 \mathrm{E}+02$ & $6,23 \mathrm{E}+02$ \\
\hline Efeitos severos hereditários & $6,23 \mathrm{E}+01$ & $9,34 \mathrm{E}+01$ & $1,56 \mathrm{E}+02$ \\
\hline TOTAL & & & $2,14 \mathrm{E}+03$ \\
\hline
\end{tabular}

\subsubsection{Termelétricas na França}

Os resultados dos impactos de emissões atmosféricas de termelétricas contidos no programa são apresentados na TAB 6.15 a TAB. 6.17. 
TABELA 6.15 - Impactos locais de emissões atmosféricas de termelétricas

\begin{tabular}{l|l|c}
\hline $\begin{array}{l}\text { Impactos locais de emissões } \\
\text { atmosféricas }\end{array}$ & & Sv homem ano \\
\hline Inalação & & $8,83 \mathrm{E}-04$ \\
\hline $\begin{array}{l}\text { Exposição externa pela nuvem } \\
\text { atividadade de deposição }\end{array}$ & & $1,23 \mathrm{E}-10$ \\
\hline $\begin{array}{l}\text { Ingestão de produtos } \\
\text { agropecuários }\end{array}$ & Carne de vaca & $3,97 \mathrm{E}-07$ \\
\hline & Carne de porco & $3,05 \mathrm{E}-20$ \\
\hline & Carne de frango & $3,58 \mathrm{E}-22$ \\
\hline & Carne de ovelha & $2,10 \mathrm{E}-21$ \\
\hline & Cereais & $6,64 \mathrm{E}-20$ \\
\hline & Vegetais verdes & $1,13 \mathrm{E}-18$ \\
\hline & Tubérculos & $3,18 \mathrm{E}-19$ \\
\hline Ingestão: casos & Leite fresco & $4,58 \mathrm{E}-19$ \\
\hline especiais & Subtotal & $2,45 \mathrm{E}-18$ \\
\hline C-14 & & \\
\hline & & $\mathbf{8 , 9 1 E - 0 4}$ \\
\hline
\end{tabular}

TABELA 6.16 - Impactos regionais de emissões atmosféricas de termelétricas

\begin{tabular}{l|l|c}
\hline $\begin{array}{l}\text { Impactos regionais de } \\
\text { emissões atmosféricas }\end{array}$ & & Sv homem ano \\
\hline Inalação & & $1,77 \mathrm{E}-02$ \\
\hline Exposição externa pela nuvem & & $2,46 \mathrm{E}-09$ \\
\hline $\begin{array}{l}\text { Irradiação externa pela atividade } \\
\text { de deposição }\end{array}$ & & $7,93 \mathrm{E}-06$ \\
\hline Ingestão de produtos agrícolas & Carne de vaca & $6,10 \mathrm{E}-19$ \\
\hline & Carne de porco & $1,92 \mathrm{E}-20$ \\
\hline & Carne de frango & $7,99 \mathrm{E}-18$ \\
\hline & Carne de ovelha & $4,21 \mathrm{E}-20$ \\
\hline & Cereais & $1,33 \mathrm{E}-18$ \\
\hline & Vegetais verdes & $2,26 \mathrm{E}-17$ \\
\hline & Tubérculos & $6,35 \mathrm{E}-18$ \\
\hline Ingestão: casos & Leite fresco & $9,16 \mathrm{E}-18$ \\
\hline especiais & Subtotal & $4,89 \mathrm{E}-17$ \\
\hline C-14 & & \\
\hline & & $1,44 \mathrm{E}-04$ \\
\hline
\end{tabular}


TABELA 6.17 - Impactos locais e regionais de emissões atmosféricas de termelétricas

\begin{tabular}{l|l|c}
\hline $\begin{array}{l}\text { Impactos locais e } \\
\text { regionais de emissões } \\
\text { atmosféricas }\end{array}$ & \multicolumn{2}{l}{$\begin{array}{l}\text { Sv homem } \\
\text { ano }\end{array}$} \\
\hline Inalação & & $1,85 \mathrm{E}-02$ \\
\hline Exposição externa pela nuvem & & $2,58 \mathrm{E}-09$ \\
\hline $\begin{array}{l}\text { Irradiação externa pela atividade } \\
\text { de deposição }\end{array}$ & & $8,33 \mathrm{E}-06$ \\
\hline Ingestão de produtos agrícolas & Carne de vaca & $6,40 \mathrm{E}-19$ \\
\hline & Carne de porco & $2,01 \mathrm{E}-20$ \\
\hline & Carne de frango & $8,39 \mathrm{E}-18$ \\
\hline & Carne de ovelha & $4,42 \mathrm{E}-20$ \\
\hline & Cereais & $1,39 \mathrm{E}-18$ \\
\hline & Vegetais verdes & $2,38 \mathrm{E}-17$ \\
\hline & Vegetais de raiz & $6,67 \mathrm{E}-18$ \\
\hline Ingestão: casos especiais & Leite fresco & $9,62 \mathrm{E}-18$ \\
\hline C-14 & Subtotal & $5,14 \mathrm{E}-17$ \\
\hline & \multicolumn{2}{|l}{} \\
\hline & Total & $1,51 \mathrm{E}-04$ \\
\hline
\end{tabular}

A TAB 6.18 apresenta os efeitos na saúde da população

TABELA 6.18 - Efeitos na saúde da população

\begin{tabular}{l|c|c|c}
\hline Parâmetro & $\begin{array}{c}\text { Local } \\
\text { (casos/ano) }\end{array}$ & $\begin{array}{c}\text { Regional } \\
\text { (casos/ano) }\end{array}$ & $\begin{array}{c}\text { Total } \\
\text { (casos/ano) }\end{array}$ \\
\hline Câncer fatal & $4,46 \mathrm{E}-05$ & $8,91 \mathrm{E}-04$ & $9,35 \mathrm{E}-04$ \\
\hline Câncer não fatal & $1,07 \mathrm{E}-04$ & $2,14 \mathrm{E}-03$ & $2,25 \mathrm{E}-03$ \\
\hline Efeitos severos hereditários & $8,91 \mathrm{E}-06$ & $1,78 \mathrm{E}-04$ & $1,87 \mathrm{E}-04$ \\
\hline
\end{tabular}

Assim como para as outras usinas de energia elétrica, outros resultados parciais são aqueles relacionados ao custo. Os dados são apresentados nas TAB. 6.19 e FIG 6.5. 


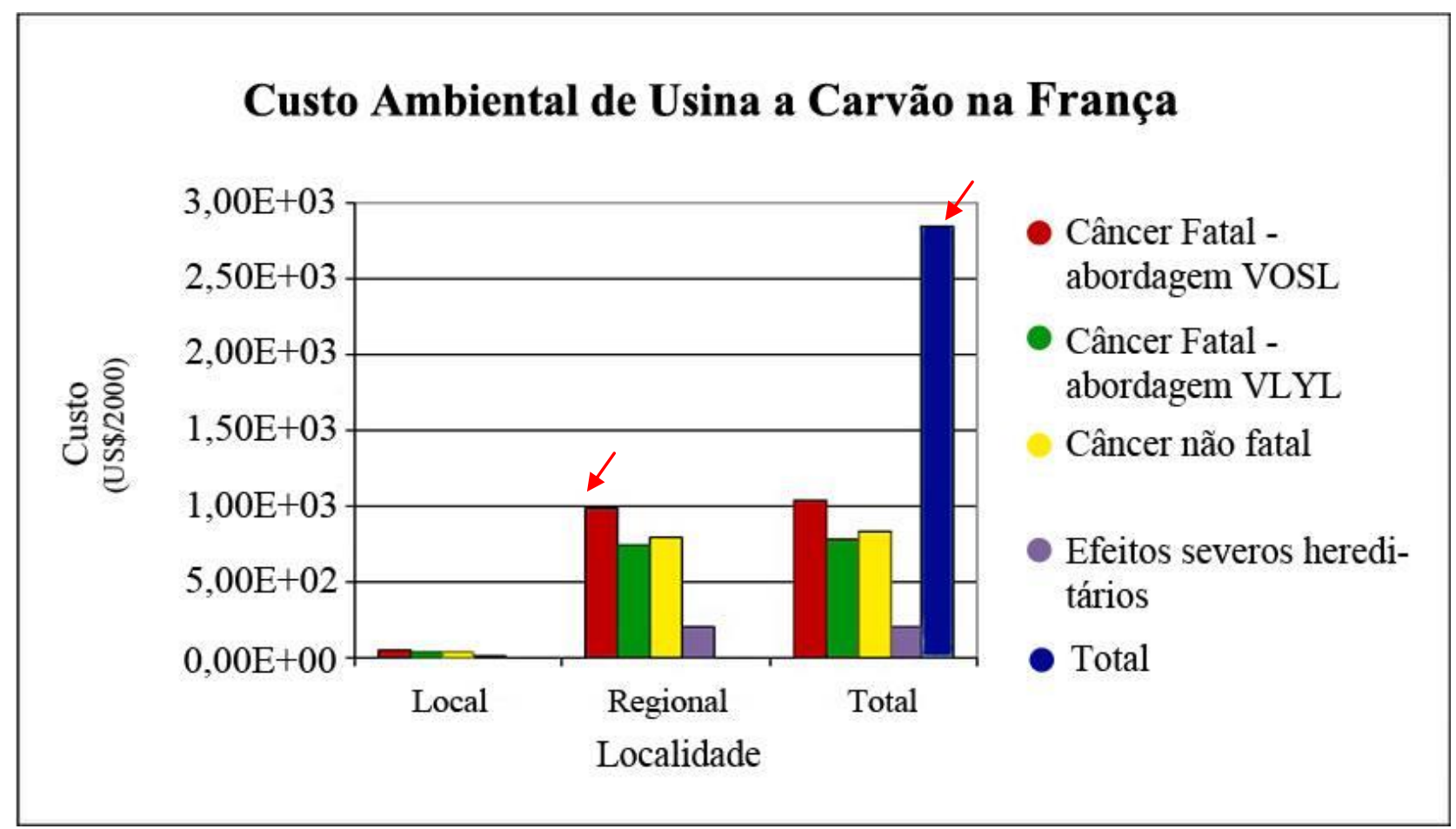

FIGURA 6.5 - Custo ambiental de usina a carvão na França

TABELA 6.19 - Resultados parciais do custo ambiental de termelétricas

\begin{tabular}{l|c|c|c}
\hline Parâmetro & $\begin{array}{c}\text { Local } \\
(\mathbf{U S} \mathbf{2 0 0 0})\end{array}$ & $\begin{array}{c}\text { Regional } \\
(\mathbf{U S} \mathbf{2 0 0 0})\end{array}$ & $\begin{array}{c}\text { Total } \\
(\mathbf{U S} \mathbf{2 0 0 0})\end{array}$ \\
\hline Câncer Fatal - abordagem VOSL & $4,95 \mathrm{E}+01$ & $9,89 \mathrm{E}+02$ & $1,04 \mathrm{E}+03$ \\
\hline Câncer Fatal - abordagem VLYL & $3,69 \mathrm{E}+01$ & $7,39 \mathrm{E}+02$ & $7,75 \mathrm{E}+02$ \\
\hline Câncer não fatal & $3,93 \mathrm{E}+01$ & $7,87 \mathrm{E}+02$ & $8,26 \mathrm{E}+02$ \\
\hline Efeitos Severos Hereditários & $9,89 \mathrm{E}+00$ & $1,98 \mathrm{E}+02$ & $2,08 \mathrm{E}+02$ \\
\hline TOTAL & & & $2,85 \mathrm{E}+03$ \\
\hline
\end{tabular}

\subsection{HIDROPACTS}

\subsubsection{Hidrelétrica Serra da Mesa}

Para o módulo HIDROPACTS, em que o cálculo de custo ambiental da hidrelétrica já veio com o programa, os resultados foram apresentados estão divididos em Impactos físicos e Impactos econômicos, demonstrados nas TAB 6.20 a 6.22. 
TABELA 6.20 - Resumo dos impactos físicos para a hidrelétrica de Serra da Mesa

\begin{tabular}{l|c}
\hline \multicolumn{2}{c}{ Impactos Físicos } \\
\hline Altura da barragem & m \\
\hline Perda de terras & $\mathbf{k m}^{2}$ \\
\hline Florestas & 709 \\
Terras agrícolas & 80 \\
Outras & 08 \\
Total & 796 \\
\hline Deslocamento e Reassentamento & Pessoas \\
\hline Pessoas deslocadas & 4.779 \\
Pessoas reassentadas & 2.390 \\
\hline Perda de vidas (acidentes) & Casos \\
\hline Perda de vidas por falhas & 1,698 por falha \\
Expectativa de perda de vidas & 0,170 por falha/ano \\
\hline
\end{tabular}

TABELA 6.21 - Impactos físicos - Emissões

\begin{tabular}{c|c|c|c}
\hline Emissões & Baixas & Médias & Altas \\
\hline & tons métricas/ano & tons métricas/ano & tons métricas/ano \\
\hline Emissões durante & & & \\
a operação & 1.195 & 14.336 & 31.858 \\
$\mathrm{CH}_{4}$ & 119.469 & 1.432 .035 & 3.185 .841 \\
$\mathrm{CO}_{2}$ & & & \\
\hline Emissões TOTAIS & & & 31.858 \\
$\mathrm{CH}_{4}$ & 1.195 & 14.894 & 3.185 .841 \\
$\mathrm{CO}_{2}$ & 39.425 & 400.265 & 1.051 .327 \\
GHG (em carbono & & & \\
equivalente) & & & \\
\hline
\end{tabular}


Observa-se que a maior parte de perda de terras se dá em florestas $\left(709 \mathrm{~km}^{2}\right)$ e que há uma diferença entre pessoas deslocadas e reassentadas, sendo as primeiras em número bem maior.

Em relação à perda de vidas em acidentes, os resultados demonstram que não ocorrem muitas falhas com acidentes fatais, já que o valor para os casos por falha/ano é baixo.

As emissões são uma parte importante do cálculo. Observa-se que o $\mathrm{CO}_{2}$ (3 milhões de toneladas) representa uma grande parcela de altas emissões. $\mathrm{O}$ metano $\left(\mathrm{CH}_{4}\right)$ é responsável por uma parcela bem menor (31 mil toneladas). 
TABELA 6.22 - Resumo dos impactos econômicos para a hidrelétrica de Serra da Mesa

\begin{tabular}{|c|c|}
\hline \multicolumn{2}{|c|}{ Impactos Econômicos } \\
\hline Reassentamento de Pessoas & Milhões US\$/2000 \\
\hline Custo total de danos & 33,69 \\
\hline Custo externo & 16,84 \\
\hline Custo externo anual & 0,34 \\
\hline Custo externo de reassentamento por & \\
\hline $\mathrm{MWh}$ & 5,20E-02 US\$2000 por MWh \\
\hline Perda de Terras & Milhões US\$/2000 \\
\hline Florestas & 141,77 \\
\hline Terras agrícolas & 19,91 \\
\hline Outras & 0,80 \\
\hline $\begin{array}{l}\text { Custo externo de perda de } \\
\text { terras }\end{array}$ & 81,24 \\
\hline Custo externo anual & 1,62 \\
\hline $\begin{array}{l}\text { Custo externo de perda de } \\
\text { terras por MWh }\end{array}$ & 2,52E-01 US\$ por MWh \\
\hline \multicolumn{2}{|l|}{ Perda de vidas (acidentes) } \\
\hline $\begin{array}{l}\text { Custo externo anual dos } \\
\text { dados }\end{array}$ & US\$ 0,08 milhões \\
\hline $\begin{array}{l}\text { Custo externo de perda de } \\
\text { vidas por MWh }\end{array}$ & $1,22 \mathrm{E}-02 \mathrm{US} \$ / 2000$ \\
\hline \multicolumn{2}{|l|}{ Perda de produção agrícola e pecuária } \\
\hline $\begin{array}{l}\text { Custo externo anual dos } \\
\text { danos }\end{array}$ & US\$ 14,67 milhões \\
\hline $\begin{array}{l}\text { Custo externo anual da perda por } \\
\text { MWh }\end{array}$ & $2,26 \mathrm{E}+00 \mathrm{US} \$ / 2000$ \\
\hline \multicolumn{2}{|l|}{ Custo das emissões } \\
\hline $\begin{array}{l}\text { Custo externo anual dos danos } \\
\text { Custo externo das emissões por } \\
\text { MWh }\end{array}$ & $\begin{array}{l}\text { US\$ 8,01 milhões } \\
1,24 \mathrm{E}+00 \text { US } \$ / 2000\end{array}$ \\
\hline CUSTO EXTERNO TOTAL & 3,82E+00 US\$/2000 por MWh \\
\hline
\end{tabular}


Os dados econômicos dizem respeito ao ano de 2000 e são divididos em: reassentamento de pessoas; perda de terras; perda de vidas; perda de produção agrícola e pecuária e custo das emissões. O custo externo total por MWh é dado pelo somatório dos custos externos de cada um dos itens mencionados, totalizando US\$ 3,82 por MWh gerado. Esses resultados são demonstrados na FIG 6.6.

Observa-se que a maior parte dos custos externos está ligada à perda de produções agrícola e pecuária (2,26 US\$2000 por MWh) e emissões de gases $(1,24$ US\$2000 por MWh).

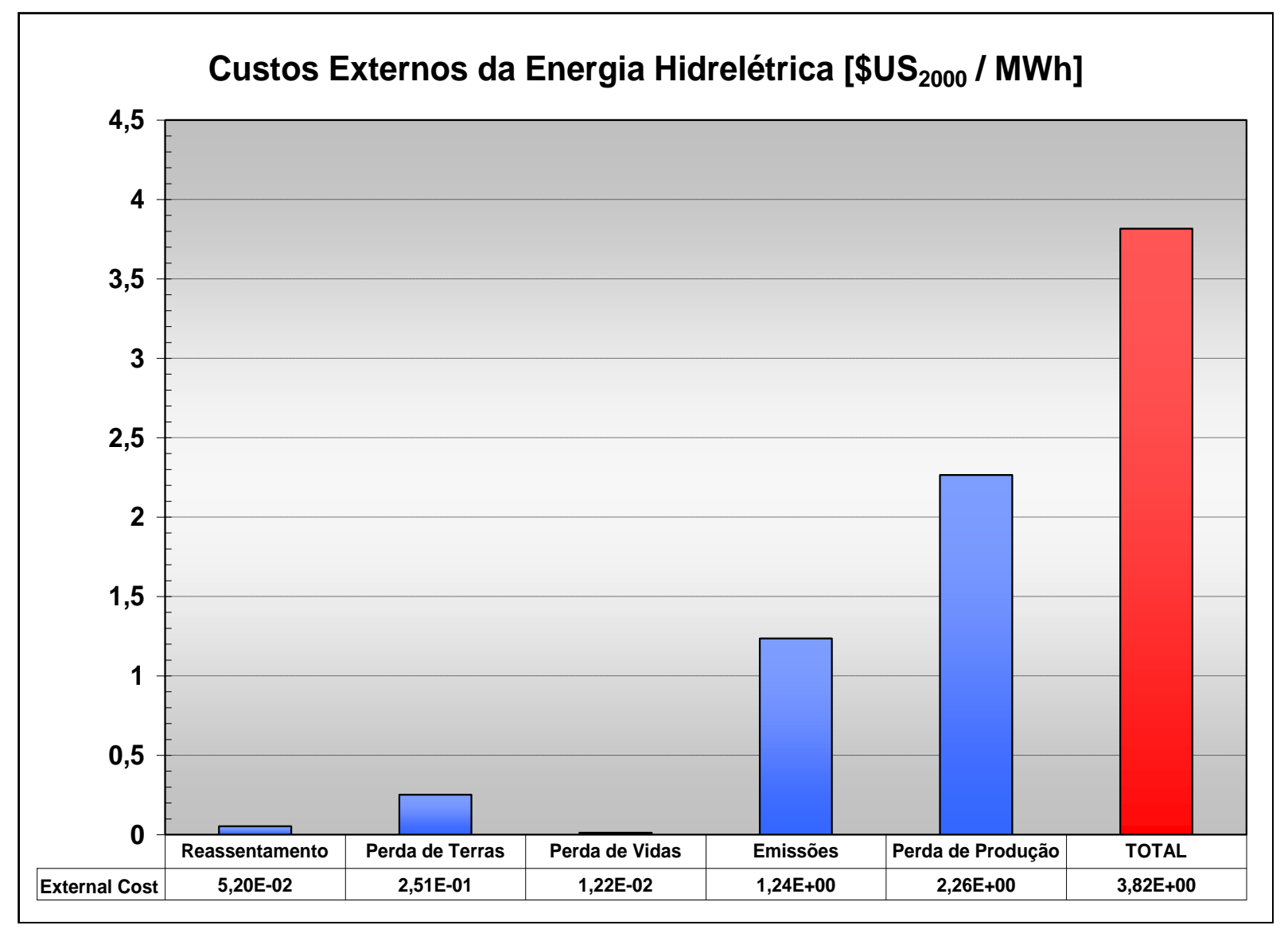

FIGURA 6.6 - Custo ambiental da energia hidrelétrica

Para comparar os resultados do HIDROPACTS com os do NUKPACTS, a unidade do resultado final deverá estar em US\$ por ano. O valor do custo ambiental para hidrelétrica Serra da mesa é de 3,82 US\$/MWh. Por 1 ano este valor é de 33.463,2 US\$MW. Finalmente, valor acima multiplicado pela potência instalada da hidrelétrica (1275 MW) e pelo seu fator de capacidade médio $(0,58)$, demonstra que o custo ambiental relativo a esta instalação é de 24.746.036,4 US\$ por ano ou 2,475E+07 US\$. 
Cabe destacar as emissões de gases durante a operação da hidrelétrica, que produzem um impacto ambiental significativo, representando uma parcela considerável do custo ambiental da hidrelétrica. As emissões de $\mathrm{CH}_{4}$ e $\mathrm{CO}_{2}$, em toneladas, por ano, são demonstradas na FIG 6.7.

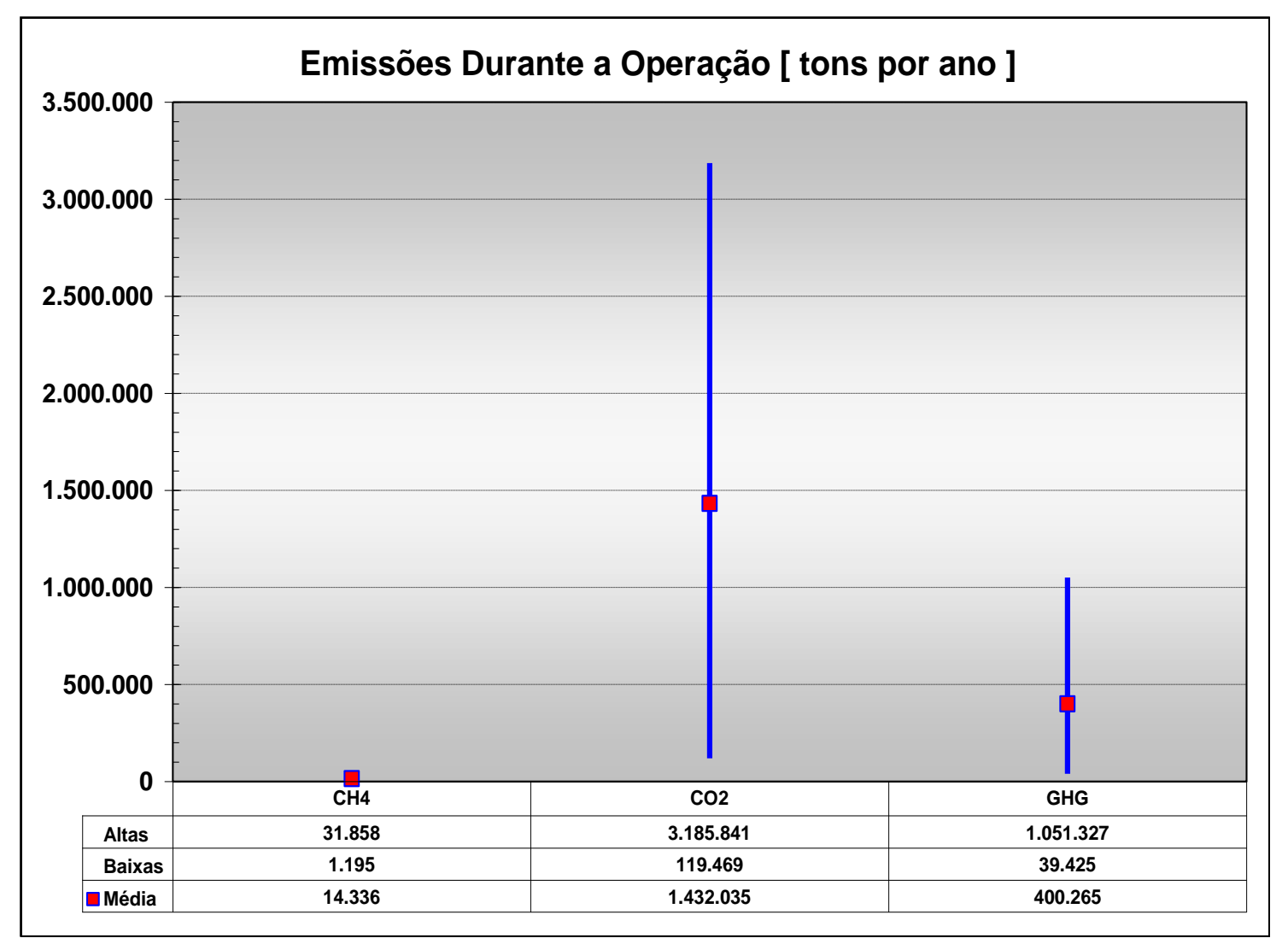

FIGURA 6.7 - Emissões durante a operação da usina hidrelétrica

Observa-se que as emissões de metano $\left(\mathrm{CH}_{4}\right)$ são pequenas quando comparadas com as emissões de gás carbônico $\left(\mathrm{CO}_{2}\right)$. Ainda, as emissões de gases de efeito estufa em carbono equivalente representam, durante a operação da hidrelétrica, mais de 1.000.000 de toneladas por ano liberadas na atmosfera.

Na próxima seção, os resultados serão discutidos de maneira mais aprofundada e as conclusões serão apresentadas.

\subsection{Comparação dos Resultados}

Os reatores nucleares de Angra 2 e 3 e o reator de Balakovo apresentaram resultados similares no tocante ao custo ambiental, possivelmente em razão da potência 
similar. A usina a carvão, considerada como exemplo no programa, também demonstrou um custo ambiental similar ao dos reatores em questão.

Angra 1 apresentou um custo da ordem de mil vezes menor do que os outros reatores nucleares estudados, representando o menor custo ambiental dentre as instalações de potência estudadas.

Em relação à hidrelétrica, seu custo ambiental é da ordem de 10 mil vezes maior do que os reatores de Angra 1, 2, 3 e Balakovo, bem como do que a usina a carvão.

Para melhor visualização dos resultados obtidos, a TAB. 6.23 apresentará os valores dos cálculos de custo ambiental dos reatores nucleares de Angra 1, de Angra 2 e 3, do reator nuclear de Balakovo, da usina a carvão genérica na França e da hidrelétrica Serra da Mesa.

TABELA 6.23 - Comparação dos resultados

\begin{tabular}{l|l}
\hline Instalação & Custo Ambiental (US\$/2000) \\
\hline Angra 1 & $1,78 \mathrm{E}+01$ \\
\hline Angra 2 e 3 & $2,79 \mathrm{E}+03$ \\
\hline Balakovo & $2,14 \mathrm{E}+03$ \\
\hline Usina a carvão & $2,85 \mathrm{E}+03$ \\
\hline Serra da Mesa & $2,475 \mathrm{E}+07$ \\
\hline
\end{tabular}

A partir desses resultados, procurou-se um meio de adequá-los aos custos para o ano de 2012.

Dessa forma, para a correção do dólar do ano de 2000 para 2012, levou-se em consideração a inflação acumulada nesse período, que foi de 1,327 ou 32,7\%, de acordo com dados do The World Bank (2013).

Os resultados dos cálculos de custo ambiental com seus respectivos valores corrigidos para o dólar atual serão apresentados na TAB 6.24.

Embora essa correção tenha sido considerada, os custos das instalações nucleares ainda são baixos, quando comparados com as outras fontes de energia estudadas nesse trabalho. 
TABELA 6.24 - Resultados em US\$/2012

\begin{tabular}{l|l}
\hline Instalação & Custo Ambiental (US\$/2012) \\
\hline Angra 1 & $2,36 \mathrm{E}+01$ \\
\hline Angra 2 e 3 & $3,70 \mathrm{E}+03$ \\
\hline Balakovo & $2,83 \mathrm{E}+03$ \\
\hline Usina a carvão & $3,78 \mathrm{E}+03$ \\
\hline Serra da Mesa & $3,28 \mathrm{E}+07$ \\
\hline
\end{tabular}

Após a utilização da ferramenta SIMPACTS, nesse trabalho, algumas considerações sobre o modo como o programa opera foram feitas e serão listadas a seguir. Algumas questões referentes aos resultados obtidos neste trabalho também serão discutidas.

\subsection{Discussão}

O programa SIMPACTS possui algumas particularidades, que serão apontadas e discutidas nesta seção.

O programa apresenta dados econômicos referentes ao ano 2000. Esses dados não foram atualizados pelo Programa, mas o usuário pode modificá-los, inserindo dados mais recentes. No caso desse trabalho, os dados de 2000 foram utilizados para uma homogeneização do resultado, uma vez que não foi possível obter todos os dados econômicos mais recentes.

O programa apresenta poucos dados rodados como exemplo, dificultando a escolha por instalações para serem comparadas neste trabalho. Além disso, o trabalho seria muito aprimorado caso fosse possível realizar comparações com outras formas de energia, que não foram abordadas, e se fosse possível encontrar na literatura exemplos de cálculos de custo ambiental feitos por meio do programa SIMPACTS.

Cabe salientar que o programa SIMPACTS foi desenvolvido para reatores de potência, e está sendo utilizado para um reator de pesquisa, principalmente para capacitação e conhecimento dos dados de entrada por parte do usuário.

Considera-se também que os dados relativos ao consumo de alimentos no módulo NUKPACTS, embora não tenham muita relevância em relação ao custo final, como demonstrado no ANEXO B, seriam mais realistas se fossem considerados para o estado em questão, e não para o país como um todo, uma vez que o Brasil possui grandes diferenças regionais. 
Foram utilizados dois módulos diferentes do programa para os cálculos realizados, cada qual referido às fontes específicas de energia elétrica. Cada módulo possui diferentes dados de entrada, considerando as especificidades de cada instalação. No entanto, no caso da comparação entre os reatores nucleares e a hidrelétrica, tomou-se como base a equivalência da energia gerada.

Outra questão importante em relação aos módulos é que tanto as usinas a carvão quanto os reatores nucleares têm seus cálculos efetuados por meio do módulo NUKPACTS, que leva em consideração apenas a emissão de radionuclídeos. Foi considerada como uma deficiência do programa o fato de não apresentar um módulo separado para fontes fósseis de energia, onde seria considerada a emissão de gases poluentes, que constituem grande parte dos impactos causados por esse tipo de instalação.

A seguir, como parte da reflexão deste trabalho, uma comparação entre as vantagens e desvantagens das fontes de energia consideradas será apresentada na TAB. 6.25 .

TABELA 6.25 - Vantagens e desvantagens dos tipos de instalação considerados no trabalho

\begin{tabular}{|c|c|c|}
\hline Instalação & Vantagens & Desvantagens \\
\hline Reator nuclear & $\begin{array}{l}\text { Emissões desprezíveis de } \\
\mathrm{CO}_{2} \text { e } \mathrm{CH}_{4} \\
\text { Ocupa área pequena } \\
\text { Não depende de fatores } \\
\text { climáticos }\end{array}$ & $\begin{array}{l}\text { Destinação dos rejeitos } \\
\text { Necessidade de isolar a } \\
\text { instalação após } \\
\text { descomissionamento } \\
\text { Alto custo }\end{array}$ \\
\hline Usina a carvão & $\begin{array}{l}\text { Alto rendimento de produção } \\
\text { de energia } \\
\text { Rápida construção } \\
\text { Podem ser instaladas } \\
\text { próximas às regiões de } \\
\text { consumo }\end{array}$ & $\begin{array}{l}\text { Poluição atmosférica } \\
\text { Custo alto quando comparado } \\
\text { a hidrelétricas }\end{array}$ \\
\hline Hidrelétrica & $\begin{array}{l}\text { Fonte de energia renovável e } \\
\text { barata } \\
\text { Não há gasto com } \\
\text { combustível } \\
\text { Alto potencial hídrico no } \\
\text { país. }\end{array}$ & $\begin{array}{l}\text { Reassentamento de pessoas e } \\
\text { perda de terras } \\
\text { Emissão de } \mathrm{CH}_{4} \\
\text { Alteração do microclima }\end{array}$ \\
\hline
\end{tabular}




\section{CONCLUSÕES}

Os resultados demonstraram que um reator nuclear, quando comparado a uma hidrelétrica de potência similar, possui menores impactos associados e, portanto, um menor custo ambiental, conforme demonstraram os cálculos. Isto se deve ao fato de uma hidrelétrica estar associada a uma série de impactos sociais, como reassentamento e deslocamento, assim como perda de terras produtivas, o que representa um alto custo associado.

Quanto à usina a carvão, conclui-se que o resultado de custo ambiental similar aos das demais instalações deve-se ao fato da não consideração dos gases poluentes liberados na atmosfera. Esses gases causam grande impacto ambiental, e, portanto, sua consideração na análise provavelmente elevaria o custo dessa fonte de energia. Seria necessário um módulo específico do programa para a produção de energia elétrica a partir de fontes fósseis para uma comparação mais adequada.

Ainda, ao analisar os resultados dos impactos do reator de pesquisa IEA-R1, pode-se afirmar que este apresentou um valor muito mais baixo do que os reatores de potência em questão. Isso é facilmente compreendido pela análise dos dados de entrada, principalmente pela observação dos dados referentes à taxa de liberação de radionuclídeos. Por ser um reator de pesquisa, o IEA-R1 quase não emite radionuclídeos para a atmosfera em operação normal, e quando o faz, é em uma parcela muito pequena, comparado aos reatores de potência.

Os reatores de Angra 2 e 3 apresentaram um custo similar ao de Balakovo. Isso pode ser explicado pela semelhança entre as potências desses reatores e por serem todos eles do tipo PWR de mesma geração. O que se espera é que reatores nucleares de nova geração sejam mais seguros e apresentem menor impacto ambiental, devido aos projetos inovadores nesta área.

Com relação à Angra 1, os resultados demonstraram o menor custo ambiental dentre os reatores de potência analisados. Isto pode ser explicado pela menor emissão de radionuclídeos, único parâmetro que a diferencia dos demais reatores.

As dificuldades encontradas durante o trabalho resumem-se a questões relacionadas à obtenção e utilização do programa. No início da execução do trabalho houve dificuldade para a obtenção do programa. Porém, após o seu recebimento pela AIEA, o trabalho se desenvolveu rapidamente, com a ajuda do canal de comunicação online criado 
pela Agência para contato com os usuários do programa, o que muito contribuiu para a execução do trabalho.

Com relação à utilização, o programa não permite que alguns dados de entrada sejam alterados como, por exemplo, a paridade de poder aquisitivo de cada país, que está fixo para o ano 2000 e repercute em outros dados de entrada do programa. Tal alteração seria importante para tornar os resultados mais verossímeis, enriquecendo o trabalho.

\subsection{Propostas Futuras}

A AIEA está desenvolvendo uma nova versão do programa, que provavelmente estará disponível no ano de 2014 e poderá ser utilizada para a realização de outros cálculos de custo ambiental relacionados com as fontes estudadas. Também será solicitado o programa fonte do SIMPACTS para adequá-lo à realidade brasileira.

Além disso, um projeto para a criação de um banco de dados mais confiável, que possibilitará a atualização dos dados de entrada, está em desenvolvimento. Em paralelo, um projeto para o levantamento de casos de câncer nas proximidades de algumas instalações nucleares escolhidas, em um raio de 1 km, 10km, 100 km e 1000 km, no Brasil está sendo desenvolvido. 


\section{ANEXO A - Equações utilizadas no NUKPACTS}

A seguir serão apresentadas as equações adicionais que não foram demonstradas no corpo do trabalho, e que são utilizadas para cada um dos cálculos descritos.

As equações apresentadas abaixo foram retiradas do Manual do Módulo NUKPACTS, desenvolvido pela AIEA (IAEA, 2003b).

Modelo de dispersão da pluma gaussiana (A.1):

$$
C(i, d)=\frac{Q}{2 \Pi^{2} x \delta_{z} \bar{u}} * e^{-\frac{x}{u}(\lambda+\Lambda)} * e^{\left(\frac{V d}{H} * \frac{x}{u}\right)}
$$

Onde:

$\mathrm{C}(\mathrm{i}, \mathrm{d})=$ concentração atmosférica de radionuclídeo i na distância d da fonte $\left(\mathrm{Bq}\right.$ por $\left.\mathrm{m}^{3}\right)$;

$\mathrm{Q}=$ índice de emissão de radionuclídeo i (Bq por segundo);

$\mathrm{H}=$ altura de liberação efetiva $(\mathrm{m})$;

$\mathrm{x}=$ distância radial $(\mathrm{m})$;

$\mathrm{u}=$ velocidade média anual do vento ( $\mathrm{m}$ por segundos);

$\lambda=$ decomposição radioativa constante de radionuclídeo $\mathrm{i}$;

$\mathrm{Vd}=$ velocidade de decomposição (m por segundos);

$\Lambda=$ coeficiente de depleção úmida;

$\delta z=$ desvio padrão da distribuição gaussiana horizontal e vertical.

A concentração calculada do modelo de dispersão gaussiana é, então, usada para determinar os níveis de doses de inalação de radionuclídeos no ar com a seguinte equação (A.2):

$$
\mathrm{I}_{\text {inh }}(\mathrm{I}, \mathrm{d})=\mathrm{C}(\mathrm{I}, \mathrm{d}) \times \mathrm{Br}
$$

Onde:

$\mathrm{I}_{\mathrm{inh}}=$ consumo individual médio anual do radionuclídeo i em dias $\left(\mathrm{Bq}\right.$ por $\left.\mathrm{m}^{2}\right)$;

$\mathrm{Br}=$ índice de frequência respiratória média anual de uma pessoa. 
A equação (A.3) calcula o consumo médio anual individual de cada radionuclídeo, usando a concentração calculada na equação (A.2).

$$
\mathrm{AH}_{\text {inh }}(\mathrm{I}, \mathrm{d})=\mathrm{I}_{\mathrm{inh}}(\mathrm{I}, \mathrm{d}) \times \mathrm{EDE}_{\mathrm{inh}}
$$

Onde:

$\mathrm{AH}_{\mathrm{inh}}(\mathrm{I}, \mathrm{d})=$ dose média individual da inalação de radionuclídeo I na distância d da fonte; $\operatorname{EDE}_{\text {inh }}(\mathrm{I})=$ dose efetiva equivalente da inalação do radionuclídeo I, durante 50 anos para um adulto ( $\mathrm{Sv}$ por $\mathrm{Bq})$.

Usando o consumo médio individual de cada radionuclídeo e a dose equivalente efetiva para um adulto acima de 50 anos, a dose média individual para cada radionuclídeo é calculada facilmente na equação (A.2). Depois, todas as doses médias individuais são somadas na equação (A.3), e a dose média individual da inalação de todos os radionuclídeos é determinada.

$\mathrm{H}_{\mathrm{inh}}(\mathrm{d})=\Sigma A H_{\text {inh }}(\mathrm{I}, \mathrm{d})$

Onde:

$\mathrm{H}_{\mathrm{inh}}(\mathrm{d})$ = dose média individual da inalação de todos os radionuclídeos na distância d da fonte.

A dose coletiva anual total é, então, calculada (A.5) por meio de doze bandas de distância, multiplicando a densidade populacional conhecida pela dose individual média da inalação de todos os radionuclídeos calculada acima.

$\mathrm{TH}_{\mathrm{inh}}=\Sigma H_{\text {inh }}(d) \mathrm{x} \mathrm{P}(\mathrm{d})$

Onde:

$\mathrm{TH}_{\mathrm{inh}}=$ dose coletiva total anual para todas as 12 bandas de distância (homem Sv por ano de emissões);

$\mathrm{P}(\mathrm{d})=$ população total (pessoas);

$\mathrm{P}=\left(\Pi r_{1}^{2}-\Pi r_{2}^{2}\right) \times$ densidade populacional média. 
A dose coletiva total de radionuclídeos imersos nas nuvens por meio das doze bandas de pluma gaussiana é calculada com as seguintes equações (A.6 a A.8):

$\mathrm{AH}_{\text {ext.c }}(\mathrm{I}, \mathrm{d})=\mathrm{C}(\mathrm{I}, \mathrm{d}) \times$ EDEext.c $(\mathrm{I})$

Onde:

$\mathrm{AH}_{\text {ext.c }}(\mathrm{I}, \mathrm{d})$ = dose média individual de exposição externa ao radionuclídeo I na nuvem passageira na distância d da fonte $(\mathrm{Sv})$;

$\operatorname{ED}_{\text {ext.c }}(\mathrm{I}, \mathrm{d})=$ dose efetiva equivalente da exposição ao radionuclídeo I na nuvem passageira ( $\mathrm{Sv}$ pó $\mathrm{Bq}$ por $\mathrm{m}^{2}$ ).

$\mathrm{H}_{\mathrm{ext}, \mathrm{c}}(\mathrm{d})=\Sigma A H_{\text {ext } c}(I, d)$

Onde:

$\mathrm{H}_{\text {ext.c }}(\mathrm{d})$ = dose individual média da exposição a todos os radionuclídeos na nuvem passageira sobre distância d da fonte.

$\mathrm{TH}_{\mathrm{ext}, \mathrm{c}}=\Sigma H_{\text {ext, }}(d) \times \mathrm{P}(\mathrm{d})$

Onde:

$\mathrm{TH}_{\text {ext.C }}=$ dose coletiva total para todas as 12 bandas de distância (homem Sv por ano de emissões);

$\mathrm{P}(\mathrm{d})=$ população total na região de distância d da fonte.

A dose coletiva total de radionuclídeos depositados no solo por meio das doze bandas é calculada com as seguintes equações (A.9 a A.11):

$$
\mathrm{AH}_{\text {ext,g }}(\mathrm{I}, \mathrm{d})=\mathrm{w}(\mathrm{I}, \mathrm{d}) \mathrm{x} \operatorname{EDEext}, \mathrm{g}(\mathrm{I})
$$

Onde:

$\mathrm{AH}_{\text {ext,g }}(\mathrm{I}, \mathrm{d})=$ dose individual média de exposição externa de radionuclídeo I integrado no começo da deposição (Sv);

$\mathrm{W}(\mathrm{I}, \mathrm{d})=\mathrm{C}(\mathrm{I}, \mathrm{d}) \times \mathrm{Vd}=$ índice de deposição média de radionuclídeos $\mathrm{I}$ em d $\left(\mathrm{Bq}\right.$ por $\mathrm{m}^{2}$, segundo);

$\operatorname{EDE}_{\text {ext,g }}(\mathrm{I})=$ equivalente de dose efetiva da exposição a radionuclídeo I depositado no solo integrado do começo da deposição até o tempo $\mathrm{t}\left(\mathrm{Sv}\right.$ por Bq por $\mathrm{m}^{2} / \mathrm{segundo}$ ). 
$\mathrm{H}^{\mathrm{ext}, \mathrm{g}}(\mathrm{d})=\Sigma \mathrm{AH}_{\mathrm{ext}, \mathrm{g}}(\mathrm{I}, \mathrm{d})$

Onde:

$\mathrm{H}_{\text {ext,g }}(\mathrm{d})$ = dose individual média da exposição de todos os radionuclídeos depositados no solo.

$\mathrm{TH}_{\mathrm{ext}, \mathrm{g}}=\Sigma \mathrm{H}_{\mathrm{ext}, \mathrm{g}}(\mathrm{d}) \times \mathrm{P}$

Onde:

$\mathrm{TH}_{\mathrm{ext}, \mathrm{g}}=$ dose total coletiva para todas as 12 bandas de distância (homem Sv por ano de emissões)

$\mathrm{P}(\mathrm{d})=$ população total (Pessoas) 


\section{ANEXO B - Teste de Sensibilidade do SIMPACTS}

Ao se utilizar um programa de cálculo, é importante verificar como cada um dos parâmetros de entrada influencia no resultado final. Assim, foram feitos testes mudando as variáveis de entrada de cada um dos módulos estudados, verificando de que forma estas mudanças afetam o custo ambiental das instalações.

\section{NUKPACTS}

Para a realização dos testes em relação ao módulo NUKPACTS, foram utilizados os dados de entrada da instalação nuclear de Balakovo como referência, em razão de serem dados contidos no próprio programa e, portanto, sem a possibilidade de erros por parte do usuário. Sendo assim, os seguintes testes foram realizados:

(1) teste relativo à altura da chaminé. Para uma altura de chaminé de 36 metros, o custo ambiental final foi de 2,14E+03. O valor de altura de chaminé foi alterado para ver o quanto afetaria o custo final. Na TAB. B.1 observa-se que quanto maior a altura da chaminé, menor o impacto das emissões atmosféricas e, portanto, menor custo ambiental. Nota-se, porém, que a variação da altura das chaminés não apresenta mudanças significativas no resultado final.

TABELA B.1 - Teste de altura da chaminé

\begin{tabular}{l|l}
\hline Altura da Chaminé $(\mathrm{m})$ & Custo ambiental (US\$/2000) \\
\hline 10 & $2,24 \mathrm{E}+03$ \\
\hline 20 & $2,21 \mathrm{E}+03$ \\
\hline 36 (caso original) & $2,14 \mathrm{E}+03$ \\
\hline 40 & $2,12 \mathrm{E}+03$ \\
\hline
\end{tabular}

(2) teste relativo à taxa de liberação de radionuclídeos. Para cada radionuclídeo listado nos dados de entrada, um teste foi realizado da seguinte maneira: um a um dos radionuclídeos liberados foram igualados a zero e, então, observou-se como cada radionuclídeo, igual a zero, afetaria o custo final. As variações do custo ambiental final podem ser visualizadas na TAB. 
B.2. Observa-se que somente a mudança de dois radionuclídeos altera significativamente os resultados, sendo eles o C-14 e o Xe-133, que passam a representar $38 \%$ e $63 \%$ do seu valor original, respectivamente.

TABELA B.2 - Teste de liberação de radionuclídeos

\begin{tabular}{l|l}
\hline Radionuclídeos & Custo ambiental (US\$/2000) \\
\hline Todos radionuclídeos $>0$ (caso original) & $2,14 \mathrm{E}+03$ \\
\hline $\mathrm{H}-3=0$ & $2,12 \mathrm{E}+03$ \\
\hline $\mathrm{C}-14=0$ & $8,37 \mathrm{E}+02$ \\
\hline Co-58 $=0$ & $2,14 \mathrm{E}+03$ \\
\hline Co-60 $=0$ & $2,13 \mathrm{E}+03$ \\
\hline $\mathrm{Kr}-85=0$ & $2,13 \mathrm{E}+03$ \\
\hline $\mathrm{I}-131=0$ & $2,11 \mathrm{E}+03$ \\
\hline $\mathrm{I}-133=0$ & $2,14 \mathrm{E}+03$ \\
\hline $\mathrm{Xe}-133=0$ & $1,35 \mathrm{E}+03$ \\
\hline Cs-134 =0 & $2,14 \mathrm{E}+03$ \\
\hline Cs-137 =0 & $2,14 \mathrm{E}+03$ \\
\hline
\end{tabular}

(3) teste realizado com os dados referentes à densidade populacional. Para fins de comparação, utilizou-se as densidades demográficas local e regional de Angra 2 no reator de Balakovo. Essa alteração na densidade demográfica afetou o resultado em uma ordem de grandeza 10 vezes maior, fazendo com que o custo ambiental passasse de 2,14E+03 para 1,59E+04. Com isso, constata-se que quanto maior a densidade demográfica do local e região que a instalação está inserida, maior o custo ambiental. Estes resultados são apresentados na TAB. B.3. 
TABELA B.3 - Teste de densidade demográfica

\begin{tabular}{l|c|c|c}
\hline Reator & $\begin{array}{l}\text { Densidade Populacional } \\
\left.\text { Local (pessoas } / \mathrm{km}^{2}\right)\end{array}$ & $\begin{array}{l}\text { Densidade Populacional } \\
\text { Regional }\left(\text { pessoas } / \mathrm{km}^{2}\right)\end{array}$ & $\begin{array}{l}\text { Custo ambiental } \\
(\mathrm{US} \$ / 2000)\end{array}$ \\
\hline Balakovo & 82,3 & 35,2 & $2,14 \mathrm{E}+03$ \\
\hline Angra 2 & 246,02 & 365,23 & $1,59 \mathrm{E}+04$ \\
\hline
\end{tabular}

(4) teste realizado relativo à velocidade do vento. A velocidade do vento da região de Balakovo foi alterada de pouco mais de $3 \mathrm{~m} / \mathrm{s}$ para $7,5 \mathrm{~m} / \mathrm{s}$, velocidade esta da região onde está localizada Angra 2. Essa mudança provocou uma considerável alteração no resultado final, fazendo com que o custo se reduzisse em torno de $11 \%$, ou seja, passasse de 2,14E+03 para 1,92E+03. Conclui-se, então, que quanto maior a velocidade do vento na região, menor o custo ambiental, uma vez que o vento permite que os radionuclídeos se dissipem melhor na atmosfera. A TAB. B.4 demonstra estes resultados.

TABELA B.4 - Teste de velocidade do vento

\begin{tabular}{l|c|c}
\hline Reator & $\begin{array}{l}\text { Velocidade do vento } \\
(\mathrm{m} / \mathrm{s})\end{array}$ & $\begin{array}{l}\text { Custo ambiental } \\
(\mathrm{US} \$ / 2000)\end{array}$ \\
\hline Balakovo & 3,1 & $2,14 \mathrm{E}+03$ \\
\hline Angra 2 & 7,5 & $1,92 \mathrm{E}+03$ \\
\hline
\end{tabular}

(5) o último teste foi relativo ao parâmetro de consumo de alimentos. O valor de consumo de cada alimento no país do reator de Balakovo foi alterado para $10 \%$ a mais e $10 \%$ a menos. Observa-se, na Tabela B.5, que o aumento ou diminuição do consumo de cada alimento não causou alteração no custo final. Somente houve uma alteração insignificante de US\$100 ao se aumentar em $50 \%$ o consumo de cada alimento. 
TABELA B.5 - Teste de consumo de alimentos

\begin{tabular}{l|c|c|c|c}
\hline $\begin{array}{l}\text { Consumo de } \\
\text { Alimentos }\end{array}$ & Exemplo & $+10 \%$ & $-10 \%$ & $+50 \%$ \\
(kg/pessoa/ano) & & & & \\
\hline Carne de Vaca & 18 & 19,80 & 16,20 & 27 \\
\hline Carne de Porco & 20 & 22 & 18 & 30 \\
\hline Carne de Frango & 08 & 8,8 & 7,2 & 12 \\
\hline Carne de Ovelha & 07 & 7,7 & 6,3 & 10,5 \\
\hline Cereais & 67 & 73,7 & 36 & 60 \\
\hline Vegetais verdes & 40 & 44 & 45 & 225 \\
\hline Tubérculos & 50 & 55 & 135 & 19,5 \\
\hline Leite Fresco & 150 & 165 & $2,14 \mathrm{E}+03$ & $2,15 \mathrm{E}+03$ \\
\hline Leite (outros) & 13 & 14,3 & & \\
\hline Custo ambiental & $2,14 \mathrm{E}+03$ & $2,14 \mathrm{E}+03$ & & \\
(US\$/2000) & & & & \\
\hline
\end{tabular}

Os testes realizados demonstram a importância de algumas variáveis de entrada do NUKPACTS na composição do resultado final obtido pelo programa, ou seja, no custo ambiental total da fonte de energia estudada. Algumas variáveis afetam o resultado final mais do que outras, permitindo uma melhor visualização e entendimento da razão pela qual algumas regiões, onde a instalação nuclear se encontra, bem como diferentes fontes de energia elétrica, condições climáticas e emissões, têm como resultado um custo ambiental maior do que outras.

Por meio dos testes, pode-se constatar que dentre as variáveis consideradas, a densidade demográfica regional e local da região onde a instalação está localizada é a que mais influencia no impacto e, consequentemente, no custo ambiental. A taxa de emissão de radionuclídeos também é uma variável importante, na medida em que quando a emissão de dois radionuclídeos em particular (C-14 e Xe-133) é igual a zero, o custo ambiental tornase consideravelmente menor. Tal modificação do resultado permite concluir que esses dois radionuclídeos devem ter sua taxa de emissão minimizada ao máximo, uma vez que sua liberação provoca impactos e custos consideráveis à instalação. 
Variáveis como velocidade do vento e altura da chaminé influenciam no custo ambiental final em menor grau, de maneira que a diminuição da altura da chaminé e uma menor velocidade do vento ocasionam um aumento no custo ambiental final. Ainda cabe observar que entre essas duas variáveis, a velocidade do vento tem maior influência no custo ambiental, segundo os testes realizados.

O consumo de alimentos representa uma parte ínfima do cálculo, sendo que a alteração dos valores deste parâmetro praticamente não influencia no custo ambiental final.

\section{HYDROPACTS}

O mesmo foi feito para o módulo HYDROPACTS do programa, sendo a instalação Serra da Mesa, estudada no trabalho, utilizada como referência. Assim como Balakovo, essa instalação tem os dados de entrada contidos no próprio programa. Para a hidrelétrica em questão, foram realizados os seguintes testes:

(1) teste relativo à altura da barragem. Para uma altura de 150 metros, o custo ambiental foi de 3,82US\$ por MWh. O valor da altura da barragem foi modificado para diferentes valores, para ver o quanto afetaria o custo final. É possível observar que quanto maior a altura da barragem, maior o custo ambiental, sendo que o valor do custo cresce de maneira considerável ao se aumentar a altura da barragem, conforme demonstrado na TAB B.6.

TABELA B.6 - Teste de altura da barragem

\begin{tabular}{l|l}
\hline Altura da barragem (metros) & Custo ambiental (US\$2000/MWh) \\
\hline 100 & 2,96 \\
\hline 120 & 3,26 \\
\hline 150 (caso original) & 3,82 \\
\hline 200 & 5,01 \\
\hline 250 & 6,55 \\
\hline
\end{tabular}

(2) outro teste realizado foi referente à capacidade (potência) da instalação. Diferentemente do NUKPACTS, o HYDROPACTS apresenta a capacidade da planta em MW elétricos como um dos dados de entrada. O resultado final desse módulo é dado em US\$2000/MWh e, portanto, quanto maior a potência da planta menor será o custo ambiental, já que o resultado é dividido por MWh. 
Os resultados para esse teste são apresentados na TAB. B.7.

TABELA B.7 - Teste de capacidade da instalação

\begin{tabular}{l|l}
\hline Capacidade da planta (MW) & Custo ambiental (US\$2000/MWh) \\
\hline 1000 & 4,87 \\
\hline 1200 & 4,05 \\
\hline 1275 (caso original) & 3,82 \\
\hline 1300 & 3,74 \\
\hline 1350 & 3,6 \\
\hline
\end{tabular}

(3) foi feito um teste relativo à parcela de pessoas reassentadas/compensadas.

No cálculo original, essa parcela é de 50\%. Resultados na TAB.B.8 demonstram que quanto maior essa parcela, menor o custo ambiental.

TABELA B.8 - Teste de parcela de pessoas reassentadas/compensadas

\begin{tabular}{l|l}
\hline Parcela $(\%)$ & Custo ambiental (US\$2000/MWh) \\
\hline 25 & 3,84 \\
\hline 50 (caso original) & 3,82 \\
\hline 75 & 3,79 \\
\hline
\end{tabular}

(4) o último teste referente a esse módulo foi o de preço do carbono. As emissões de carbono representam parte significativa do custo ambiental em hidrelétricas e, por isso, o valor do preço do carbono, em dólares por tonelada, foi alterado. Observa-se que quanto maior o preço do carbono, maior o custo ambiental, conforme TAB. B.9.

TABELA B.9 - Teste de preço do carbono

\begin{tabular}{l|l}
\hline Preço do carbono (US\$/ton) & Custo ambiental (US\$2000/MWh) \\
\hline 15 & 3,51 \\
\hline 20 (caso original) & 3,82 \\
\hline 30 & 4,43 \\
\hline 50 & 5,67 \\
\hline
\end{tabular}


Assim como no módulo NUKPACTS, pode-se observar que algumas variáveis afetam o resultado final mais do que outras. Por meio dos testes, pode-se compreender melhor a composição do custo final, assim como meios de minimizar o impacto e, consequentemente, o custo ambiental.

Para o HYDROPACTS, dentre as variáveis consideradas, o preço do carbono é a que mais influencia no custo ambiental, seguido pela altura da barragem. As emissões de carbono correspondem à boa parte do custo ambiental de uma hidrelétrica, por isso seu custo afeta diretamente o custo total ambiental da hidrelétrica estudada. Em relação à altura da barragem, o teste demonstra que barragens menores impactam menos o ambiente, gerando um custo ambiental menor. No que diz respeito ao impacto ambiental, pode-se concluir que pequenas centrais hidrelétricas são melhores do que grandes.

As outras variáveis analisadas, como capacidade da instalação e parcela de pessoas reassentadas/compensadas afetam menos o custo ambiental final. A potência da instalação só possui efeito direto no resultado em razão deste ser dado em custo por MWh. Portanto, quanto maior a capacidade de produção de MWh da planta, maior a divisão e menor o resultado do custo ambiental. Em relação à parcela de pessoas, o teste demonstrou que quanto mais pessoas forem reassentadas ou compensadas de alguma forma, menor será o custo socioambiental. 


\section{REFERÊNCIAS BIBLIOGRÁFICAS}

ALVIM, C. F.; FEIDELMAN, F.; MAFRA, O.; FERREIRA, O. C. Energia nuclear em um cenário de trinta anos. Estudos avançados, v. 21, n.59, 2007.

ANUÁRIO BRASILEIRO DO ARROZ 2011. Editora Gazeta. Disponível em: http://www.gaz.com.br/tratadas/eo_edicao/3/2011/03/20110311_7c80f2d35/pdf/2803_arro z2011flip.pdf. Acesso em: 23 abr. 2012.

ANUÁRIO BRASILEIRO DE AVES E SUÍNOS 2011. Editora Gazeta. Disponível em: http://www.gaz.com.br/tratadas/eo_edicao/21/2011/05/20110511_7263f739d/pdf/2804_av es2011_flip.pdf. Acesso em: 23 abr. 2012.

ANUÁRIO BRASILEIRO DAS HORTALIÇAS 2011. Editora Gazeta. Disponível em: < http://www.gaz.com.br/tratadas/eo_edicao/6/2011/06/20110614_572861e72/pdf/2919_hort alicas2011.pdf> Acesso em: 02 maio 2012.

ANUÁRIO BRASILEIRO DA PECUÁRIA 2011. Editora Gazeta. Disponível em: http://www.gaz.com.br/tratadas/eo_edicao/22/2011/08/20110816_d0d5c74b5/pdf/2921_pe curia_2011.pdf. Acesso em: 23 abr. 2012.

ATHAR, G.R. Radiological Emissions I. IAEA In: WORKSHOP ON THE USE OF THE SIMPACTS MODEL FOR ESTIMATING HUMAN HEALTH AND ENVIRONMENTAL DAMAGES FROM ELECTRICITY GENERATIONS, May 12-23, 2003, Trieste, Italy.

BAECHER G., PATE M.E. Risk of Dam Failure in Benefit-Cost Analysis. Water Resources Research, v.16, n.3, p. 449-456, 1980.

BRANDESTEN C., MOLLER B., and U. NORSTEDT. Swedish dam safety and the potential of enhancement. In: CONFERENCE ON HYDROPOWER, ENERGY, AND THE ENVIRONMENT. Jun 14-16, 1993, Stockholm. Proceedings of the IEA. Stockholm: IEA, 1993. p.87-95.

BRASIL. Ministério de Minas e Energia. Projeto Luz para Todos. Disponível em: http://luzparatodos.mme.gov.br/luzparatodos/Asp/o_programa.asp Acesso em: 06 mar. 2012.

BRODE, R.W. e WANG, J. User's Guide for the Industrial Source Complex (ISCLT2) Dispersion Models, Volumes I, II and III, Technical Reports EPA-450/492-008a-c, US Environmental Protection Agency, Research Triangle Park, NC, USA, 1992.

BROWN, C.A. e W.J. GRAHAM. Assessing the Threat to Life from Dam Failure. Water Resources Bulletin, v. 24, n. 6, p. 1303-1309, 1988.

CARBONELL, L.T. Radiological Emissions I. IAEA In: WORKSHOP ON THE USE OF THE SIMPACTS MODEL FOR ESTIMATING HUMAN HEALTH AND 
ENVIRONMENTAL DAMAGES FROM ELECTRICITY GENERATIONS, May 12-23, 2003, Trieste, Italy

CARDOSO, E. M. Aplicação da Energia Nuclear. Comissão Nacional de Energia Nuclear (CNEN), Apostilas Educativas. Disponível em:

<http:// www.cnen.gov >. Acesso em: 12 abr. 2011.

CEPEL - Centro de Pesquisas de Energia Elétrica. Atlas do Potencial Eólico Brasileiro. Brasília, 2001. Disponível em:

<http://www.cresesb.cepel.br/publicacoes/download/atlas_eolico/Atlas\%20do\%20Potencia 1\%20Eolico\%20Brasileiro.pdf> Acesso em: 18 jun 2011.

CEPA - Centro de Ensino e Pesquisa Aplicada. Energia - A Essência dos Fenômenos. Disponível em <http://cepa.if.usp.br/energia/energia1999/Grupo1A/carvao.html> Acesso em: 29 set 2013.

CETESB - Companhia Ambiental do Estado de São Paulo. Qualidade do ar no Estado de São Paulo 2010. São Paulo: CETESB, 2011.

CHRISTIAN J.T. e G.B. BAECHER. Dam Failure, Excerpt from Why Things Fall Apart: A Collection of Readings on Lessons Learned from Systems Failures. Draft Report, Setembro, 1999. Disponível em: http://www.glue.umd.edu/ gbaecher/WinnipegRisk. Acesso em: 15 jan. 2013.

COASE, Ronald H. The Problem of Social Cost. The Journal of Law and Economics, October, p. 1-44, 1960.

COMISSÃO NACIONAL DE ENERGIA NUCLAR - CNEN. Reator Multipropósito Brasileiro pode tornar Brasil autossuficiente na produção de radioisótopos. Disponível em: http://www.cnen.gov.br/noticias/lst-noticias informe.asp?ano=2009\&num=1. Acesso em: 22 jan. 2011.

CORREIO BRASILIENSE. CNEN desenvolve projeto de reator para atender setor de medicina nuclear. Agência Brasil, 23/06/2010. Disponível em: http://www.correiobraziliense.com.br/app/noticia/brasil/2010/06/23/interna_brasil,199135/ index.shtml. Acesso: em 22 jan. 2011.

CZARNOWSKA, L.; FRANGOPOULOS, C.A., Dispersion of pollutants, environmental externalities due to a pulverized coal power plant and their effect on the cost of electricity, Energy, v.41, n. 1,p. 212-219, 2011.

DOE/EIA. International Energy Outlook 2001, DOE/EIA-0484(2001), U.S. Department of Energy/Energy Information. Administration, Washington, DC, March 2001, Disponível em: www.eia.doe.gov/oiaf/ieo/index.html. Acesso em: 15 jan. 2013.

DONALD, A.M. Nuclear Expansion: Projections and Obstacles in the Far East and South Asia. The World Nuclear Association 2004. Annual Symposium. Disponível em: www.world-nuclear.org/sym/2004/macdonald.htm. Acesso: em 29 fev. 2012. 
ELETRONUCLEAR. Final Safety Analysis Report - Central Nuclear Almirante Álvaro Alberto - Unit 1" ELETRONUCLEAR S.A, Rev. 33. 2005.

ELETRONUCLEAR. Final Safety Analysis Report - Central Nuclear Almirante Álvaro Alberto - Unit 2" ELETRONUCLEAR S.A, Doc Ident. MA/2-0809.2/060000, Rev. 3. 2006

ELETRONUCLEAR. Panorama da Energia Nuclear no Mundo. Junho, 2009. Disponível em: http://www.eletronuclear.gov.br/pdf/panorama.pdf. Acesso em: 24 abr. 2010.

ELETRONUCLEAR. Eletrobrás Termonuclear S.A. Disponível em: < http://www.eletronuclear.gov.br/AEmpresa/CentralNuclear/InformaçõesAngra1.aspx> Acesso em: 06 fev. 2013.

EMBRAPA. Embrapa Gado de leite. Tabela: Brasil - Produção, importação, exportação e consumo de leite, 2010. Disponível em:

<www.cnpgl.embrapa.br/nova/informacoes/estatisticas/consumo/tabela0706.php> Acesso em: 31 jan. 2012.

EMBRAPAa. Cultivo do milho. Setembro/2011. Disponível em:

http://sistemasdeproducao.cnptia.embrapa.br/FontesHTML/Milho/CultivodoMilho_7ed/ec onomia.htm. Acesso em: 23 abr. 2012.

EMBRAPAb. Disponível em: http://www.cnpt.embrapa.br/noticias/2011/not1116.htm. Acesso em: 23 abr. 2012.

FURNAS. Parque Gerador - Usina Hidrelétrica da Serra da Mesa. Disponível em: http://www.furnas.com.br/hotsites/sistemafurnas/usina_hidr_serramesa.asp. Acesso em 27 maio 2013.

GEO- Global Energy Observatory. Overview of Energy Systems by Country. Disponível em: <http://globalenergyobservatory.org/list.php?db=PowerPlants\&type=Coal $>$ Acesso em 29 set. 2013.

GODDARD, W.B; GODDARD, C.B. A comparative study of the total environmental costs associated with electrical generation systems. Renewable Energy, v. 3, n. 2/3, p. 113-120, 1993.

GOLDEMBERG, J.; O, LUCON. Energia, Meio Ambiente e Desenvolvimento. 2 ed. São Paulo: Edusp - Editora da Universidade de São Paulo, 2007.

GONÇALVES, O. D. ; ALMEIDA, I. P. S. A energia nuclear e seus usos na sociedade. Ciência Hoje, v. 37, p. 36-44, 2005.

HAINOUN, A; ALMOUSTAFA, A.; M.S. ALDIN. Estimating the health damage costs of Syrian electricity generation system using impact pathway approach. Energy, v. 35, p.628638, 2010.

HOCHMAN, JOEL A. Cleaning Up Environmental Accounting. National Public Accountant, June, p. 20-23, 1998. 
IAEA - Department of Nuclear Energy. B-Glad. Viena, Austria, 1999.

IAEA Decades. Case Studies to Assess and Compare different Energy Sources in Sustainable Energy and Electricity Supply Strategies. - TECDOC- 1370. Final Report of a Co-ordinated Project 1997-2000.

IAEA. Comparative Assessment for Sustainable Energy Development. Annual Report 2001. IAEA: Viena, Austria, 2001.

IAEA (a) Simplified Methodology to Quantify Environmental Impacts of Large Hydro

Dams. Methodology and Model Guide. Vienna, Austria. Março, 2003.

IAEA (b). Review of Nuckpacts: An Environmental Assessment Package. Vienna, Austria. Agosto, 2003.

IAEA. Tools and Methodologies for Energy System Planning and Nuclear Energy System Assessments. Sustainable Energy for the 21st Century. IAEA: Viena, Austria, 2009. Disponível em: http://www.iaea.org/NuclearPower/Downloads/INPRO/Files/INPROPESSbrochure.pdf. Acesso em: 28 nov. 2011.

IAEA. Department of Nuclear Energy: SIMPACTS Disponível em: http://www.iaea.org/OurWork/ST/NE/Pess/PESSenergymodels.shtml. Acesso em: $01 \mathrm{dez}$. 2011.

IAEA. Externalities of Energy. A Research Project of the European Commision. Disponível em: http://www.externe.info/. Acesso em: 06 mar. 2012.

IAEA. PRIS - Power Reactor Information System. Disponível em: <http://www.iaea.org/programmes/a2/> Acesso em: 22 jan. 2014.

IBGE - Instituto Brasileiro de Geografia e Estatística. Produção Agrícola Municipal Cereais Leguminosas e Oleaginosas. 2007. Disponível em: < http://www.ibge.gov.br/home/estatistica/economia/pamclo/2007/pamclo2007.pdf> Acesso em: 24 abr. 2012.

IBGE - Instituto Brasileiro de Geografia e Estatística. CENSO 2010 - SÃO PAULO. 29 de novembro de 2010. Acesso em: 31 jan. 2012.

ICOLD. World Register of Dams, International Commission on Large Dams (ICOLD), 1998, Paris.

IEA - International Energy Agency. Benign Energy, The Environmental Implications of Renewables, Appendix F, Large Scale Hydro, Report by the International Energy Agency (IEA), October 1998, Disponível em: <http://www.iea.org/pubs/studies/files/benign/pubs/index.htm>. Acesso em: 15 jan. 2013.

IEA - International Energy Agency. Energy Balances of non-OECD Countries. International Energy Agency, Paris, 2005. 
IEA - International Energy Agency. World Energy Outlook 2011. Disponível em: <http://www.iea.org/publications/freepublications/publication/WEO2011_WEB.pdf> Acesso em 29 set. 2013.

IPEN - INSTITUTO DE PESQUISAS ENERGÉTICAS E NUCLEARES. Relatório Final de Análise de Segurança. São Paulo, 1998.

IPEN - INSTITUTO DE PESQUISAS ENERGÉTICAS E NUCLEARES. IEA-R1. Disponível em: <https://www.ipen.br/sitio/?idm=251> Acesso em: 22 nov. 2012.

ISLAS, P.M. Damage costs produced by electric power plants - An externality valuation in the Mexico City Metropolitan Area. Science of the Total Environmental, v. 408, p. 45114523, 2010.

JANNUZZI, G.M.; SWISHER, J. Planejamento Integrado de Recursos Energéticos: Meio Ambiente, Conservação de Energia e Fontes Renováveis. Campinas: Autores Associados, 1997.

KREWITT, W; HECK, T.; TRUKENMULLER, A; FRIEDRICH, R. Environmental damage costs from fossil electricity generation in Germany and Europe. Energy Policy, v. 27, p.173-183, 1997.

LIUN, E.; KUNCORO, A.H.; SARTONO, E. Environmental Impacts Assessment of Java's Electricity Generation Using Simpacts Model. International Conference on Advances in Nuclear Science and Engineering in Conjunction with LKSTN 2007 (379384). BATAN, Jakarta, Indonesia, 2007.

MARKANDYA, A. Valuation of the External Impacts of Hydrodams, Prepared for the International Atomic Energy Agency, University of Bath, Bath, UK, November, 2000 .

MARKANDYA, A; BOYD, R. AIRPACTS Economic Valuation, University of Bath, UK, for the International Atomic Energy Agency (IAEA), Vienna, Austria, April 2002.

MECCA, F. Origem da Radiação - Radioatividade - Interação da Radiação com a Matéria - Grandezas Dosimétricas. Instituto Nacional de Câncer (INCA). Ministério da Saúde.

Disponível em:

<http://www.inca.gov.br/pqrt/download/trab/minicurso_radioprotecao_aula2.pdf> Acesso em: 05 jun. 2012.

MOLNARY, L. Avaliação da Torre Meteorológica do IPEN. Ano de 2011. Relatório Técnico PSE.CENT.IEAR1.111.00 RELT. 001.00. Centro de Engenharia Nuclear - CEN. 2012.

MOTTA, R.S. O uso dos instrumentos econômicos na gestão ambiental. Abril, 2000. Disponível em:

http://www.undp.org.cu/eventos/instruverdes/Instr\%20Econ\%20Gestion\%20Ambiental\%2 0R\%20Seroa\%20da\%20Motta.pdf. Acesso em: 23 jan. 2012. 
MURAlHA, J. ANTÓNIO. Contabilidade, Auditoria e Meio Ambiente, Jornal de Contabilidade, n. 270, Setembro, p.291-299, 1999.

NAKICENOVIC. Energy Scenarios for Sustainable Development. Disponível em: www.iiasa.ac.at/Research/ECS/IEW2004/docs/Nakicenovic_2004IEW.ppt. Acesso em: 29 fev. 2012.

NISAN, S.; BENZARTI, N. A comprehensive economic evaluation of integrated desalination systems using fossil fuelled and nuclear energies and including their environmental costs. Desalination, v.229, p 125-146, 2008.

NUCLEAR FILES. Project of the Nuclear Age Peace Foundation. Accidents 1980's. Disponível em: http://www.nuclearfiles.org/menu/keyissues/nuclearweapons/issues/accidents/accidents-1980\%27s-05.htm. Acesso em 26 maio 2013.

PACCA, S.; KAMMEN, D.M. Assessing the costs of energy. Annual Review of Environment and Resources, v.29, p. 301-344, 2004.

PEREIRA, C.; FRANCO, V. S. Contabilidade Analítica, 5a Edição, 1992.

PUCCINI, A. Matemática financeira objetiva e aplicada, $7^{\mathrm{a}}$ ed., Ed. Atlas, SP, 2006, 432 pp.

REIS, M.M. Custos ambientais associados à geração elétrica: hidrelétricas $\boldsymbol{X}$ termelétricas a gás natural. 2001. Dissertação (Mestrado) - Universidade Federal do Rio de Janeiro, Rio de Janeiro.

RIBEIRO, J.A. Um estudo simplificado da percepção pública dos benefícios e riscos de centrais termonucleares: sugestões para a comunicação de valor com o público. 2007. Dissertação (Mestrado) - Instituto de Pesquisas Energéticas e Nucleares, São Paulo.

SEINFELD, J. H.; PANDIS, S. N. Atmospheric Chemistry and Physics. From Air Pollution to Climate Change, USA: John Wiley \& Sons, 1988.

SEMARNAT - Secretaria de Meio Ambiente y Recursos Naturales. Evaluación de las externalidades ambientales de la generación termoeléctrica en México. CEPAL. LC/MEX/L.644. 2004.

SOLER, MANUEL A. Manual de Gestión del Medio Ambiente, 1997.

THE WORLD BANK. Inflation, consumer prices (anuual\%). Disponível em: http://data.worldbank.org/indicator/NY.GDP.DEFL.KD.ZG/countries/1WUS?display=graph Acesso em 03 out. 2013.

THOMAS, J.; CALLAN. Economia Ambiental: aplicações, políticas e teoria. São Paulo: Cengage Learning, 2010, p. 65-90.

TURNER, D.B. Workbook of Atmospheric Dispersion Estimates. PH Publication No 999AP-26, U.S. Department of Health, Education Welfare, National Air Poluttion Control Administration, Cincinnati, Ohio, 1970. 
WCD - World Comission on Dams and Development. A New Framework for Decision Making, The Report of the World Commission on Dams, November 2000. Disponível em: http://www.dams.org. Acesso em: 15 jan. 2013. 